\title{
WestVirginiaUniversity
}

THE RESEARCH REPOSITORY @ WVU

Graduate Theses, Dissertations, and Problem Reports

2018

\section{Religiousness and Political Attitudes in Adolescence}

Rebecca Olson

Follow this and additional works at: https://researchrepository.wvu.edu/etd

\section{Recommended Citation}

Olson, Rebecca, "Religiousness and Political Attitudes in Adolescence" (2018). Graduate Theses,

Dissertations, and Problem Reports. 6352.

https://researchrepository.wvu.edu/etd/6352

This Dissertation is protected by copyright and/or related rights. It has been brought to you by the The Research Repository @ WVU with permission from the rights-holder(s). You are free to use this Dissertation in any way that is permitted by the copyright and related rights legislation that applies to your use. For other uses you must obtain permission from the rights-holder(s) directly, unless additional rights are indicated by a Creative Commons license in the record and/ or on the work itself. This Dissertation has been accepted for inclusion in WVU Graduate Theses, Dissertations, and Problem Reports collection by an authorized administrator of The Research Repository @ WVU.

For more information, please contact researchrepository@mail.wvu.edu. 
Religiousness and Political Attitudes in Adolescence

Rebecca Olson, M.S.

\author{
Dissertation submitted to \\ the Eberly College of Arts and Sciences \\ at West Virginia University \\ in partial fulfillment of the requirements \\ for the degree of \\ Doctor of Philosophy \\ in \\ Life-Span Developmental Psychology
}

Aaron Metzger, Ph.D., Chair Julie Hicks Patrick, Ph.D. Kevin Larkin, Ph.D. Christopher Scheitle, Ph.D.
Department of Psychology Morgantown, West Virginia 2018

Keywords: adolescent, religiousness, spirituality, political attitudes, Social Domain Theory Copyright 2018 Rebecca Olson 


\section{Abstract \\ Religiousness and Political Attitudes in Adolescence}

\section{Rebecca Olson}

Adolescent civic engagement has been shown to uniquely develop in certain contexts. However, few studies have examined the potential role of religiousness on youth's budding political attitudes about social issues. Religious organizations provide a particular atmosphere for civic development as these institutions and their members often have unique political outlooks. Youth who are associated with religious organizations (i.e. institutional religion), feel connected to a higher power (i.e. spirituality), or have certain religious beliefs (i.e. religious conservatism) may hold specific political attitudes about social issues including capital punishment, euthanasia, abortion, and environmentalism. Further, Social Domain Theory posits that informational assumptions, or what people believe to be factually true about the world, influence their attitudes about these issues. These informational assumptions may mediate the association between adolescent religiousness and political attitudes. The current study sought to investigate the potential link between youth religiousness and political attitudes as explained by informational assumptions. Participants included 481 high school students from three East Coast states. Structural equation modeling was used to examine direct pathways between religiousness and political attitudes as well as indirect pathways between key variables via informational assumptions. Results indicated that institutional religion was associated with less positive views of capital punishment and religious conservativism was associated with less positive views of abortion and environmentalism. Associations between spirituality and political attitudes was mixed, yet informational assumptions were shown to link spirituality and political attitudes

toward capital punishment and euthanasia. Finally, informational assumptions regarding belief in climate change and the impact of humans on the environment were shown to mediate the association between religious conservativism and less positive views of environmentalism. Findings highlight the important role of religiousness on adolescent views toward capital punishment, euthanasia, abortion, and environmentalism. 


\section{TABLE OF CONTENTS}

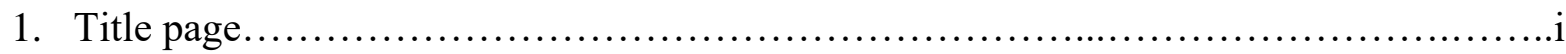

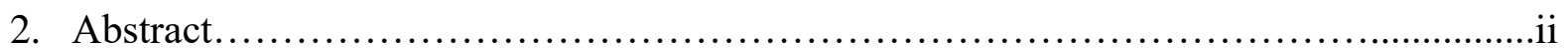

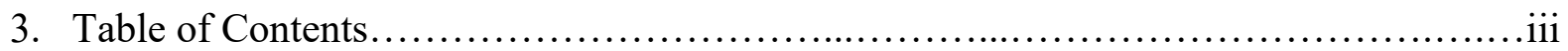

4. Acknowledgements........................................................ vii

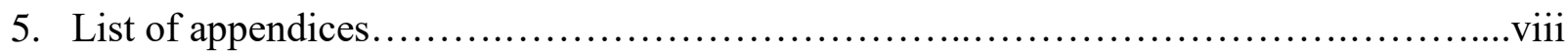

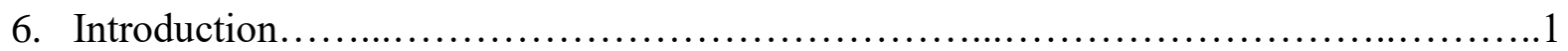

6.1 Political Attitudes........................................................

6.2 Religiousness and Political Attitudes ......................................5

6.2.1 Institutional Religion .........................................6

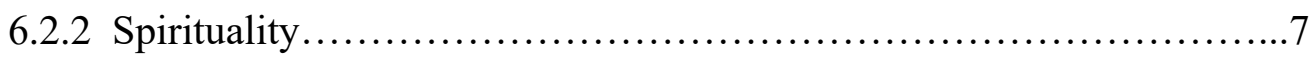

6.2.3 Religious Conservatism ....................................8

6.3 Social Domain Theory................................................ 10

6.4 Religiousness and Informational Assumptions ..............................14

6.4.1 Capital Punishment........................................................................ 14

6.4.2 Abortion and Euthanasia............................................................... 15

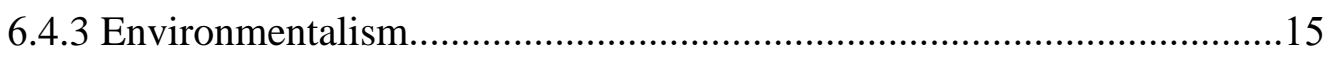

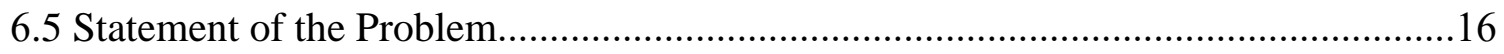

6.6 Research Question and Hypothesis ...................................... 18

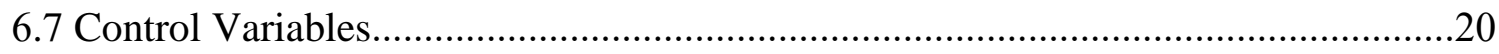

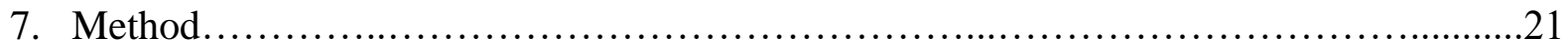

7.1 Participants............................................................ 21

7.2 Power Analysis.........................................................21 


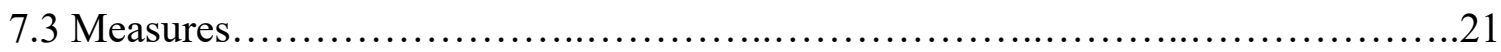

7.3.1 Demographic Information.........................................21

7.4 Religiousness.......................................................22

7.4.1 Institutional Religion...................................... 22

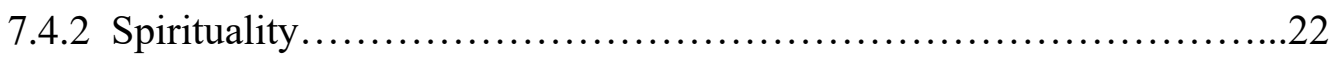

7.4.3 Religious Conservatism .....................................22

7.5 Political Attitudes ........................................................23

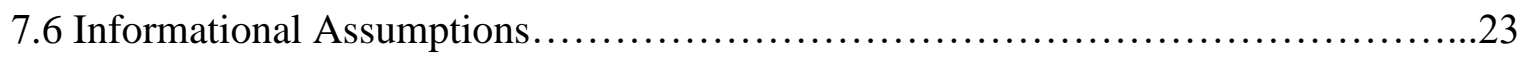

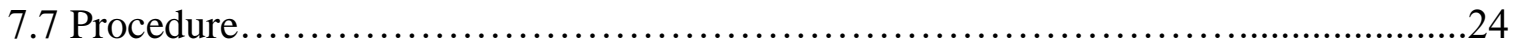

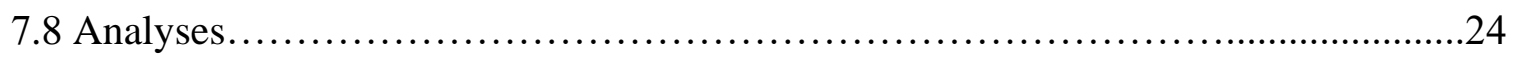

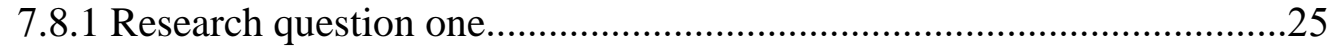

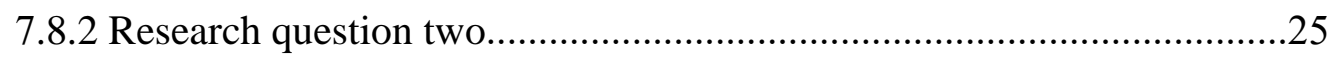

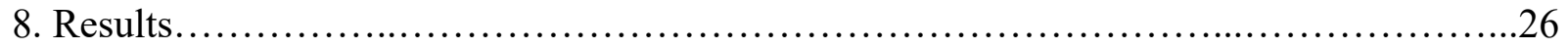

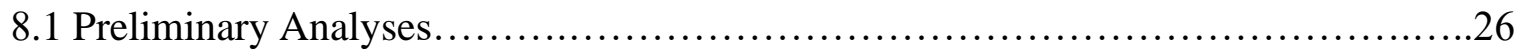

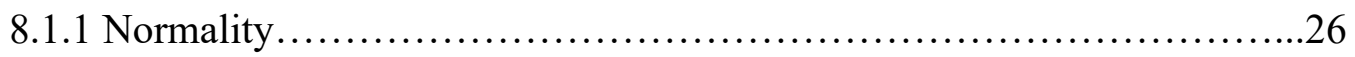

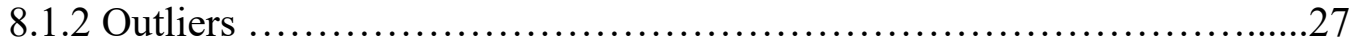

8.1 .3 Validity Checks.............................................27

8.1.4 Independent Sample t-tests ..................................27

8.1.5 Missingness...................................................27

8.1.6 Demographics and Bivariate Correlations...........................28

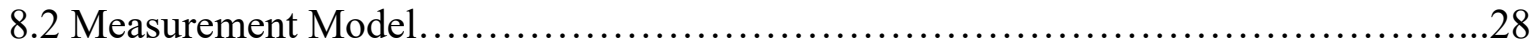

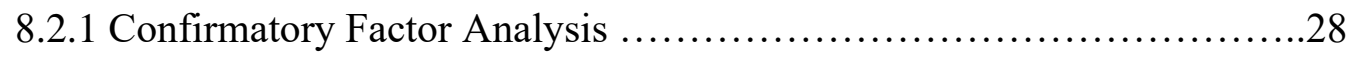

8.2.2 Measurement Invariance ......................................29 


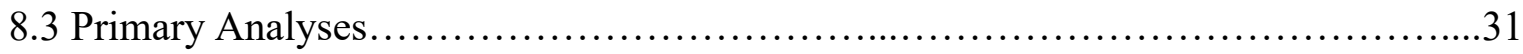

8.3.1 Predicting Youth Political Attitudes: Full Sample Models ...............31

8.3.1.1 Direct Effects............................................... 31

8.3.1.2 Indirect Effects.......................................... 31

8.3.1.2.1 Capital Punishment....................................32

8.3.1.2.2 Abortion and Euthanasia.............................33

8.3.1.2.3 Environmentalism..................................34

8.3.2 Predicting Youth Political Attitudes: Religious Sample.............................34

8.3.2.1 Direct Effects............................................. 34

8.3.2.2 Indirect Effects.......................................... 35

8.3.2.2.1 Capital Punishment..................................36

8.3.2.2.2 Abortion and Euthanasia............................37

8.3.2.2.3 Environmentalism.................................38

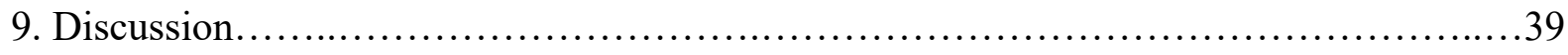

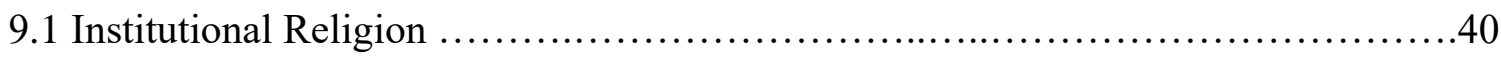

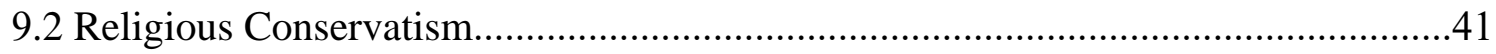

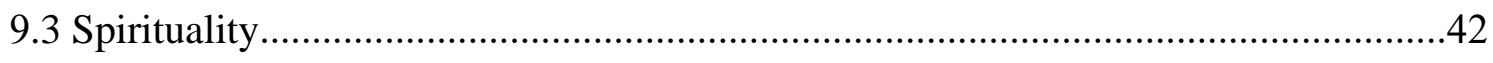

9.4 The Role of Informational Assumptions.................................................................

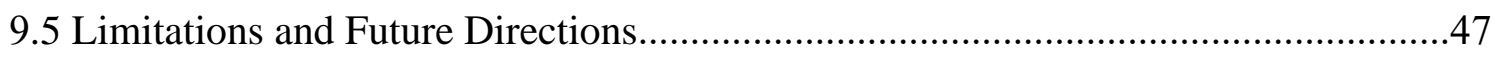

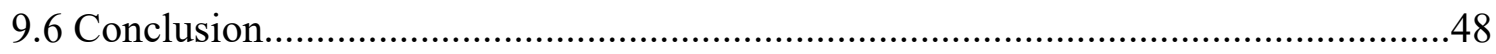




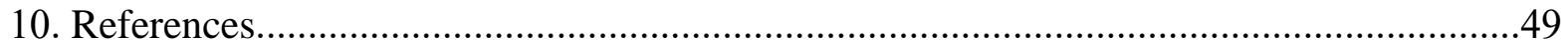

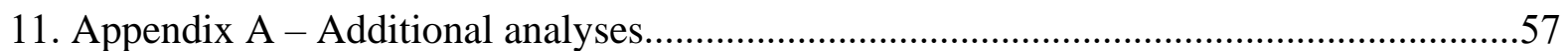

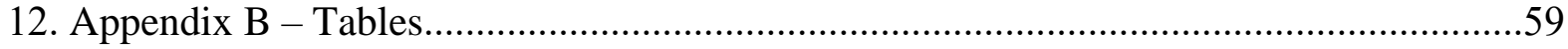

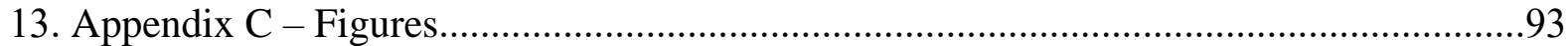

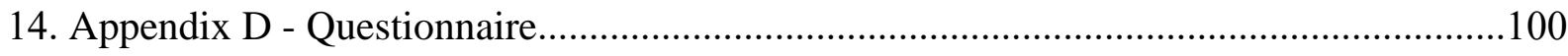

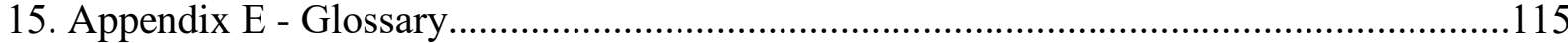




\section{ACKNOWLEDGEMENTS}

I would like to thank the Department of Psychology and the Eberly College of Arts and Sciences for their financial contribution and support for this project. I also would like to thank my primary advisor and mentor, Dr. Aaron Metzger, without whom I could not have completed this project. I am also appreciative of the time and feedback provided by my committee members Drs. Julie Patrick, Kevin Larkin, and Christopher Scheitle. Finally, I would like to thank my research assistant, Christopher Mishik, for all of his time and assistance in data collection. Thank you all! 


\section{LIST OF APPENDICIES}

\section{Appendix A: Additional analyses}

Measurement invariance

\section{Appendix B: Tables}

Table 1: Demographic information for participants

Table 2: Religious denominations of participants

Table 3: Means and standard deviations for key study variables

Table 4: Bivariate correlations - religiousness, political attitudes, control variables

Table 5: Bivariate correlations - political attitudes, informational assumptions, control variables

Table 6: Bivariate correlations - religiousness, informational assumptions

Table 7: Direct associations between religiousness and political attitudes - full sample

Table 8: Direct associations between religiousness and informational assumptions for capital punishment - full sample

Table 9: Direct associations between religiousness and informational assumptions for euthanasia - full sample

Table 10: Direct associations between religiousness and informational assumptions for euthanasia and abortion - full sample

Table 11: Direct associations between religiousness and informational assumptions for environmentalism - full sample

Table 12: Direct associations between harsh punishments and capital punishment - full sample 
Table 13: Direct associations between good/bad person and capital punishment - full sample

Table 14: Direct associations between quality of life and euthanasia - full sample Table 15: Direct associations between personal choice and euthanasia - full sample Table 16: Direct associations between personal choice and abortion - full sample Table 17: Direct associations between climate change threat and environmental influence and environmentalism - full sample

Table 18: Indirect effects for good/bad person item one on capital punishment - full sample

Table 19: Indirect effects for good/bad person item three on capital punishment - full sample

Table 20: Indirect effects for quality of life item two on euthanasia - full sample

Table 21: Direct associations between religiousness and political attitudes - religious sample

Table 22: Direct associations between religiousness and informational assumptions for capital punishment - religious sample

Table 23: Direct associations between religiousness and informational assumptions for euthanasia - religious sample

Table 24: Direct associations between religiousness and informational assumptions for euthanasia and abortion- religious sample

Table 25: Direct associations between religiousness and informational assumptions for environmentalism - religious sample 
Table 26: Direct associations between harsh punishments and capital punishment religious sample

Table 27: Direct associations between good/bad person and capital punishment religious sample

Table 28: Direct associations between personal choice and euthanasia - religious sample Table 29: Direct associations between personal choice and euthanasia - religious sample Table 30: Direct associations between personal choice and abortion - religious sample Table 31: Direct associations between climate change threat and environmental influence and environmentalism - religious sample

Table 32: Indirect effects for harsh punishments on capital punishment - religious sample Table 33: Indirect effects for climate change threat on environmentalism - religious sample

Table 34: Indirect effects for environmental influence on environmentalism - religious sample

\section{Appendix C: Figures}

Figure 1: Confirmatory factor analysis - religiousness

Figure 2: Confirmatory factor analysis - political attitudes

Figure 3: Confirmatory factor analysis - informational assumptions

Figure 4: Conceptual model for direct effects - full sample

Figure 5: Conceptual model for indirect effects - full sample

Figure 6: Conceptual model for direct effects - religious sample

Figure 7 - Conceptual model for indirect effects - religious sample

\section{Appendix D: Questionnaire}

\section{Appendix E: Glossary}




\section{Religiousness and Political Attitudes in Adolescence}

Adolescence is an important developmental period during which youth begin to establish their religious and political identities (Hardy, Pratt, Pancer, Olsen, \& Lawford, 2010). Increases in autonomy, enhanced critical and abstract reasoning capacities, and contextual experiences combine to influence adolescents' engagement in formal religious practices and developing religious and spiritual beliefs (i.e. religiousness). These developmental abilities may also aid in the formation of youth's budding political attitudes or personal opinions about current political issues. Antecedents of adolescents' political attitudes are particularly important to examine as early political attitudes will inform later voting behaviors in adulthood (Metzger \& Smetana, 2010). Religious and spiritual values may inform adolescents' fundamental beliefs about the world giving religious youth a unique political outlook. However, while substantial research has demonstrated that religiousness is associated with political attitudes in adult populations (Bulmer, Bohnke, \& Lewis, 2017; Miller \& Hayward, 2008), these associations have not been investigated within adolescent samples. It is also important to consider potential mechanisms that explain these connections such as the role of religiousness on adolescents' socio-moral informational assumptions about political issues. The current study will take a social domain approach to examine the association between religiousness and attitudes towards several political issues.

Although traditional models of civic engagement focus primarily on civic and political behavior, recent developmental rubrics have stressed the importance of psychological processes such as socio-political values (i.e. right-wing authoritarianism; Altemeyer \& Hunsberger, 1992; Pratto, Sidanius, Stallworth, \& Malle, 1994) and attitudes towards political issues (i.e. capital 
punishment; Miller \& Hayward, 2008). Specifically, political attitudes refer to the degree to which individuals favor a policy regarding a political issue. Examples of political attitudes include one's willingness to endorse capital punishment, support the legalization of euthanasia and abortion, and agree with laws designed to protect the environment (i.e. environmentalism). These early political beliefs during adolescence are potential antecedents of adult-level political views and may be linked to adolescents' later civic participation and voting behaviors; this makes it important to consider the contexts and experiences which influence the formation of these attitudes (Metzger \& Smetana, 2010). Empirical research on adolescent political development has widely focused on social and individual antecedents of these values and attitudes, including parents' political ideology and behavior, school or community activities, civics education, and sociopolitical context (Youniss, Bales, Christmas-Best, Diversi, McLaughlin, \& Silbereisen, 2002). However, few studies have examined additional contexts, experiences, or belief systems which may influence adolescents' attitudes towards specific political issues. The religious and spiritual behaviors and beliefs that youth form during adolescence may inform political attitudes.

Definitions of religiousness vary across the adolescent religious development literature and include both facets of organized religious involvement (King \& Roeser, 2008; Miller \& Thoresen, 2003) and private spiritual behaviors and beliefs (Barry \& Nelson, 2008; Haug, 1998). Components of institutional religion include attendance at religious services and the degree to which religion is important in one's life (i.e. devotionalism; Lindsey, Sigillo, \& Miller, 2013) while spirituality concerns the connection one feels to a higher power (i.e. transcendence; King, Clardy, \& Ramos, 2014) and spiritual behaviors such as prayer and meditation (Good, Willoughby, \& Busseri, 2011). Studies have shown that beliefs and values set forth by religious 
organizations are mirrored in their members' political attitudes (Bloom, 2007; Burdette, Hill, \& Moulton, 2005; Miller \& Hayward, 2008). Individual's political attitudes may also reflect what they believe to be the will of a higher power. In addition to institutional religion and spirituality, however, there are less explored components of religiousness that may be more salient in predicting political attitudes, such as religious conservatism.

Religious conservatism refers to an individual's loyalty to their religious ideals and is composed of religious fundamentalism, adherence to religious texts, and religious in-group favoritism. Religious fundamentalism is the belief that there is one inherent truth about humanity and that individuals who follow that truth have a special relationship with God (Altemeyer \& Hunsberger, 1992; Miller \& Hayward, 2008). Conversely, researchers have examined individuals' willingness to question their religious beliefs based on their life experiences (Batson, 1976). People who strongly profess that their religious beliefs are the only set of correct beliefs may be more likely to draw on their religious teachings when considering political policy compared to individuals who are open to questioning their religious ideals. Political attitudes may also be influenced by one's adherence to laws set forth by religious texts. Specifically, individuals who use religious scripture to guide their own lives may assert that the teachings of these documents should impact laws set forth by the government. Finally, favoring people from a single religious group may indicate increased orientation to the religious ideals of that community. Collectively, these facets of religious conservatism make up an under-examined yet potentially important predictor of political attitudes during adolescence. The current study sought to explore how institutional religion (i.e. religious attendance, devotionalism), spirituality (i.e. transcendence, prayer, meditation) and religious conservatism (i.e. religious fundamentalism, 
adherence to religious texts, religious in-group favoritism) uniquely contribute to political attitudes in adolescence.

Researchers should also consider the mechanisms through which religiousness is connected to political attitudes. From a social domain perspective, religiousness may affect the ways in which adolescents interpret and prioritize different features of complex political issues, which may affect their opinions about such issues. Social Domain Theory posits that social and political issues are comprised of multiple and potentially conflicting facets informed by different domains of social reasoning including moral, social conventional, and personal dimensions. Specifically, morality concerns the rights, justice, and welfare of people, social conventions concern the social expectations, norms, and traditions of certain contexts, and personal behaviors concern individual choice, personal prerogative, and are outside of conventional regulation or moral concept (Smetana, 2006; Turiel, Hildebrandt, Wainryb, \& Saltzstein, 1991). Many disputed political issues in the United States constitute multifacted issues which entail elements that can be interpreted from multiple domains of social reasoning (Smetana \& Turiel, 2005). Social-domain research has found that individuals' political attitudes are tied to their prioritization of moral, conventional, or personal facets of political issues (Smetana, 1979). The ways which individuals prioritize these facets has been shown to be influenced by what they believe to be factually true about the world, or their informational assumptions (Wainryb, 1991). Religious and spiritual individuals might hold unique informational assumptions which may then undergird their attitudes about political issues, yet these associations have not yet been explored. The current study will investigate the explanatory role of socio-moral informational assumptions on the link between adolescent religiousness and attitudes toward multifaceted issues including capital punishment, euthanasia, abortion, and environmentalism. 


\section{Political attitudes}

As mentioned above, political attitudes refer to the degree to which one favors a policy regarding a political issue; People have been found to vary in their willingness to support certain issues. For instance, individuals might think differently about capital punishment depending on the severity or circumstances of the crime. People may also vary on the degree to which they think euthanasia should be legal in that some argue that it is always wrong, that it should only be used in cases of painful and terminal illness, or that it should be a person's right to choose when they die regardless of the circumstances. Similarly, some people believe that abortion should be illegal in all cases while others think that it should be legal in cases of rape or endangering the mother's life. Still others believe that it should be a woman's right to choose if she has an abortion in all cases (Gallup, 2017). Finally, individuals may vary on the extent to which they believe government should take steps to protect the environment including policies regarding factory and car emissions, energy sources, and recycling. The complexity surrounding capital punishment, euthanasia, abortion, and environmentalism suggests that people might vary on the amount they are for or against policies regarding these issues rather than simply endorsing them or not. Research has examined a number of antecedents that contribute to variations in political attitudes, including religious and spiritual behaviors and beliefs.

\section{Religiousness and political attitudes}

Research has investigated ways in which religiousness influences individuals' political attitudes concerning a number of social and political issues. As highlighted above, religiousness is a complex and multidimensional construct composed of institutional religion, spirituality, and specific religious beliefs (i.e. religious conservatism). These unique facets of religiousness may independently or in combination influence adolescent political attitudes. The following provides 
a summary of existing research on religiousness and attitudes towards multifaceted political issues including capital punishment, euthanasia, abortion, and environmentalism.

Institutional religion. Institutional religion refers to a person's activity in a religious organization such as a church, synagogue, or mosque including attendance at religious services and social events, as well as the degree to which one values or is devoted to their religious organization (i.e. devotionalism; Lindsey et al., 2013). Institutional religion is both conceptually and empirically related to political attitudes in a number of ways. Religious creeds are similar to political ideologies in that they are organized around a shared set of beliefs, rules, and doctrines (McIntosh \& Youniss, 2010). Attending religious services allows youth to hear messages put forth by religious organizations which may include viewpoints and interpretations of specific social and political issues. Because of this consistent exposure to political discussion, members of a single religious group potentially hold similar political beliefs to each other which provides religiously involved youth with the opportunity to interact with people who share similar values. Religious organizations also offer youth opportunities to participate in community service events and serve in leadership roles which promote civic engagement.

Feeling a sense of devotion to a religious organization may further influence ones’ political attitudes to be consistent with a specific institution of faith. Adolescents who are actively engaged in religious communities might be more influenced by religious doctrine than youth who attend out of family obligation. For these reasons, it is likely that institutional religion is related to adolescents' opinions about specific political issues, yet these links have not yet been explored.

The majority of research on religiousness and political attitudes in adulthood has included measures of attendance at religious services or devotion to religious organizations. For instance, 
people who attend church regularly have been shown to have less concern for the environment (Guth, Green, Kellstedt, \& Smidt, 1995) while devotionalism contributes to negative views of euthanasia (Bulmer et al., 2017; Burdette et al., 2005). Further, both devotionalism and attendance at religious services has been linked to less endorsement of policy which permits abortion (Hess \& Rueb, 2005; Lindsey et al., 2013). However, devotionalism has been linked to attitudes both for (Evans \& Adams, 2003) and against capital punishment (Miller \& Hayward, 2008). Religious organizations often vary on their institutional opinions about political issues making it likely that people who have high levels of religious attendance and devotionalism do not universally hold the same opinions about political issues. These inconsistent findings point to the need for future research on the role of institutional religion, as well as exploration of other facets of religiousness, on political attitudes.

Spirituality. Independent of institutional religion, spirituality may be uniquely linked to political attitudes. One common definition of spirituality is a feeling of connectedness towards the world, or transcendence. This includes connection to religious figures, such as God or a higher power, or non-religious figures, such as the universe or other people (Good \& Willoughby, 2008; Hyland, Wheeler, Kamble, \& Masters, 2010; Seidlitz et al., 2002; Underwood \& Teresi, 2002). Definitions of spirituality have also included frequency of spiritual behaviors such as prayer and meditation (Good et al., 2011).

Certain components of spirituality, such as connection to a higher power, attributing certain qualities to a transcendent authority figure, and spiritual behaviors, such as prayer, have also been shown to be associated with political ideology and attitudes (Jensen, 2009; Pratto et al., 1994). For instance, spiritual virtues such as forgiveness have been negatively associated with support for the death penalty (Applegate, Cullen, Fisher, \& Vander Ven, 2000). Further, 
connection to the world may give individuals a sense of purpose which has been found to be negatively associated with pursuit of physician-assisted suicide (Smith, Harvath, Goy, \& Ganzini, 2015). Feeling connected to something or someone outside of oneself may also be positively associated with pro-environmental attitudes and behaviors. Further research is needed to examine if and how spiritual behaviors and beliefs are related to political attitudes.

Religious conservatism. In addition to institutional religion and spirituality, religious conservatism may play a unique role in the formation of adolescents' political attitudes. As mentioned above, religious conservatism refers to the degree to which one is loyal to their own religious beliefs. This includes the belief that a single religion is true (i.e. religious fundamentalism), obedience to the laws and regulations set forth by a religious text (i.e. adherence to religious texts), and a preference to surround oneself with others who belong to the same religious group (i.e. religious in-group favoritism). Religious organizations often have rules and regulations which coincide with political issues such as opposition to euthanasia and abortion (Bulmer et al., 2017). People who exhibit high levels of religious fundamentalism may prioritize religious viewpoints about these issues which affects their personal political attitudes. Social issues cited in religious texts may also be related to issues such as capital punishment, euthanasia, abortion, and environmentalism (Burdette et al., 2005; Evans \& Adams, 2003; Miller \& Hayward, 2008). People who strictly adhere to these documents may be more likely to rely on them as the grounds for their political attitudes. Finally, favoring members of one's own religious group may be related to prioritization of a single religious doctrine when appraising political policy. Adolescents who prefer to associate with members of their own religious group, even outside of a religious context, might be more influenced by the homogeneous political attitudes of that group than adolescents who simply attend religious services. 
Researchers have explored ways which various facets of religious conservatism are associated with specific political values and attitudes in adult samples. For example, research has found that religious fundamentalism is associated with positive views of the death penalty (Applegate et al., 2000; Miller \& Hayward, 2008) while willingness to question religious authority has been linked with support for a woman's legal right to choose if she has an abortion (Lindsey et al., 2013). Further, people who identify as religious and have high levels right-wing authoritarianism have been found to have low levels of support for physician-assisted suicide (Bulmer et al., 2017) and religious conservativism has been linked with less support for laws which regulate the environment (Greeley, 1993; Guth et al., 1995). Right-wing authoritarianism has also been linked with religious fundamentalism and reading religious texts (Altemeyer \& Hunsberger, 1992; Laythe, Finkel, \& Kirkpatrick, 2001). While simply reading religious texts might be a behavior consistent with institutional religion, people who read religious texts frequently may closely adhere to their teachings. Research has also found that individuals who interpret religious documents literally are in favor of the death penalty and believe that God requires the death penalty for murderers (Applegate et al., 2000; Miller \& Hayward, 2008). Finally, preferring to associate with members of a single religious community might strengthen one's connection to their faith, contributing to religious conservatism. Despite these potential links, however, religious in-group favoritism has not been empirically examined in regards to political attitudes including capital punishment, euthanasia, abortion, or environmentalism with either adult or adolescent samples.

Much research has been dedicated to examining the role of institutional religion, spirituality, and religious conservatism on political attitudes. However, little research has examined connections among multiple facets of religiousness and a comprehensive array of 
political issues. Moreover, existing research has focused exclusively on adult populations making it unclear if and how religiousness is connected with political attitudes in adolescence. Overall, the theoretical and empirical connection between religiousness and political attitudes provides a solid foundation on which to explore the association between institutional religion, spirituality, and religious conservatism on political attitudes in adolescence.

\section{Social Domain Theory}

Political issues can be interpreted from many different perspectives which often contribute to individual differences in political attitudes. Religious experiences may contribute to these different perspectives or interpretations by leading youth to prioritize certain facets of political issues. The social-cognitive domain perspective, or Social Domain Theory (SDT) posits that individuals' social and moral beliefs about the world are divided into distinct domains of social knowledge (Smetana, 2006; Smetana \& Turiel, 2005). These domains include moral, social conventional, and personal.

According to SDT, the moral domain pertains to individual rights, justice, and welfare of others (Smetana, 2006; Smetana et al., 2012; Smetana \& Turiel, 2005). Examples of behaviors that constitute moral violations include stealing, hitting, slander, and acting dishonestly (Smetana $\&$ Turiel, 2005). Moral issues are viewed as universally obligatory regardless of context or the presence of rules, laws, or authority (Smetana, 2006; Smetana et al., 2012; Smetana \& Turiel, 2005), including the authority of a higher power (i.e., God; Nucci \& Turiel, 1993). In contrast, social conventional issues are agreed upon uniformities that serve to direct social behavior within specific societal contexts. Social conventions established by tradition and/or authority figures, and are considered alterable within certain contexts (Smetana, 2006; Smetana et al., 2012, Smetana \& Turiel, 2005). For example, while eating ice cream with fingers is generally 
considered unacceptable in society, it does not violate the rights, justice, and welfare of others as do moral issues (Smetana et al., 2012). Finally, personal issues involve individual prerogative and choice, which are not regulated by social conventions and lie outside of moral considerations (Turiel et al., 1991). Examples of personal issues include that which involves one's body, personal choice, or privacy, such as one's length of hair or choice of friends (Metzger \& Smetana, 2009; Smetana, 2006; Smetana \& Turiel, 2005). Personal issues within this domain are considered to be outside the scope of moral and social conventional domains as they affect only the individual who is making the choice (Smetana, 2006; Turiel et al., 1991).

Research has shown that some social and political issues are multifaceted in that they involve some combination of moral, conventional, or personal components. Previous research has assessed differences in individual's reasoning about political issues through socio-moral judgements, or one's belief about a social issue, including the issue being obligatory and worthy of social praise (moral), contingent on authority (conventional), or a matter of personal prerogative or choice (personal; Metzger \& Smetana, 2009). For instance, capital punishment has moral components in that it concerns human welfare (i.e., life of prisoner) and conventional components with regard to the effectiveness it has on deterring crime. Further, euthanasia and abortion have moral components in that they concern welfare of human life and personal components with regard to individual medical decisions concerning one's own body (Smetana, 1979). Similarly, environmentalism has moral components in that the quality of the environment affects the welfare of living beings, conventional components concerning what is acceptable environmental practice for businesses, and personal components which involve a human's decision to choose if and how they participate in environmentally friendly behaviors. 
The ways which individuals prioritize various moral, conventional, and personal facets of political issues may be strongly influenced by informational assumptions. Informational assumptions refer to a person's general concept of reality and what they believe to be factually true about the world. (Smetana, 2006; Wainryb, 1991). These informational assumptions have been shown to undergird and inform socio-moral judgements concerning multifaceted social issues. For instance, while spanking a child for no reason was viewed as morally wrong, the belief that spanking was an effective punishment was found to make individuals believe that it was okay (Wainryb, 1991). In other words, hitting is universally considered to be a moral issue, yet spanking might be considered a conventional issue under the informational assumption that it is effective at reducing unwanted behavior. Further, it is typical for parents in one culture to physically harm their male children because they hold the informational assumption that boys must endure pain to be able to assume the adult responsibilities of a man. When participants trusted that both parents and boys believe this assumption to be true, they saw the act of harm as conventionally acceptable regardless of moral considerations (Shaw \& Wainryb, 1999). These examples illustrate the importance of considering informational assumptions in regards to multifaceted issues.

Informational assumptions may similarly influence the ways that people interpret political issues, affecting their political attitudes. For instance, killing human life is universally considered to be a moral issue. Concordantly, research has found that individuals who hold the informational assumption that an unborn fetus constitutes a human life are more likely to prioritize moral facets of the issue (Smetana, 1981). In contrast, individuals who hold the informational assumption that life does not begin until birth are more likely to believe that abortion should be a personal decision. Variations in prioritization of moral or personal facets of 
abortion have also been shown to influence mothers' decisions regarding unwanted pregnancies and could have implications for political attitudes towards abortion (Smetana, 1981).

While previous research has found associations between informational assumptions and attitudes towards abortion, the potential role of these assumptions on other political issues has not yet been examined. For example, under the social domain framework, capital punishment might be considered a moral issue because it involves that act of killing. However, there may be certain informational assumptions under which people view capital punishment as a conventional issue. Such assumptions might include that harsh punishment for criminals is an effective way to deter crime (Gallup, 2017) or that criminals are bad people who cannot change or be rehabilitated (vs. good people; i.e. good/bad person). People who hold these informational assumptions might believe view capital punishment from a conventional domain and hold more favorable views of the death penalty.

There may be other informational assumptions that link religiousness to political attitudes as well. Similarly to capital punishment, euthanasia requires taking the life of a human being, making it a moral concern. However, as euthanasia seeks to end the lives of people with terminal and painful illnesses upon request, some people might prioritize personal facets of the issue under certain informational assumptions. Such assumptions might include that quality of life is more important than quantity of life or that it is important for people to be able to make choices regarding their own lives (i.e. personal choice). These assumptions might, in turn, be linked with greater favorability of euthanasia.

Finally, informational assumptions might influence the domain under which people view environmentalism. Specifically, some people might believe that human actions could threaten the environment in which we live (i.e. environmental influence) or that climate change jeopardizes 
human welfare (i.e. climate change threat). These concerns of welfare might be indicate prioritization of moral facets of environmentalism. Conversely, people who do not believe in the harmful effects of climate change might prioritize one's individual choice to make environmentally friendly decisions. Overall, variations in the way individuals prioritize domainrelevant information within multifaceted social issues have been shown to contribute to differences in political attitudes (Smetana, 1979; Smetana, 1981; Smetana, 2006; Turiel et al., 1991) and it is expected that further associations will be found in regards to capital punishment, euthanasia, abortion, and environmentalism.

\section{Religiousness and informational assumptions}

There are several components of religiousness that may contribute to informational assumptions and influence an individual's interpretation of social and political issues. For instance, informational assumptions held by individuals who are high in religious conservatism may be informed by the teachings of religious authority or scripture. In other words, these facets of religiousness may help individuals to evaluate and interpret factional information about the world in a way that is consistent with their faith. Informational assumptions may, therefore, mediate the association between religiousness and political attitudes in the following ways.

Capital punishment. Religious scriptures (e.g. Bible, Quran) almost universally assert that killing is wrong and many religious organizations hold punitive attitudes about retaliation for sins (Miller \& Hayward, 2008). These teachings might lead individuals who are high in institutional religion and religious conservatism to hold the informational assumption that harsh punishments are effective when it comes to deferring crime. Religious institutions also commonly assert that there is good and evil in the world, a belief which is likely to be associated with the informational assumption that there are good and bad people in the world. These 
assumptions may help to explain the association between institutional religion, religious conservatism, and favorable views of capital punishment. Conversely, spiritual individuals have been shown to have higher levels of forgiveness (Lawler-Row, 2010) which may be negatively associated with the belief that criminals should be subject to harsh punishments and that there are exclusively good and bad people in the world. For these reasons, spirituality is likely associated with less favorable views of capital punishment via these informational assumptions.

Abortion and euthanasia. Another common religious teaching is that people are children of God and that this relationship extends from conception until death (Burdette et al. 2005). Religious individuals have also been shown to exhibit higher levels of authoritarianism (Altemeyer \& Hunsberger, 1992). As such, religious and spiritual individuals may prioritize religious doctrine and "God's will" over personal choice to determine when and how someone dies. These informational assumptions may explain the association between religiousness and attitudes toward euthanasia and abortion.

Environmentalism. Religious organizations often assert that the world is God's creation. As such, religiousness may be associated with the belief that God is responsible for the quality of Earth rather than human beings. Conversely, spiritual individuals may feel more connected to something outside of themselves and feel a sense of duty to protect the Earth. For these reasons, it is anticipated that institutional religion and religious fundamentalism will be negatively associated with the belief that people influence the quality of the environment and that climate change is a threat to the Earth. Spiritual individuals, however, are likely to agree with these assumptions and hold more favorable views towards environmentalism. 


\section{Statement of the problem}

Adolescence is a critical time during which youth form both their religious and political beliefs, and these budding attitudes may be important antecedents of later adult political behavior. However, the current body of research has primarily explored these associations in adult populations (e.g. Bulmer et al., 2017), making it unclear if similar associations between religiousness and political attitudes are present during adolescence. The current study sought to explore the association between religiousness (i.e. institutional religion, spirituality, religious conservativism) and political attitudes toward capital punishment, euthanasia, abortion, and environmentalism in adolescence.

Research which has examined correlates of political attitudes in adolescence has primarily focused on parent socialization, failing to examine other adolescent contextual experiences. The rules, doctrines, and teachings set forth by religious organizations may influence political outlook for religiously involved youth. Specifically, religious organizations often preach retaliation for sins which might be connected to more favorable views of capital punishment. In contrast, feeling connected to a higher power and other people has been linked with forgiveness which may be associated with less favorable views of capital punishment for spiritual youth. Further, religious and spiritual youth might believe that it is up to God to take human life, resulting in more negative views of euthanasia and abortion. Finally, people who are high in institutional religion and religious conservativism might oppose laws which seek to regulate the environment if they believe it is God's responsibility to do so. However, spiritual individuals who feel connected to something outside of themselves may feel a sense of duty to protect the environment and favor such laws. Collectively, attitudes toward these issues have both conceptual and empirical links to religiousness in adult populations, yet these associations have not been explored in adolescence. The first aim of the current study will be to investigate 
the link between adolescent institutional religion, spirituality, and religious conservatism and political attitudes toward capital punishment, euthanasia, abortion, and environmentalism.

From a developmental perspective, it is also important to consider how socio-cognitive processes such as adolescents' informational assumptions may affect associations between religiousness and political attitudes. In other words, attitudes toward capital punishment, euthanasia, abortion, and environmentalism may be prioritized from various domains of social reasoning which is informed by the fundamental beliefs youth hold about the world. Religious individuals may have a unique set of informational assumptions based on the teachings of their religious organizations. For example, religious individuals who promote the importance of retaliation for sins might believe that harsh punishments are the most effective way to deter crime. In turn, the belief that harsh punishments are effective at preventing crimes, such as murder, is expected to be related to more favorable views of capital punishment. Religious individuals may also be more likely to believe that there are exclusively good and bad people in the world. The belief that criminals are bad people and cannot change may also be associated with endorsement of capital punishment. Conversely, spiritual individuals might be more likely to believe that criminals can be rehabilitated, resulting in less favorable capital punishment attitudes. Further, religious and spiritual people who prioritize God's will in matters such as length of life might disagree with the assumptions that quality is more important than quantity of life or that people should be free to make their own decisions. These beliefs may serve to explain the association between religiousness and less favorability toward abortion and euthanasia. Finally, religious individuals who assert that it is God's responsibility to take care of creation might be less likely to believe that climate change is a threat or that humans can influence the environment. People who hold these assumptions might, in turn, have less favorable views of 
laws which regulate the environment while spiritual individuals who feel a sense of duty to protect the Earth might hold more favorable attitudes toward environmental law. The second aim of the current study will be to examine informational assumptions as a mediator between facets of religiousness and political attitudes.

\section{Research questions and hypotheses}

Research Question 1. Are institutional religion, spirituality, and religious conservatism uniquely associated with political attitudes toward capital punishment, euthanasia, abortion, and environmentalism?

Hypothesis 1. Institutional religion, spirituality, and religious conservatism will be uniquely associated with political issues.

a. Institutional religion will be associated with more favorable views of capital punishment and less favorable views of euthanasia, abortion, and environmentalism.

b. Spirituality will be associated with more favorable views of environmentalism and less favorable views of capital punishment, euthanasia, and abortion.

c. Religious conservatism will be associated with more favorable views of capital punishment and less favorable views of euthanasia, abortion, and environmentalism.

Research Question 2. Will informational assumptions mediate the association between religiousness and political attitudes?

Hypothesis 1. Informational assumptions will be associated with political attitudes.

a. Harsh punishments and good/bad people will be associated with more favorable views of capital punishment. 
b. Quality of life will be associated with more favorable views of euthanasia.

c. Personal choice will be associated with more favorable views of euthanasia and abortion.

d. Environmental influence and climate change threat will be associated with more favorable views of environmentalism.

Hypothesis 2. Religiousness will be associated with informational assumptions.

a. Institutional religion and religious conservatism will be positively associated with harsh punishments and good/bad people.

b. Spirituality will be negatively associated with harsh punishments and good/bad people.

c. Institutional religion, spirituality, and religious conservatism will be negatively associated with quality of life and personal choice.

d. Institutional religion and religious conservatism will be negatively associated with environmental influence and climate change threat.

e. Spirituality will be positively associated with environmental influence and climate change threat.

Hypothesis 3. Informational assumptions will mediate the association between religiousness and political attitudes.

a. Institutional religion and religious conservatism will be associated with more favorable views of capital punishment via harsh punishments and good/bad people.

b. Spirituality will be associated with less favorable views of capital punishment via harsh punishments and good/bad people. 
c. Institutional religion, spirituality, and religious conservatism will be associated with less favorable views of euthanasia via quality of life.

d. Institutional religion, spirituality, and religious conservatism will be associated with less favorable views of euthanasia and abortion via personal choice.

e. Institutional religion and religious conservatism will be associated with less favorable views of environmentalism via environmental influence and climate change threat.

f. Spirituality will be associated with more favorable views of environmentalism via environmental influence and climate change threat.

\section{Control Variables}

Demographic differences have emerged in their association to a variety of political attitudes making them important to consider in the proposed study. Gender, education, age, and race have all been found to contribute to differences in political attitudes (Burdette et al., 2005; Miller \& Hayward, 2008; Rosik, Griffith, \& Cruz, 2007; Rowatt, LaBouff, Johnson, Froese, \& Tsang, 2009; Smetana, 1979). Political ideology (i.e. conservative versus liberal) and sociopolitical values, such as Right-wing Authoritarianism and Social Dominance Orientation, have also been widely found to contribute to political attitudes on a number of issues (Bulmer et al., 2017; Pratto et al., 1994). Finally, political attitudes have been shown to differ between religious denominations (Burdette et al., 2005; Knoll, 2009; Lipka, 2017; Miller \& Hayward, 2008; Smith, Denton, Faris, \& Regnerus, 2002). Based on these findings, gender, education, age, ethnicity, political ideology, socio-political values, and religious denomination were included in the current study as control variables. 


\section{Method}

\section{Participants}

Five hundred and two $9-12^{\text {th }}$ grade adolescents $\left(14-20\right.$ years old; $M_{\text {age }}=16.95$, S.D. $=$ 1.11) were recruited from five high schools in three Eastern states. From the five high schools, three were public and two were private Catholic schools. Two schools were located in rural settings, two schools were located in a mid-sized city, and one school was located in a suburban setting. School enrollment ranged from 210 to 1763 students. Counties in which schools were located varied in their 2016 voting trends such that one county voted primarily Democrat (64.6\% Democrat; $32.2 \%$ Republican), one county was primarily Republican (23.6\% Democrat; $73.1 \%$ Republican) and one county had an approximately even number of Democratic and Republican votes, with slightly more Democratic votes (51.2\% Democrat; 40.8\% Republican).

\section{Power analyses}

Structural equation modeling (SEM) was used as the primary analysis for the current study. The largest model in the current study estimated the association between devotionalism, spirituality, religious conservatism, five control variables, and environmentalism via climate change threat (66 parameters; 4 covariances). Given the number of parameters for this model, a final sample size of $\sim 330$ participants provided sufficient power for analyses to be performed (MacCallum, Brown, \& Sugawara, 1996).

\section{Measures}

Demographic information. Participants self-reported their gender, date of birth, ethnicity, sexual orientation, socio-economic status, grades in school, religion, and religious denomination. Age was computed using participants' date of birth and the date that that survey was taken. For the purpose of analyses, ethnicity was dichotomized into two categories (white 
vs. non-white). Participants also reported on their own political ideology (i.e. liberal, conservative), their primary caregiver(s)' political ideology, and Right-wing Authoritarianism (5 items; $\alpha=.77$; Altemeyer, 1996). Social Dominance Orientation was also assessed but did not provide a reliable measure and was not included in analyses.

\section{Religiousness}

Institutional religion. Institutional religion was measured using three items to assess attendance at religious services and six items to assess devotionalism. Participants reported their frequency of attendance at religious services, social events, and participation in religious leadership roles using a five-point Likert-type scale $(1=$ never; $5=$ more than once/week; $\alpha=$ .82, Oosterhoff, Ferris, \& Metzger, 2014). Participants also reported devotionalism (e.g. My ideas about religion are one of the most important parts of my philosophy of life) on a five-point Likert-type scale $(1=$ strongly disagree; $5=$ strongly agree $; \alpha=.83 ;$ Putney \& Middleton, 1961).

Spirituality. Connection to a higher power was assessed using a modified version of the Spiritual Transcendence Index (STI). The STI consists of eight items (e.g. My spirituality gives me a feeling of fulfillment) and was measured on a five-point Likert-type scale $(1=$ strongly disagree $; 5=$ strongly agree $; \alpha=.95 ;$ Putney \& Middleton, 1961). For the purposes of this study, the STI was modified such that references to "God" were replaced with "higher power". Participants also reported the frequency that they participate in spiritual behaviors including prayer and meditation on a five-point Likert-type scale $(1=$ never; $5=$ more than once/day $)$.

Religious conservatism. Religious fundamentalism (e.g. To lead the best, most meaningful life, one must belong to the one, true religion) was assessed using 12 items from a modified version of an established measure $(\alpha=.88$; Altemeyer \& Hunsberger, 1992; Altemeyer \& Hunsberger, 2004). Adherence to religious texts (e.g. I feel that scripture is God's word, and is to be taken literally, word for word) was assessed using four items on a five-point Likert-type 
scale ( $\alpha=.90$; Applegate et al., 2000; Lam, 2002). Religious in-group favoritism (e.g. I prefer to be with other people who are in the same religion as me) was assessed using four items $(\alpha=.79$, Dunkel \& Dutton, 2016). All items on religious conservatism measures were assessed using a five-point Likert-type scale ( 1 = strongly disagree, 5 = strongly agree $)$.

\section{Political attitudes}

To assess political attitudes, participants were asked to report the amount they agree or disagree with statements regarding policy about political issues. Items were measured on a 100 point slider scale $(1=$ strongly disagree, $100=$ strongly agree $)$ and item wording was adapted from national polling data questionnaires for the current study (Gallup, 2017). The 16-item political attitudes scale included four items assessing attitudes towards each of the following issues including capital punishment (e.g. I am in favor of the death penalty for a person convicted of murder; $\alpha=.78$ ), euthanasia (e.g. Doctors should be allowed to painlessly end a patient's life if the patient requests it; $\alpha=.84$ ), abortion (e.g. Women should be allowed to get an abortion if they choose to do so; $\alpha=.87$ ), and environmentalism (e.g. Protection of the environment should be given priority over economic growth; $\alpha=.86$ ).

\section{Informational assumptions}

To assess informational assumptions, participants were asked to report the degree to which they endorse statements regarding their factual beliefs about the world. The 18-item informational assumptions scale included three items to assess each of the following assumptions: harsh punishments (e.g. Harsh punishments teach people what they can and cannot $d o ; \alpha=.76$ ), environmental influence (e.g. People have the ability to both help and harm the environment; $\alpha=.71$ ), and climate change threat (e.g. The effects of global warming have already begun affecting the environment; $\alpha=.81)$. The good/bad person (e.g. There are two 
types of people in the world: good people who do good things and bad people who do bad things), quality of life (e.g. Living a happy life is more important than living a long life), and personal choice (e.g. It is important for people to make their own choices) informational assumptions did not provide reliable measures and were not used as scales in primary analyses. Item wording was adapted from national polling data questionnaires (Gallup, 2017) and were assessed on a five-point Likert-type scale $(1=$ strongly disagree to $5=$ strongly agree $)$.

\section{Procedure}

Prior to the study, adolescents were given parental consent forms in their advisory or social studies classroom to be completed by a parent or guardian. Adolescents who returned a signed parental consent form were required to provide informed assent prior to participating in the study. Participants who obtained both parental consent and informed assent completed a survey assessing all measures on an electronic laptop or tablet in their advisory or social studies class. It took participants approximately 30 minutes to complete the survey. Participants were entered into a drawing to win one of ten-\$100 Amazon gift cards.

\section{Analyses}

All analyses were conducted using SPSS and AMOS version 24. Preliminary analyses included an assessment of missingness, outliers, and skewness. Full-information maximum likelihood (FIML) was used to address missingness in models assessing direct effects. Mean imputation was used to address missingness in mediation models, as bootstrapping procedures do not allow for missing data. Descriptive statistics and bivariate correlations were also conducted as preliminary analyses. Adequate model fit in SEMs was indicated by $\chi^{2} / d f<3.0$, CFI $>.90$, and RMSEA < .05 (Tabachnick \& Fidell, 2013). 
Research question 1. Are institutional religion, spirituality, and religious conservatism uniquely associated with political attitudes towards capital punishment, euthanasia, abortion, and environmentalism? A structural equation model was used to test associations between latent variables for institutional religion, spirituality, and religious conservatism and political attitudes towards capital punishment, euthanasia, abortion, and environmentalism. Mean scores were computed for all religiousness scales with more than one item (i.e. attendance, devotionalism, transcendence, religious fundamentalism, adherence to religious texts, religious in-group favoritism). Each item of the attendance scale and a composite devotionalism item were used as observed variables to create the institutional religion latent variable. The eight items of the transcendence scale were compiled into four parcels which were used as observed variables to create the spirituality latent variable. Religious fundamentalism, adherence to religious texts, and religious in-group favoritism were used to create the religious conservatism latent variable. A confirmatory factor analysis (CFA) was conducted to assess model fit at the measurement level for religiousness and each political attitude, with facets of each latent variable being allowed to co-vary. Upon achieving a good-fitting measurement model for each latent variable, a structural model was used to test pathways between facets of religiousness and political attitudes.

Research question 2. Will informational assumptions mediate the association between religiousness and political attitudes? An additional SEM was used to test indirect effects between facets of religiousness and political attitudes by way of informational assumptions. Latent variables were created for informational assumptions using the items that corresponded to each assumption as observed variables. Additional CFAs were conducted on latent variables for each informational assumption (i.e. harsh punishments, good/bad person, quality of life, personal choice, environmental influence, climate change threat). Upon achieving acceptable goodness- 
of-fit, informational assumption latent variables were entered as mediating variables into a model with religiousness variables as exogenous variables and political attitudes as endogenous variables in a structural model. Indicator variables were allowed to co-vary. Bootstrapping procedures were used to assess indirect effects religiousness on political attitudes via informational assumptions.

\section{Results}

\section{Preliminary analyses}

Normality. The distribution characteristics of all variables was examined. A skewness statistic/standard error ratio greater than 3.2 indicated problems with skewness. Results showed that attendance and one capital punishment item (The death penalty should be imposed more often) were slightly positively skewed and that transcendence, climate change threat, environmental influence, RWA, SES, two capital punishment items (The death penalty is imposed too often; The death penalty is applied unfairly in this country today), three euthanasia items (If a patient has an incurable disease, they should have the right to request life-ending drugs from their doctor; It should be illegal for doctors to prescribe life-ending drugs, even if a patient requests it; There should be a law preventing doctors from prescribing life-ending drugs for any reason), one abortion item (Abortion should be illegal in all circumstances), and three environment items (The US government is doing too little in terms of protecting the environment; The US government should more strongly enforce federal environmental regulations; The US government should spend more government money on developing sources of clean energy such as solar and wind power) were slightly negatively skewed. Although these variables were slightly skewed, no skewness statistic/standard error exceeded 6.5, indicating only mild skewness. Because structural equation modeling is robust against minor violations of normality, 
and in order to maintain the integrity of variables, no transformations were performed on skewed variables.

Outliers. Mahalanobis distance was calculated to determine multivariate outliers. One participant had a Mahaloanobis distance score indicating that they were a multivariate outlier and were not included in analyses.

Validity checks. Throughout the survey, participants were asked to answer two validity check questions (e.g. This question is to make sure you are paying attention. Mark "agree" and continue). Twenty-one participants answered both validity check questions incorrectly and were not included in analyses. Fifty-five participants answered one validity check incorrectly but were retained in analyses if they were not a multivariate outlier. One participant answered one validity check question incorrectly and had a Mahalanobis distance value of greater than 70 . This participant was removed from analyses, leaving a final sample of 481 participants.

Independent samples t-tests. A series of independent samples t-tests were performed to determine if the final sample differed from participants who were removed from the sample on religious and political attitude variables. Results indicated that participants who were removed from the sample had significantly higher religious fundamentalism scores $(M=1.99$, S.D. $=$ 0.40) than participants who were retained $(M=1.56, S . D .=0.72 ; t(498)=-2.91, p<.01)$. Groups did not differ on any other variables.

Missingness. While there were several missing data points across participants, all but two participants in the final sample completed the entire survey. Each of the two participants who did not complete the entire survey completed at least $73 \%$ of the survey. For models examining direct effects between religiousness and political attitudes, FIML (Full Maximum Likelihood 
Estimation) was used to account for missingness. For mediation models with bootstrapping procedures, mean scores were imputed for all composite variables used in mediation models.

Demographics and bivariate correlations. Descriptive statistics can be found in Tables

1-3. Bivariate correlations were calculated between all independent and outcome variables.

Overall, results indicated that religiousness variables were negatively correlated with all political attitudes. Political attitudes were also positively correlated with their corresponding informational assumptions. Finally, religiousness was, overall, positively correlated with harsh punishments and good/bad person, negatively correlated with quality of life, climate change threat, and environmental influence, and not correlated with personal choice. Bivariate correlations for key study variables can be found in Tables 4-6.

\section{Measurement model}

Confirmatory Factor Analysis. Latent variables were created for all religious variables (i.e. institutional religion, spirituality, religious conservatism), political attitudes (i.e. capital punishment, euthanasia, abortion, environmentalism), and informational assumptions (i.e. harsh punishment, good/bad person, quality of life, personal choice, environmental influence, climate change threat). A measurement weight of greater than .5 indicated that an indicator variable was an appropriate fit to its corresponding latent construct (Segars \& Grover, 1993).

Results showed that indicators mapped on to institutional religion and religious conservatism. However, mediation did not map on to the spirituality latent construct. To replace this variable, a latent construct was created using four, two-item parcels from the eight-item spiritual transcendence index.

Latent constructs were successfully created for each political attitude and for informational assumptions including harsh punishments, climate change threat, and 
environmental influence. However, indicator variables for good/bad person, quality of life, and personal choice were less than .5 , demonstrating that items for each scale did not create wellfitting latent constructs. Due to the low factor loadings for each of these informational assumptions, observed variables for each item, rather than latent variables, were used in primary analyses. Standardized measurement weights for each variable on its corresponding latent construct can be found in Figures 1-3.

Measurement invariance. Multi-group analyses tested for measurement invariance between gender, age, ethnicity (white/non-white), religion (protestant, catholic, non-affiliated), and state (West Virginia, Pennsylvania, New Jersey). In order to determine measurement invariance, an unconstrained model was compared with a model in which factor loadings were constrained to be equal (metric invariance), as well as a model in which factor loadings and intercepts were constrained to be equal (scalar invariance). Fit indices were compared between models and a CFI difference of less than .01 indicated measurement invariance.

Measurement invariance was tested in three separate models for religiousness variables (institutional religion, spirituality, religious conservatism), political attitudes (capital punishment, euthanasia, abortion, environmentalism), and informational assumptions (harsh punishment, climate change threat, environmental influence). Results indicated that the factor loadings for each model were invariant for gender, age, race, and state. Factor loadings were also invariant across religious affiliation for political attitudes. However, factor loadings for religious affiliation varied across the religiousness (CFI difference $=.01)$ and informational assumptions models (CFI difference $=.02)$.

A series of analyses were conducted to determine where measures varied across religious groups. Results indicated that when the non-affiliated group was removed, informational 
assumptions were invariant across religious groups (Protestant vs. Catholic), yet religiousness continued to vary at the factor loading level. In order to examine this further, separate models were run for each facet of religiousness (i.e. institutional religion, spirituality, religious conservatism). A latent variable was created using two-item parcels from the devotionalism scale. Findings showed that factor loadings for spirituality and religious conservatism were invariant across Protestant and Catholic groups, yet factor loadings for devotionalism continued to significantly differ across groups. After further examination (Appendix A), one item from the devotionalism scale was dropped and the final latent variable for devotionalism was invariant across religious groups. Findings demonstrated that facets of religiousness had fundamentally different meanings for religious versus non-religious youth. Due to problems with measurement invariance, separate models were estimated using observed religious variables for the entire sample and acceptably fitting latent variables for a sample which included only religious youth $(n=385)$.

Results also indicated that intercepts for several variables varied across groups. Intercepts varied between political ideologies for religiousness variables (CFI difference $=.03$ ). Intercepts also varied across religious affiliation for political attitudes (CFI difference $=.02$ ). Finally, intercepts varied for political attitudes and informational assumptions varied by gender and state $(\mathrm{CFI}$ differences $=.02$, respectively $)$ and intercepts for political attitudes varied by ethnicity (CFI difference $=.02$ ). Variation in intercepts between groups indicated potential mean level differences between variables. In order to achieve partial invariance, critical ratio differences were examined and intercepts which significantly differed across groups were freely estimated. After intercepts were allowed to be freely estimated, partial measurement invariance at the intercept level was achieved. 


\section{Primary analyses}

\section{Predicting youth political attitudes: Full sample models}

Direct effects. Structural equation models were estimated to examine association between religiousness and political attitudes for all youth (Figure 4). Observed composite variables were created for religious attendance, spirituality (STI), and mediation to account for failed invariance tests for religious latent variables. All models controlled for gender, ethnicity, SES, adolescent political ideology, and right-wing authoritarianism (RWA).

Results indicated that increased attendance at religious services was associated with more negative views of capital punishment $(\mathrm{B}=-3.85$, S.E. $=0.94, p<.001)$, euthanasia $(\mathrm{B}=-3.35$, S.E. $=1.17, p<.01)$, and abortion $(\mathrm{B}=-4.79$, S.E. $=0.93, p<.001)$. Increased spirituality was also associated with more negative views of capital punishment $(\mathrm{B}=-6.38$, S.E. $=1.32, p$ $<.001)$, euthanasia $(\mathrm{B}=-5.61$, S.E. $=1.60, p<.001)$, and abortion $(\mathrm{B}=-5.86$, S.E. $=1.27, p$ $<.001 ; \mathrm{X}^{2}=3.49, \mathrm{CFI}=.90, \mathrm{RMSEA}=.07 ;$ Table 7$)$. Meditation was not associated with any political attitudes.

Indirect effects. Bootstrapping procedures were used to examine potential indirect effects between religious variables and political attitudes via informational assumptions for all youth (Figure 5). Due to the high correlations among informational assumptions, separate models were conducted for each informational assumption to avoid potential problems with multicollinearity. Gender, ethnicity, SES, adolescent political ideology, and right-wing authoritarianism (RWA) were included as control variables in each model.

First, direct effects were examined between religious variables and informational assumptions. Direct effects were then examined between informational assumptions and their 
corresponding political attitudes. Finally, indirect effects between religious variables and political attitudes via informational assumptions were examined.

Capital punishment. No facet of religiousness was significantly associated with the harsh punishment informational assumption, but harsh punishments was associated with more positive attitudes toward capital punishment $\left(\mathrm{B}=16.74\right.$, S.E. $=2.19, p<.001 ; \mathrm{X}^{2}=5.42, \mathrm{CFI}=.89$, RMSEA = .10). There were no significant indirect effects between religiousness and capital punishment via harsh punishments.

Estimation of direct effects between religiousness and the good/bad person informational assumptions indicated that increased spirituality $(\mathrm{B}=-.11$, S.E. $=0.05, p<.05)$ and meditation $(\mathrm{B}=-.09$, S.E. $=.04, p<.05)$ were associated with more of the belief that everyone has a little bit of good and a little bit of bad in them (i.e. everyone is a little good and a little bad, reverse coded; $\left.\mathrm{X}^{2}=10.70, \mathrm{CFI}=.96, \mathrm{RMSEA}=.14\right)$. Results further indicated that less belief that everyone is a little good and a little bad $(\mathrm{B}=2.75$, S.E. $=0.96, p<.01)$, as well as the belief that there is no such thing as a "good person" or a "bad person" (e.g. no such thing as a good/bad person, reverse coded; $\mathrm{B}=3.52$, S.E. $=1.08, p<.01)$ were associated with more support for capital punishment $\left(\mathrm{X}^{2}=6.01, \mathrm{CFI}=.88, \mathrm{RMSEA}=.10\right)$. Estimation of indirect effects indicated that meditation was indirectly associated with capital punishment attitudes through the belief that there are two types of people in the word: good people who do good things and bad people who do bad things (i.e. good and bad people; $\mathrm{B}=-.34 . p<.05$ ) such that meditation was not significantly associated with this belief but this belief was associated with more support for capital punishment $\left(\mathrm{B}=3.60\right.$, S.E. $\left.=1.08, p<.001 ; \mathrm{X}^{2}=4.59, \mathrm{CFI}=.90, \mathrm{RMSEA}=.09\right)$. Meditation was also indirectly associated with capital punishment via the belief that everyone is a little good and a little bad $(B=.25 . p<.05)$ such that increased meditation was associated with 
more of this belief $(\mathrm{B}=-.09$, S.E. $=.04, p<.05)$ which was, in turn, associated with less support for capital punishment $\left(\mathrm{B}=-2.85\right.$, S.E. $\left.=1.40, p<.05 ; \mathrm{X}^{2}=4.45, \mathrm{CFI}=.90, \mathrm{RMSEA}=.09\right)$.

Euthanasia and abortion. For quality of life, results indicated that increased spirituality was associated with greater beliefs that maintaining a good quality of life is more important than how long it is (i.e. maintain quality of life; $\mathrm{B}=.14$, S.E. $=.04, p<.01$ ). However, spirituality was also associated with more of the belief that we should strive to keep people alive as long as possible even if their quality of life is compromised (i.e. keep people alive, reverse coded; B = .24, S.E. $\left.=.06, p<.001 ; \mathrm{X}^{2}=51.05, \mathrm{CFI}=.80, \mathrm{RMSEA}=.32\right)$. Belief that we should strive to keep people alive was associated with less positive views of euthanasia $(\mathrm{B}=12.54$, S.E. $=1.28, p$ $\left.<.001 ; \mathrm{X}^{2}=2.29, \mathrm{CFI}=.98, \mathrm{RMSEA}=.05\right)$. Results further indicated that spirituality was indirectly associated with euthanasia via the belief that we should keep people alive $(\mathrm{B}=-3.45, p$ $<.01)$ such that increased spirituality was associated with less of this belief $(\mathrm{B}=-.28$, S.E. $=.06$, $p<.001)$ and this belief was associated with more positive views of euthanasia $(\mathrm{B}=12.54$, S.E. $\left.=1.28, p<.001 ; \mathrm{X}^{2}=2.31, \mathrm{CFI}=.97, \mathrm{RMSEA}=.05\right)$.

For personal choice, results indicated that no facet of religiousness was directly associated with any personal choice item. However, more belief that it is important for people to make their own choices was associated with more positive views of both euthanasia (i.e. own choices; $\mathrm{B}=4.31$, S.E. $=1.91, p<.05)$ and abortion $(\mathrm{B}=4.44$, S.E. $=1.51, p<.01)$. The belief that when it comes to making decisions, it is sometimes necessary for others to intervene so people don't make wrong choices (i.e. make wrong choices, reverse coded) was associated with more support for euthanasia $\left(\mathrm{B}=-3.90\right.$, S.E. $=1.67, p<.05 ; \mathrm{X}^{2}=3.25, \mathrm{CFI}=.94, \mathrm{RMSEA}=$ .04). There were no significant indirect effects between religiousness and either euthanasia or abortion via personal choice. 
Environmentalism. Results indicated that religiousness was not directly associated with either climate change threat or environmental influence. However, increased belief in both climate change threat $\left(\mathrm{B}=20.55\right.$, S.E. $\left.=1.91, p<.001 ; \mathrm{X}^{2}=1.10, \mathrm{CFI}=1.00, \mathrm{RMSEA}=.02\right)$ and environmental influence $\left(\mathrm{B}=23.20\right.$, S.E. $=2.78, p<.001 ; \mathrm{X}^{2}=1.27, \mathrm{CFI}=.99, \mathrm{RMSEA}=$ .02) were directly associated with more positive views of environmentalism. No indirect associations were found between religiousness and environmentalism through either climate change threat or environmental influence.

\section{Predicting youth political attitudes: Religious sample}

Direct effects. A structural equation model was estimated to assess all facets of religiousness as predictors of youth political attitudes for only religious youth (Figure 6). The same control variables, including gender, ethnicity, SES, adolescent political ideology, and rightwing authoritarianism (RWA), were included in the model $\left(\mathrm{X}^{2}=2.43, \mathrm{CFI}=.91, \mathrm{RMSEA}=.06\right.$; Table 8).

Results indicated that increased devotionalism was associated with less support for capital punishment $(\mathrm{B}=-21.41$, S.E. $=10.08, \mathrm{p}<.05)$. Further, spirituality was associated with more support for both euthanasia $(\mathrm{B}=29.64$, S.E. $=10.07, p<.01)$ and abortion $(\mathrm{B}=19.00$, S.E. $=7.51, p<.05)$. Finally, religious conservativism was associated with less support for abortion $(\mathrm{B}=-16.33$, S.E. $=8.03, p<.05)$, and environmentalism $(\mathrm{B}=-18.95$, S.E. $=6.79, p<.01)$.

Findings for devotionalism and religious conservativism were consistent with bivariate correlations. However, there was a negative correlation between spirituality and euthanasia and abortion whereas direct effects indicated a positive association. To explore possible issues with suppression, separate structural equation models examined associations between each facet of religiousness and political attitudes. Each model included gender, SES, ethnicity, adolescent 
political ideology, and Right Wing Authoritarianism as control variables. Results indicated that increased devotionalism was consistently associated with less support for capital punishment (B $=-9.26$, S.E. $=2.04, p<.001)$, as well as euthanasia $(\mathrm{B}=-10.91$, S.E. $=2.69, p<.001)$, and abortion $\left(\mathrm{B}=-12.75\right.$, S.E. $\left.=2.23, p<.001 ; \mathrm{X}^{2}=2.75, \mathrm{CFI}=.89, \mathrm{RMSEA}=.07\right)$. Similarly, religious conservativism was associated with less support for abortion $(\mathrm{B}=-22.10$, S.E. $=3.34, p$ $<.001)$ and euthanasia $(\mathrm{B}=-21.19, S . E .=3.51, p<.001)$, as well as more support for capital punishment $\left(\mathrm{B}=-8.06\right.$, S.E. $\left.=2.67, p<.01 ; \mathrm{X}^{2}=2.87, \mathrm{CFI}=.89, \mathrm{RMSEA}=.07\right)$. However, when examined separately, increased spirituality was associated with more negative views of euthanasia $(\mathrm{B}=-6.24$, S.E. $=2.50, p<.001)$ and abortion $\left(\mathrm{B}=-8.81\right.$, S.E. $=2.00, p<.001 ; \mathrm{X}^{2}=$ 2.68, CFI = .90, RMSEA = .07), as well as capital punishment $(\mathrm{B}=-6.35$, S.E. $=1.84, p<.001)$. These findings indicate that when all facets of religiousness were included in the model, devotionalism and religious conservatism served as suppressor variables, causing the association between spirituality and euthanasia and abortion to switch directions.

Indirect effects. A series of models was used to examine potential indirect effects between religiousness and political attitudes via informational assumptions (Figure 7). Each informational assumption was examined independently in all models to avoid potential problems with multicollinearity. Gender, ethnicity, SES, adolescent political ideology, and right-wing authoritarianism (RWA) were included as control variables in each model.

First, direct effects were examined between religious variables and informational assumptions. Direct effects were then examined between informational assumptions and their corresponding political attitudes. Finally, bootstrapping procedures were used to examine indirect effects between religious variables and political attitudes via informational assumptions. 
Capital punishment. Examination of direct effects indicated that spirituality $(B=.41$, S.E. $\left.=0.17, p<.05 ; \mathrm{X}^{2}=2.49, \mathrm{CFI}=.96, \mathrm{RMSEA}=.06\right)$ was associated with increased belief that harsh punishments are effective at deterring crime. Further, increased belief in harsh punishments was associated with more positive views of capital punishment $(\mathrm{B}=21.74$, S.E. $=$ $\left.3.65, p<.001 ; \mathrm{X}^{2}=4.24, \mathrm{CFI}=.89, \mathrm{RMSEA}=.09\right)$. Indirect effects between religiousness and capital punishment via harsh punishments were then examined. Results indicated that spirituality was indirectly associated with capital punishment via harsh punishments informational assumption $(\mathrm{B}=8.98, p<.05)$ such that increased spirituality was associated with increased beliefs that harsh punishments are an effective way to deter crime $(\mathrm{B}=.44$, S.E. $=0.18, p<.05)$ which was, in turn, associated with more support for capital punishment $(\mathrm{B}=20.50$, S.E. $=3.75$, $\left.p<.001 ; \mathrm{X}^{2}=2.59, \mathrm{CFI}=.94, \mathrm{RMSEA}=.07\right)$.

Because good/bad person did not create an acceptably fitting latent construct, observed variables for each of the three good/bad person items were used as potential mediators. Results indicated that increased devotionalism $(\mathrm{B}=-.11, S . E .=0.50, p<.05)$ was associated with less of the belief that there are two types of people in the world: good people who do good things and bad people who do bad things (i.e. good people and bad people) while religious conservatism was associated with more of this belief $(\mathrm{B}=1.05, S . E .=0.41, p<.05)$. Increased devotionalism was further associated with more of the belief that there is no such thing as a "good person" or $a$ "bad person" (i.e. no such thing as a good/bad person, reverse coded; B $=-1.49, S . E .=0.59, p$ $<.05)$. Finally, increased spirituality was associated with more of the belief that everyone has $a$ little bit of good and a little bit of bad in them (i.e. everyone is a little good and a little bad, reverse coded; $\mathrm{B}=-.66, S . E .=0.23, p<.01)$ while religious conservatism was associated with less of this belief $\left(\mathrm{B}=1.06, S . E .=0.26, p<.001 ; \mathrm{X}^{2}=3.00, \mathrm{CFI}=.95, \mathrm{RMSEA}=.07\right)$. Results 
further indicated that the belief that there are good people and bad people $(\mathrm{B}=4.59, S . E .=1.19$, $p<.001)$ and that there is such a thing as a good or bad person $(\mathrm{B}=2.95, S . E .=1.07, p<.01)$ were associated with more endorsement of capital punishment $\left(\mathrm{X}^{2}=4.59, \mathrm{CFI}=.88, \mathrm{RMSEA}=\right.$ 1.00). Despite these direct associations, however, there were no indirect effects between religiousness and capital punishment via good/bad person.

Euthanasia and abortion. Examination of direct effects for quality of life indicated that increased spirituality was associated with more belief that maintaining a good quality of life is more important than how long it is (i.e. maintain quality of life; $\mathrm{B}=.65, S . E .=0.22, p<.01$ ) while increased religious conservatism was associated with less of this belief $(\mathrm{B}=-.84, S . E .=$ $0.26, p<.01)$. Increased spirituality was also associated with less of the belief that we should strive to keep people alive as long as possible even if their quality of life is compromised (i.e. keep people alive, reverse coded; $\mathrm{B}=.65, S . E .=0.32, p<.05 ; \mathrm{X}^{2}=2.77, \mathrm{CFI}=.95, \mathrm{RMSEA}=$ $.07)$ and this belief was associated with more positive views of euthanasia $(\mathrm{B}=12.20, S . E .=$ $\left.1.52, p<.001 ; \mathrm{X}^{2}=2.18, \mathrm{CFI}=.97, \mathrm{RMSEA}=.06\right)$. However, no indirect effects between religiousness and euthanasia via quality of life emerged.

Examination of direct effects for personal choice indicated that increased religious conservatism was associated with less belief that it is important for people to make their own choices $(\mathrm{B}=-.80$, S.E. $=0.26, p<.01)$. Further, increased spirituality was associated with more of the belief that when it comes to making decisions, it is sometimes necessary for others to intervene so people don't make wrong choices (i.e. make wrong choices, reverse coded; B = -.55, S.E. $=0.24, p<.05)$ while increased religious conservatism was associated with more of this belief $(\mathrm{B}=.76$, S.E. $=0.27, p<.01)$. Finally, increased devotionalism was associated with less of the belief that when making a decision, people always know what is best for themselves $(\mathrm{B}=-$ 
.96$, S.E. $=0.47, p<.05)$ whereas religious conservatism was associated with more of this belief $\left(\mathrm{B}=1.23\right.$, S.E. $\left.=0.40, p<.01 ; \mathrm{X}^{2}=2.68, \mathrm{CFI}=.96, \mathrm{RMSEA}=.07\right)$. However, no personal choice items were associated with either euthanasia or abortion and further results indicated no indirect effects between religiousness and euthanasia or abortion via personal choice.

Environmentalism. Estimation of direct effects indicated that increased religious conservatism was associated with less belief that climate change is a threat to the earth $(\mathrm{B}=-$ 1.03, S. E. $\left.=0.23, p<.001 ; \mathrm{X}^{2}=2.69, \mathrm{CFI}=.95, \mathrm{RMSEA}=.07\right)$ and that this belief was associated with more positive views of environmentalism $\left(\mathrm{B}=20.30, S . E .=2.23, p<.001 ; \mathrm{X}^{2}=\right.$ $1.34, \mathrm{CFI}=.99, \mathrm{RMSEA}=.03)$. Results also indicated that religious conservatism was indirectly associated with environmentalism via climate change threat $\left(\mathrm{B}=-22.07, p<.01 ; \mathrm{X}^{2}=2.13, \mathrm{CFI}\right.$ $=.96$, RMSEA $=.06)$ such that increased religious conservatism was negatively associated with the belief that climate change is a threat to the earth $(\mathrm{B}=-1.03, S . E .=0.24, p<.001)$ and belief in climate change threat was associated with less positive views of environmentalism $(B=21.41$, S. $E .=2.70, p<.001)$.

Associations were also explored between religiousness and environmental influence and between environmental influence and environmentalism. Results indicated that increased religious conservatism was associated with fewer beliefs that humans influence the environment $\left(\mathrm{B}=-.81, S . E .=0.23, p<.001 ; \mathrm{X}^{2}=2.58, \mathrm{CFI}=.95, \mathrm{RMSEA}=.07\right)$, which was, in turn, associated with more support for environmentalism $\left(\mathrm{B}=25.46, S . E .=3.76, p<.001 ; \mathrm{X}^{2}=1.23\right.$, $\mathrm{CFI}=.99, \mathrm{RMSEA}=.03)$. When indirect effects were examined, results indicated that environmental influence mediated the association between religious conservatism and environmentalism $\left(\mathrm{B}=-20.84, p<.05 ; \mathrm{X}^{2}=2.09, \mathrm{CFI}=.96, \mathrm{RMSEA}=.06\right)$ such that religiously conservative youth were less likely to believe that people influence the environment 
$(\mathrm{B}=-.79, S . E .=0.22, p<.001)$ and that this belief was associated with less positive views of the environment $(\mathrm{B}=26.28, S . E .=4.54, p<.001)$.

\section{Discussion}

The current study showcases the link between religiousness and political attitudes in adolescence. Developmental competencies such as abstract thought allow youth to critically consider and form opinions about religious and political issues. Adolescent's political ideology, values, and beliefs have been shown to be influenced by their parents' views, school contexts, and community activities (Youniss et al., 2002), yet this is the first known study that demonstrates associations between religiousness and political attitudes in adolescence. Indeed, adolescents' involvement with religious organizations, religiously conservative beliefs, and spiritual connection to a higher power were associated with attitudes toward capital punishment, euthanasia, abortion, and environmentalism. Further, associations between religiousness and political attitudes were not universally consistent with traditionally liberal versus conservative ideology, indicating that the association between religiousness and youth's developing political attitudes are differentiated and unique.

The current study also indicates the importance of considering individual facets of youth religiousness. Institutional religion entails religious behaviors such as attending religious services and the devotion youth feel toward religious organizations while religious conservativism refers to the belief that a certain religion and the religious texts of that religion are true and correct. Spirituality involves the connection youth feel to a higher power, as well as the world around them (meditation). Institutional religion, religious conservatism, and spirituality were shown to have fundamentally different measurement characteristics hinting at the fact that these constructs have various meanings for religious versus non-religious youth. 
These differences between religious and non-religious youth required associations to be examined between both a full sample and one consisting of only religious youth. The related, yet unique components of religiousness were also differentially associated with youth's political attitudes toward capital punishment, euthanasia, abortion, and environmentalism. These differences illustrate diversity in the way religious youth view political issues and are informed by their involvement with religious organizations, religious conservativism, and spirituality.

Institutional religion. Institutional religion (i.e. religious attendance, devotionalism) was associated with less supportive views of capital punishment while youth who frequently attended religious services also exhibited less support for euthanasia and abortion. Institutional religion may be important for youth's formation of political attitudes as religious organizations often have their own unique set of beliefs and doctrines which correspond to social and political issues (McIntosh \& Youniss, 2010). Youth who attend religious services are exposed to the messages which are put forth by religious organizations (King, 2003). Religious youth are also surrounded by an intergenerational community who are likely share similar views on political issues (Bloom, 2007; Burdette et al., 2005; Miller \& Hayward, 2008). Attending religious services serves as one context which may contribute to the formation of youth's own political attitudes. Hearing consistent messages in religious services and from church members at religious social events may explain why institutional religion was associated with less support for capital punishment, euthanasia, and abortion.

Research has also shown that with increased autonomy, religious attendance in adolescence decreases as youth get older (Hackerman \& King, 1998; Keretes, Youniss, \& Metz, 2004; Smith et al., 2002). Youth who feel particularly devoted to their religious organization might continue to attend religious services for intrinsic reasons and be more likely to infuse 
religious doctrines into their own developing beliefs about social and political issues.

Collectively, institutional religion was linked with less support for all political policies which concern the killing of life (i.e. capital punishment, euthanasia, abortion). For example, while research has shown that devotionalism has been linked to more support for the death penalty in adult populations (Miller \& Hayward, 2008), current findings suggest that youth who are involved with and devoted to religious organizations have less positive views of capital punishment. Moreover, institutional religion was not shown to exclusively follow a single political viewpoint as traditional liberal ideology often condemns capital punishment while conservative ideology traditionally lacks support for euthanasia and abortion (Democrats, 2018; Republican Views, 2018). This might indicate a cohort effect for religiously involved youth in that today's adolescents view all issues of life in a similar way rather than supporting capital punishment but disapproving of euthanasia or abortion which would be consistent with a conservative political viewpoint. Results illustrate the distinct role of religious organizations in the formation of political attitudes toward capital punishment, euthanasia, and abortion in adolescence.

Religious conservatism. Religious conservatism (i.e. religious fundamentalism, adherence to religious texts, religious in-group favoritism) was also associated with less support for abortion, as well as environmentalism. Beyond religious attendance and devotionalism, youth who believe that their own religion is the only true and correct religion may more consistently subscribe to the teachings of their faith. Messages that are set forth by religious texts are also consistent with many political issues and the political attitudes of youth who adhere to these texts are likely to be influenced by them (Burdette et al., 2005; Evans \& Adams, 2003; Miller \& Hayward, 2008). Finally, while youth who attend religious services and social events are 
exposed to people who likely have similar political viewpoints, religious in-group favoritism refers to the preference to surround oneself with people of the same faith. Indeed, youth who prefer to be around people with similar religious and political viewpoints may be further influenced by these people when considering their own political attitudes.

It is also important to note the ways which religious conservatism was linked with political attitudes compared to institutional religion. When accounting for institutional religion, religious conservatism was only linked with abortion rather than capital punishment and euthanasia. Religious conservatism was also the only facet of religiousness associated with less support of environmentalism while institutional religion and spirituality were not. Certain religions may assert that God is responsible for the quality of the earth rather than humans (Guth et al., 1995). Under this belief, religiously conservative youth might not see the need for environmental regulations as only God can affect the environment. Associations between religious conservativism and both abortion and environmentalism were also consistent with traditionally conservative attitudes which lack support for both abortion and environmentalism (Republican Views, 2018). It is likely that religiously conservative youth have similarly conservative ideals in other areas, such as their political beliefs. Collectively, findings demonstrate the nuanced ways which religiously conservative youth differ in their political attitudes compared to adolescents who are simply involved with or devoted to religious organizations. Differences between religious youth showcase the importance of examining religiousness as a multidimensional construct.

Spirituality. Findings for the association between spirituality and political attitudes were mixed. When examined separately, spirituality was associated with less endorsement of capital punishment, euthanasia, and abortion. Conversely, spiritual youth were shown to have more 
support for euthanasia and abortion when devotionalism and religious conservatism were included in the model. Youth who have higher levels of institutional religion and religious conservatism are likely to feel greater levels of connection to a higher power than non-religious youth. This might explain why spirituality, when examined independently, was linked with political attitudes in a similar way as other facets of religiousness. However, when accounting for devotionalism and religious conservatism, which are more greatly centered on organized religious groups, spirituality contributed to attitudes toward euthanasia and abortion in the opposite direction.

It could be that traditionally conservative viewpoints which disapprove of euthanasia and abortion are more tied with religious organizations than connection with a higher power. This may explain why more formal facets of religiousness (i.e. institutional religion, religious conservativism) contributed to political attitudes differently than informal facets of religiousness which are not tied to any one religion (i.e. spirituality). Youth who believe in and/or feel a strong sense of connection to a higher power may consider these beliefs when forming their opinions about political issues. For example, youth who believe that a higher power does not want people to suffer might be more supportive of laws which allow terminally sick people to end their own lives. Results also suggest that individual facets of religiousness may interact in the ways that they contribute to political attitudes. For instance, the connection youth feel with a higher power might manifest differently for youth who attend religious services versus those who do not. Overall, current findings demonstrate the differential ways which formal and informal facets of religiousness contribute to political attitudes toward capital punishment, euthanasia, abortion, and environmentalism. 


\section{The role of informational assumptions}

As described above, Social Domain Theory posits that differences in the way people view multifaceted issues are informed by their informational assumptions, or what they believe to be fundamentally true about the world. Current findings suggest that adolescent religiousness provides one context through which youth form their beliefs and that different facets of adolescent religiousness contribute differently to assumptions youth hold about people, choice, and the environment. For example, youth who attend religious services or feel devoted to a religious organization are more likely to be influenced by their doctrines than non-religious youth. This might explain why youth who attend religious services or feel devoted to a religious organization were less likely to hold the informational assumption that believe that people should be able to make their own choices. Religiously conservative youth may be further shaped by these messages if they believe that their religion is the only correct and true religion, as religiously conservative youth were more likely to hold the informational assumption that the length of someone's life matters more than its quality. Finally, the connection that spiritual youth feel toward a higher power is likely to inform their views about the world in a way that is consistent with that higher power. For instance, spiritual youth were less likely to believe that there are exclusively good and bad people in the world. Collectively, results show the ways which components of religiousness differentially impact adolescents' informational assumptions about the world.

The current study also supports previous work which has shown that informational assumptions are associated with the attitudes people have about political issues (Smetana, 1981). This provides one potential explanation for how contexts such as religious experiences may affect the development of political beliefs. Adolescents may not form opinions about political issues exclusively by mimicking the views of their family, teachers, or religious organizations. 
Instead, religious organizations serve as one context under which adolescents' form their fundamental beliefs about the world, which further informs their political attitudes. For example, the belief that harsh punishments are effective at deterring crime or that people are exclusively good or bad corresponded to greater support for capital punishment. Youth who valued quality of life over how long it is were also shown to have more support for euthanasia and youth who believed that people should make their own choices were shown to have more positive views of euthanasia and abortion. Last, the beliefs that climate change is a threat to the environment and that humans can influence the environment were associated with more support for policies which seek to protect the environment. These associations highlight that adolescent's developing political attitudes are not arbitrary, but rather consistent with their fundamental assumptions and beliefs about people and the world.

Finally, informational assumptions were shown to mediate the association between certain aspects of religiousness and some political attitudes. In the full sample, youth who meditated more were less likely to believe that there are exclusively good and bad people in the world which explained their less positive views of capital punishment. It is important to note that meditation is unique from prayer in that this behavior may or may not be toward any specific higher power. Instead, youth who meditate might feel a stronger connection to the world and other people around them, helping them see both good and bad qualities in others (Hill et al., 2000). These practices might lead youth to prefer rehabilitation in prison systems rather than the death penalty, explaining their lack of support for capital punishment.

Informational assumptions were also shown to mediate the link between religiousness and political attitudes among youth with high levels of religious spirituality. Namely, the belief that quality of life is more important than how long it is was shown to mediate the association 
between spirituality and euthanasia. Spiritual youth may feel a stronger sense of connection to others which makes them value the quality of a person's life. The belief that harsh punishments are effective at deterring crime also mediated the association between spirituality and support for capital punishment. Although spirituality has been previously linked with forgiveness (LawlerRow, 2010), spiritual youth might still feel as if harsh punishments are a practical way to reduce crime. Mediation models also accounted for youth's devotion to religious organizations and religious conservativism, continuing to showcase how spirituality contributes to political attitudes independent of more formal religiousness. Findings continue to support the ways which formal and non-formal components of religion contribute to political attitudes in youth.

Finally, the belief that climate change is a threat to the Earth and that humans have the ability to influence the environment were shown to mediate the association between religious conservatism and less positive views of laws which protect the environment. Religious organizations might assert that God will provide people with the resources they need, regardless of the current state of the environment. Religious organizations may also posit that it is the responsibility of God rather than humans to take care of the environment. Youth who believe this might not see the need for laws which seek to protect the environment.

Despite indirect associations between facets of religiousness and political attitudes, there were also several instances where informational assumptions were associated with religiousness but did not link religiousness to political attitudes. For example, devotionalism and spirituality were linked with less of the belief that people are either all good or all bad, while religious conservatism was associated with more of this belief. The good/bad person informational assumption was further associated with support for capital punishment. However, while institutional religion and spirituality were also connected with capital punishment, the good/bad 
person informational assumption did not mediate this link. This lack of indirect effects suggests other potential mediators that might explain the association between certain facets of religiousness and political attitudes. Overall, the current study highlights the ways which religiousness informs youth's informational assumptions about the world and how these informational assumptions inform youth's political attitudes toward capital punishment, euthanasia, abortion, and environmentalism.

\section{Limitations and future directions}

Results of the current study should be interpreted under several limitations. First, data were cross-sectional meaning that causal links between variables cannot be inferred. It is also possible that youth who hold certain political beliefs may seek out religious organizations and experiences that are consistent with their views. Future research should explore potential causal and bi-directional pathways between religiousness and political attitudes as well as indirect effects via informational assumptions using longitudinal data.

The sample was also primarily Caucasian and Christian making it unclear if current findings would remain stable in more diverse populations. This lack of diversity, as well as high covariances between religious variables, does also not allow for potential differences between religious organizations to be determined. Although separate models were conducted to avoid potential problems with multicollinearity and suppression, results due to measurement artifacts might be possible. Future research should examine potential interaction effects between religious variables in their association to political attitudes.

Additionally, while the current study was able to establish a variety of new measures that contribute to the current body of work on religiousness, political attitudes, and informational assumptions, there were some limitations due to measurement. While well-fitting latent variables 
were established for harsh punishments, climate change threat, and environmental influence, latent variables could not be created for the good/bad person, quality of life, and personal choice informational assumptions. Findings using individual items as mediator variables should also be interpreted with caution and future research should seek to revise current informational assumption measures as well as consider other potential mediators. There were also several models which had poor fit indicies (e.g. CFI <.90; RMSEA > .05) and findings for these models should be interpreted with caution. Finally, the use of Likert-type scales limits information that could be gained about religious and political beliefs. Future research should consider alternate methods of examining the association between religiousness and political attitudes in adolescence such as interviews which could delve deeper into adolescents' religious and political beliefs.

\section{Conclusion}

Overall, the current study continues to highlight the links between religiousness and political attitudes as well as establishes these associations in adolescence. Results also showed the ways which different facets of religiousness contribute to political attitudes, illustrating the complex and multidimensional nature of religiousness. Finally, results further support Social Domain Theory, showcasing the ways which religiousness contributes to youth's informational assumptions about the world and how these informational assumptions inform adolescents' political attitudes. Findings provide political candidates about the political viewpoints of their religious (and non-religious) constituents and civic educators about the role of religion in the early formation of political attitudes. Future research should build on the current study by continuing to examine links between religiousness, informational assumptions, and political attitudes in adolescence. 


\section{References}

Altemeyer, B. (1996). The authoritarian specter. Cambridge, MA: Harvard University Press. Altemeyer, B., \& Hunsberger, B. (1992). Authoritarianism, religious fundamentalism, quest, and prejudice. The International Journal for the Psychology of Religion, 2(2), 113-133. doi:10.1207/s15327582ijpr0202_5

Altemeyer, B., \& Hunsberger, B. (2004). A revised religious fundamentalism scale: The short and sweet of it. The International Journal for the Psychology of Religion, 14(1), 47-54.

Applegate, B. K., Cullen, F. T., Fisher, B. S., \& Vander Ven, T. (2000). Forgiveness and fundamentalism: Reconsidering the relationship between correctional attitudes and religion. Criminology, 38(3), 719-754.

Barry, C. M., \& Nelson. L. J. (2008). The role of religious beliefs and practices on emerging adults' perceived competencies, perceived importance ratings, and global self-worth. International Journal of Behavioral Development 32(6), 509-521. doi:10.1177/0165025408095555

Batson, D. (1976). Religion as prosocial: Agent or double agent. Journal for the Scientific Study of Religion, 15(1), 29-45. doi:10.2307/1384312

Bloom, P. (2007). Religion is natural. Developmental Psychology, 10(1), 147-151. doi:10.1111/j.1467-7687.2007.00577.x

Bulmer, M., Bohnke, J. R., \& Lewis, G. J. (2017). Predicting moral sentiment towards physicianassisted suicide: The role of religion, conservatism, authoritarianism, and big Five personality. Personality and Individual Differences, 105, 244-251. doi:10.1016/j.paid.2016.09.034 
Burdette, A. M., Hill, T. D, \& Moulton, B. E. (2005). Religion and attitudes toward physicianassisted suicide and terminal palliative care. Journal for the Scientific Study of Religion, 44(1), 79-93.

Democrats. (2018, April 2). The 2016 democratic platform. Retrieved from https://www.democrats.org/party-platform

Dunkel, C., \& Dutton, E. (2016). Religiosity as a predictor of in-group favoritism within and between religious groups. Personality and Individual Differences, 98, 311-314. doi:10.1016/j.paid.2016.04.063

Evans, T., \& Adams, M. (2003). Salvation or damnation: Religion and correctional ideology. American Journal of Criminal Justice, 28(1), 15-35. doi:10.1007/BF02885750

Gallup. (2017, September 4). Abortion. Retrieved from http://www.gallup.com/poll/1576/Abortion.aspx

Gallup. (2017, September 4). Death penalty. Retrieved from http://www.gallup.com/poll/1606/Death-Penalty.aspx

Gallup. (2017, September 4). Environment. Retrieved from http://www.gallup.com/poll/1615/Environment.aspx

Gallup. (2017, September 4). Seven in 10 Americans back euthanasia. Retrieved from http://www.gallup.com/poll/171704/seven-americans-backeuthanasia.aspx?g_source=euthanasia\&g_medium=search\&g_campaign=tiles

Good, M. \& Willoughby, T. (2008). Adolescence as a sensitive period for spiritual development. Child Development Perspectives, 2(1), 32-37. doi:10.1111/j.1750-8606.2008.00038.x 
Good, M., Willoughby, T., \& Busseri, M. A. (2011). Stability and change in adolescent spirituality/religiosity: A person-centered approach. Developmental Psychology, 47(2), 538-550. doi:10.1037/a0021270

Greeley, A. (1993). Religion and attitudes toward the environment. Journal for the Scientific Study of Religion, 32(1), 19-28.

Guth, J. L., Green, J. C., Kellstedt, L. A., Smidt, C. E. (1995). Faith and the environment: Religious beliefs and attitudes on environmental policy. American Journal of Political Science, 39(2), 364-382. doi:10.2307/2111617

Hackerman, A. \& King, P. (1998). Adolescent spirituality. Alcoholism Treatment Quarterly, 16, 89-99. doi:10.1300/J020v16n03_08

Haug, I. E. (1998). Spirituality as a dimension of family therapists' clinical training. Contemporary Family Therapy, 20(4), 471-483. doi:10.1023/A:1021628132514

Hardy, S. A., Pratt, M. W., Pancer, M. S., Olsen, J. A., \& Lawford, H. L. (2010). Community and religious involvement as contexts of identity change across late adolescence and emerging adulthood. International Journal of Behavioral Development, 35(2), 125-135. doi:10.1177/0165025410375920

Hess, J. A., \& Rueb, J. D. (2005). Attitudes toward abortion, religion, and party affiliation among college students. Current Psychology, 24(1), 24-42.

Hill, P. C., Pargament, K. I., Hood, R. W., McCullough, M. E., Swyers, J. P., Larson, D. B., \& Zinnbauer, B. J. (2000). Conceptualizing religion and spirituality: Points of commonality, points of departure. Journal for the Theory of Social Behaviour, 30(1), 0021-8308. doi:10.1111/1468-5914.00119 
Hyland, M. E., Wheeler, P., Kamble, S., \& Masters, K. S. (2010). A sense of 'special connection', self-transcendent values and a common factor for religious and non-religious spirituality. Archive for the Psychology of Religion, 32(3), 293-326. doi:10.1163/157361210x533265

Jensen, L. A. (2009). Conceptions of God and the Devil across the lifespan: A culturaldevelopmental study of religious liberals and conservatives. Journal for the Scientific Study of Religion, 48(1), 121-145. doi:10.1111/j.1468-5906.2009.01433.x

Keretes, M., Youniss, J., \& Metz, E. (2004). Longitudinal patterns of religious perspective and civic integration. Applied Developmental Science, 8, 39-46. doi:10.1207/S1532480XADS0801_5

King, P. E. (2003). Religion and identity: The role of ideological, social, and spiritual contexts. Applied Developmental Science, 7(3), 197-204. doi:10.1207/S1532480XADS0703_11

King, P. E., Clardy, C. E., \& Ramos, J. S. (2014). Adolescent spiritual exemplars: Exploring spirituality in the lives of diverse youth. Journal of Adolescent Research, 29(2), 186-212. doi:10.1177/0743558413502534

King, P. B., \& Roeser, R. W. (2008). Religion and spirituality in adolescent development. Handbook of Adolescent Psychology, 1, 435-478.

Knoll, B. R. (2009). “And Who Is My Neighbor?” religion and immigration policy attitudes. Journal for the Scientific Study of Religion, 48(1), 313-331. doi:10.1111/j.14685906.2009.01449.x

Lam, P. (2002). As the flocks gather: How religion affects voluntary association participation. Journal for the Scientific Study of Religion, 41(3), 405-422. doi:10.1111/14685906.00127 Lawler-Row, K. (2010). Forgiveness as a mediator of the religiosity-health relationship. Psychology of Religion and Spirituality, 2(1), 1-16. doi:10.1037/a0017584 
Laythe, B., Finkel, D. \& Kirkpatrick, L. A. (2001). Predicting prejudice from religious fundamentalism and right-wing authoritarianism: A multiple-regression approach. Journal for the Scientific Study of Religion, 40(1), 1-10.

Lindsey, S. C., Sigillo, A. E., \& Miller, M. K. (2013). Attitudes toward parental involvement clauses in minor abortion laws and individual differences in religion, political affiliation, and attribution style among college students. Individual Differences Research, 11(2), 5969.

Lipka, M. (2017, September 4). U. S. religious groups and their political leanings. Retrieved from http://www.pewresearch.org/fact-tank/2016/02/23/u-s-religious-groups-and-theirpolitical-leanings/

MacCallum, R. C., Brown, M. W., \& Sugawara, H. M. (1996). Power analysis and determination of sample size for covariance structure modeling. Psychological Methods, 1, 130-149. doi:10.1037/1082-989X.1.2.130

McIntosh, H. \& Youniss, J. (2010). Toward a political theory of political socialization of youth. In L. R. Sherrod, J. Torney-Purta, \& C. A. Flanagan (Eds.), Handbook of Research on Civic Engagement in Youth (pp. 23-41). Hoboken, NJ: John Wiley \& Sons, Inc.

Metzger, A. \& Smetana, J. G. (2009). Adolescent civic and political development: Associations between domain-specific judgements and behavior. Child Development, 80(2), 433-441.

Metzger, A. \& Smetana, J. G. (2010). Social cognitive approaches to civic engagement. In L. Sherrod, J. Torney-Purta, \& C. A. Flanagan (Eds.), Handbook of Research on Civic Engagement in Youth (pp. 23-41). Hoboken, NJ: John Wiley \& Sons, Inc.

Miller, M. K., \& Hayward, R. D. (2008). Religious characteristics and the death penalty. Law and Human Behavior, 32(2), 113-123. doi:10.1007/s10979-007-9090-z 
Miller, W. R., \& Thoresen, C. E. (2003). Spirituality, religion, and health: An emerging research field. American Psychologist, 58(1), 24-35. doi:10.1037/0003-066X.58.1.24

Nucci, L. \& Turiel, E. (1993). God's word, religious rules, and their relation to Christian and Jewish children's concept of morality. Child Development, 64(5), 1475-1491. doi:10.1111/j.1467-8624.1993.tb02965.x

Oosterhoff, B., Ferris, K. A., \& Metzger, A. (2014). Adolescents' sociopolitical values in the context of organized activity involvement. Youth \& Society, 1-21. doi:10.1177/0044118X14560528

Pratto, F., Sidanius, J., Stallworth, L. M., \& Malle, B. F. (1994). Social dominance orientation: A personality variable predicting social and political attitudes. Journal of Personality and Social Psychology, 67(4), 741-763. doi:10.1037/0022-3514.67.4.741

Putney, S., \& Middleton, R. (1961). Dimensions and correlates of religious ideologies. Social Forces, 39(4), 285-290. doi:10.2307/2573423

Republican Views. (2018, April 2). Republican views on abortion. Retrieved from: https://www.republicanviews.org/republican-views-on-abortion/

Republican Views. (2018, April 2). Republican views on the environment. Retrieved from: https://www.republicanviews.org/republican-views-on-the-environment/

Rosik, C. H., Griffith, L. K., \& Cruz, Z. (2007). Homophobia and conservative religion: Toward a more nuanced understanding. American Journal of Orthopsychiatry, 77(1), 10-19. doi:10.1037/0002-9432.77.1.10

Rowatt, W. C., LaBouff, J., Johnson, M., Froese, P., \& Tsang, J. A. (2009). Associations among religiousness, social attitudes, and prejudice in a national random sample of American adults. Psychology of Religion and Spirituality, 1(1), 14-24. 
Segars, A. H., \& Grover, V. (1993). Re-examining perceived ease of use and usefulness: A confirmatory factor analysis. MIS Quarterly, 17(4), 517-525.

Seidlitz, L., Abernethy, A. D., Duberstein, P. R., Evinger, J. S., Chang, T. H., \& Lewis, B. L. (2002). Development of the Spiritual Transcendence Index. Journal for the Scientific Study of Religion, 41(3), 439-453. doi:10.1111/1468-5906.00129

Shaw, L. A., \& Wainryb, C. (1999). The outsider's perspective: Young adults' judgments of social practices of other cultures. British Journal of Developmental Psychology, 17(3), 451-471.

Smetana, J. G. (1979). Beliefs about the permissibility of abortion and their relationship to decisions regarding abortion. Journal of Population, 2(4), 294-305.

Smetana, J. G. (1981). Reasoning in the personal and moral domains: Adolescent and young adult women's decision-making regarding abortion. Journal of Applied Developmental Psychology, 2, 211-226. doi:10.1177/0192513X12437708

Smetana, J. G. (2006). Social-cognitive domain theory: Consistencies and variations in children's moral and social judgements. In M. Killian \& J. G. Smetana (Eds.), Handbook of Moral Development (119-153). Mahwah, NY: Lawrence Erlbaum Associates.

Smetana, J. G., Rote, W. M., Jambon, M., Tasopoulos-Chang, M., Villalobos, M., \& Comer, J. (2012). Developmental changes and individual differences in young children's moral judgments. Child Development, 83(2), 683-696. doi:10.1111/j.1467-8624.2011.01714.x

Smetana, J. G., \& Turiel, E. (2005). Moral development during adolescence. In G. Adams \& M. Berzonsky (Eds.), Blackwell Handbook of Adolescence (247-268). Oxford, UK: Blackwell Publishing. 
Smith, C., Denton, M. L., Faris, R., \& Regnerus, M., (2002). Mapping American adolescent religious participation. Journal for the Scientific Study of Religion, 41(4), 597-612. doi:10.1111/1468-5906.00148

Smith, K. A., Harvath, T. A., Goy, E. R., \& Ganzini, L. (2015). Predictors of pursuit of physician-assisted death. Journal of Pain and Symptom Management, 49(3), 555-561. doi:10.1016/j.jpainsymman.2014.06.010

Tabachnick, B. G., \& Fidell, L. S. (2013). Using multivariate statistics. New Jersey: Pearson.

Turiel, E., Hildebrant, C., Wainryb, C., \& Saltzstein, H. D. (1991). Judging social issues: Difficulties, inconsistencies, and consistencies. Monographs of the Society for Research in Child Development, 56(2). doi:10.2307/1166056

Underwood, L. \& Teresi, J. (2002). The daily spiritual experience scale: Development, theoretical description, reliability, exploratory factor analysis, and preliminary construct validity using health-related data. Annals of Behavioral Medicine, 24(1), 22-33. doi:10.1207/S15324796ABM2401_04

Wainryb, C. (1991). Understanding differences in moral judgements: The role of informational assumptions. Child Development, 62(4), 840-851.

Youniss, J., Bales, S., Christmas-Best, V., Diversi, M., McLaughlin, M., \& Silbereisen, R. (2002). Youth civic engagement in the Twenty-First Century. Journal of Research on Adolescence, 12(1), 121-148. 


\section{Appendix A - Additional analyses}

\section{Measurement invariance}

To determine which facets of religiousness varied across religious affiliation groups, a separate invariance test was conducted for each facet of religiousness (i.e. institutional religion, spirituality, religious conservatism). Latent variables for spirituality (CFI difference $=.03$ ) and religious conservatism $(\mathrm{CFI}$ difference $=.07)$ failed to be invariant across protestant, catholic, and non-affiliated religious groups. To explore whether religious variables varied across religious groups, the non-affiliated group was removed from the model. Results showed that spirituality and religious conservatism were each invariant between protestant and catholic groups.

Institutional religion continued to vary between protestant and catholic groups. To explore this further, separate latent variables were created for religious attendance and devotionalism and CFAs for each new variable were conducted. Religious attendance continued to vary across all religious groups $(\mathrm{CFI}$ difference $=.06)$. Because the use of this variable would cause results of a structural model to remain uninterpretable, the decision was made to use individual religious attendance items as observed variables in structural models.

The six devotionalism items were combined into three-two item parcels, which were used as indicators of a devotionalism latent variable. Further invariance tests determined that devotionalism varied across groups $(\mathrm{CFI}$ difference $=.06)$ and indicated that one parcel did not fit the model appropriately. To explore potentially problematic items, a separate CFA was conducted using the six individual devotionalism items and the lowest loading item on the devotionalism CFA was dropped (If my ideas about religion were different, I believe that my way

of life would be very different). The final devotionalism latent variable consisted of a single devotionalism item (My ideas about religion are one of the most important parts of my 
philosophy of life) and two two-item parcels; this latent variable for devotionalism was invariant across protestant and catholic religious groups but was not invariant for unaffiliated youth. 


\section{Appendix B - Tables}

Table 1

Demographic information for participants $(N=481)$

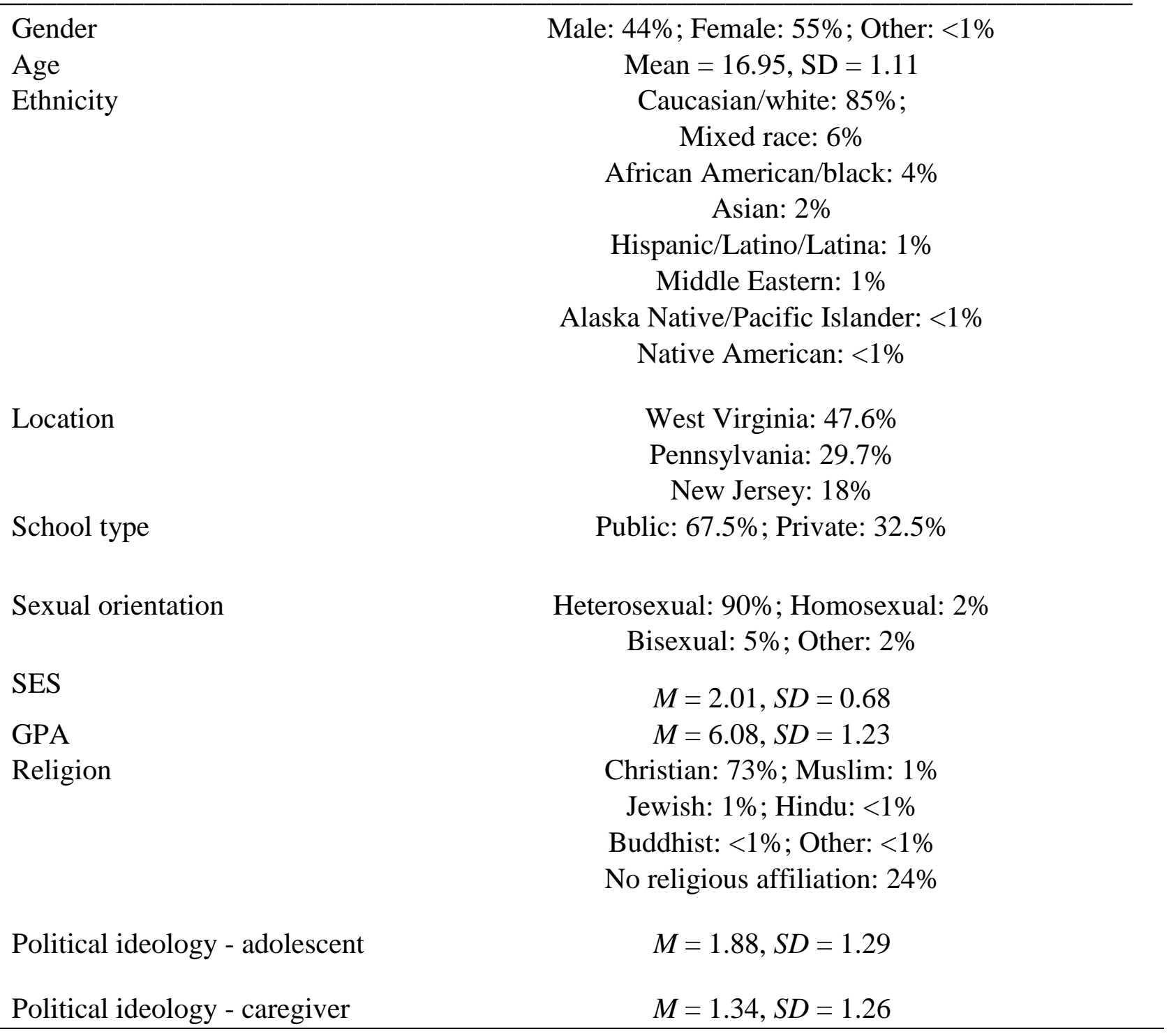


Table 2

Religious denominations $(N=841)$

Christian

Jewish

Muslim

Buddhist

Hindu

Atheist

Agnostic

Nothing in particular

African Methodist Episcopal Church
Assemblies of God
Baptist (American Churches - USA)
Baptist (National Convention)
Baptist (not specified)
Baptist (Southern)
Catholic:
Church of Christ
Church of God
Church of God in Christ
Church of the Nazarene
Episcopal
Evangelical
Lutheran (ELCA)
Methodist
Non-denominational
Orthodox Christian
Pentacostal
Presbyterian (America)
Presbyterian (USA)
United Church of Christ

$2(0.6 \%)$

$10(2.8 \%)$

$18(5.0 \%)$

$1(0.3 \%)$

$3(0.8 \%)$

$2(0.6 \%)$

$173(48.5 \%)$

$22(6.2 \%)$

$1(0.3 \%)$

$10(2.8 \%)$

$1(0.3 \%)$

$3(0.8 \%)$

$2(0.6 \%)$

$14(3.9 \%)$

$12(3.4 \%)$

$5(1.4 \%)$

$2(0.6 \%)$

$1(0.3 \%)$

$1(0.3 \%)$

$6(1.7 \%)$

4(1.1\%)

$3(0.8 \%)$
$6(1.6 \%)$
$1(0.3 \%)$
$2(0.6 \%)$
$1(0.3 \%)$
$2(0.6 \%)$
$46(12.8 \%)$ 
Table 3

Means and standard deviations for key study variables $(N=481)$

\begin{tabular}{lcc}
\hline & Full sample $(N=481)$ & Religious sample $(N=385)$ \\
\hline Variable & Mean $(S D)$ & Mean $(S D)$ \\
\hline Attendance & $1.21(1.00)$ & $1.47(0.96)$ \\
Devotionalism & $2.19(0.87)$ & $2.43(0.76)$ \\
Spirituality (STI) & $2.07(1.00)$ & $2.41(0.74)$ \\
Religious fundamentalism & $1.56(0.71)$ & $1.76(0.62)$ \\
Religious texts & $1.87(1.06)$ & $2.24(0.84)$ \\
In-group favoritism & $1.83(0.88)$ & $2.14(0.70)$ \\
Capital punishment & $52.81(24.36)$ & $53.49(24.62)$ \\
Euthanasia & $59.26(28.77)$ & $55.66(28.51)$ \\
Abortion & $55.23(33.48)$ & $49.39(32.47)$ \\
Environmentalism & $63.69(24.65)$ & $59.83(24.51)$ \\
Harsh punishments & $1.96(0.85)$ & $2.05(0.81)$ \\
Good/bad person & $1.68(0.69)$ & $1.74(0.65)$ \\
Quality of life & $2.91(0.61)$ & $2.86(0.60)$ \\
Personal choice & $2.12(0.54)$ & $2.09(0.53)$ \\
Climate change threat & $2.91(0.80)$ & $2.81(0.78)$ \\
Environmental influence & $3.17(0.64)$ & $3.11(0.59)$ \\
\hline & & \\
\hline
\end{tabular}


Table 4

Bivariate correlations between religiousness, political attitudes, and control variables $(N=481)$

\begin{tabular}{|c|c|c|c|c|c|c|c|c|c|c|c|c|c|c|c|c|c|c|}
\hline & 1 & 2 & 3 & 4 & 5 & 6 & 7 & 8 & 9 & 10 & 11 & 12 & 13 & 14 & 15 & 16 & 17 & 18 \\
\hline 1. Female & 1 & $-.11^{*}$ & -.05 & .03 & .09 & $-.14 * *$ & $-.02 *$ & -.01 & -.03 & .05 & .00 & -.06 & -.04 & -.06 & $-.15^{* *}$ & -.04 & $.16^{* *}$ & $.12 * *$ \\
\hline 2. Age & & 1 & $-.12 * *$ & .04 & .05 & -.02 & $-.10^{*}$ & .01 & .00 & -.01 & .03 & -.04 & -.05 & -.02 & .05 & .08 & .04 & -.03 \\
\hline 3. SES & & & 1 & -.02 & -.05 & .04 & $.10^{*}$ & .08 & $.10^{*}$ & .06 & -.07 & $.09 *$ & .08 & $.09 *$ & .06 & .07 & -.01 & $-.15^{* *}$ \\
\hline 4. Ethnicity & & & & 1 & $.20 * *$ & $-.14 * *$ & .02 & .05 & .07 & $.18^{* *}$ & $.21 * *$ & -.02 & .04 & -.04 & $.13^{* *}$ & -.03 & $.16^{* *}$ & $.15^{* *}$ \\
\hline $\begin{array}{l}\text { 5. Liberal } \\
\text { views (youth) }\end{array}$ & & & & & 1 & $-.55 * *$ & $-.18 * *$ & $-.24 * *$ & $-.32 * *$ & $-.22 * *$ & .05 & $-.48 * *$ & $-.41 * *$ & $-.46^{* *}$ & $-.45^{* *}$ & $.26^{* *}$ & $.59 * *$ & $.55^{* *}$ \\
\hline 6. RWA & & & & & & 1 & $.24 * *$ & $.36 * *$ & $.46^{* *}$ & $.37 * *$ & -.03 & $.56^{* *}$ & $.59 * *$ & $.52 * *$ & $.30 * *$ & $-.26 * *$ & $-.50 * *$ & $-.35^{* *}$ \\
\hline 7. Attend & & & & & & & 1 & $.59 * *$ & $.55^{* *}$ & $.59 * *$ & $.19^{* *}$ & $.47^{* *}$ & $.52 * *$ & $.62 * *$ & -.04 & $-.17 * *$ & $-.31 * *$ & $-.13^{* *}$ \\
\hline 8. Devotion. & & & & & & & & 1 & $.80 * *$ & $.69 * *$ & $.16^{* *}$ & $.60^{* *}$ & $.68 * *$ & $.73 * *$ & $-.11 *$ & $-.30 * *$ & $-.37 * *$ & $-.15^{* *}$ \\
\hline 9. Spirit & & & & & & & & & 1 & $.71 * *$ & $.17 * *$ & $.66^{* *}$ & $.80 * *$ & $.75^{* *}$ & -.03 & $-.27 * *$ & $-.32 * *$ & $-.17 * *$ \\
\hline 10. Prayer & & & & & & & & & & 1 & $.18^{* *}$ & $.54 * *$ & $.68 * *$ & $.64 * *$ & -.03 & $-.27 * *$ & $-.32 * *$ & $-.17 * *$ \\
\hline 11. Medit. & & & & & & & & & & & 1 & .01 & .03 & .07 & -.04 & .01 & .04 & .04 \\
\hline 12. Fund. & & & & & & & & & & & & 1 & $.80^{* *}$ & $.74 * *$ & .08 & $-.40 * *$ & $-.58 * *$ & $-.40 * *$ \\
\hline 13. R. texts & & & & & & & & & & & & & 1 & $.76^{* *}$ & .06 & $-.32 * *$ & $-.48 * *$ & $-.31 * *$ \\
\hline 14. Favorit. & & & & & & & & & & & & & & 1 & .05 & $-.31 * *$ & $-.45^{* *}$ & $-.30^{* *}$ \\
\hline 15. C. Pun. & & & & & & & & & & & & & & & 1 & $.13^{* *}$ & $-.18 * *$ & $-.25^{* *}$ \\
\hline 16. Euth. & & & & & & & & & & & & & & & & 1 & $.41^{* *}$ & $.19 * *$ \\
\hline 17. Abortion & & & & & & & & & & & & & & & & & 1 & $.33^{* *}$ \\
\hline 18. Enviro & & & & & & & & & & & & & & & & & & 1 \\
\hline
\end{tabular}


Table 5

Bivariate correlations between political attitudes, informational assumptions, and control variables $(N=481)$

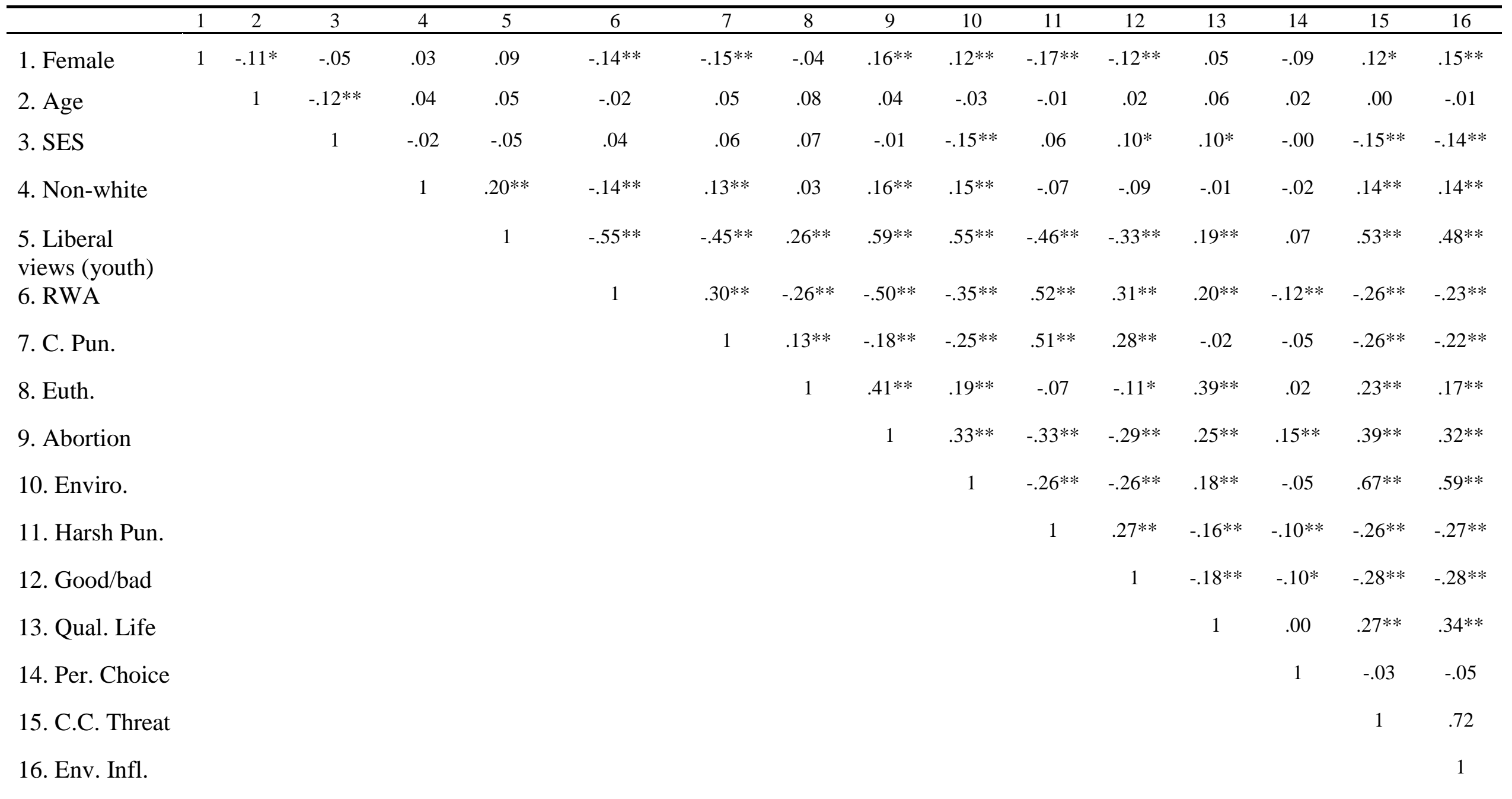


Table 6

Bivariate correlations between religiousness and informational assumptions $(N=481)$

\begin{tabular}{|c|c|c|c|c|c|c|c|c|c|c|c|c|c|c|}
\hline & 1 & 2 & 3 & 4 & 5 & 6 & 7 & 8 & 9 & 10 & 11 & 12 & 13 & 14 \\
\hline 1. Female & 1 & $.59^{* *}$ & $.55^{* * *}$ & $.59^{* *}$ & $.19^{* *}$ & $.47 * *$ & $.52^{* *}$ & $.62^{* *}$ & .10 & -.02 & -.05 & -.01 & $-.10^{*}$ & -.06 \\
\hline 2. Devotion. & & 1 & $.80 * *$ & $.69^{* *}$ & $.16^{* *}$ & $.60 * *$ & $.68 * *$ & $.73 * *$ & $.13^{* *}$ & -.01 & -.07 & $.11^{*}$ & $-.10^{*}$ & -.00 \\
\hline 3. Spirit. & & & 1 & $.71^{* *}$ & $.17 * *$ & $.66^{* *}$ & $.80^{* *}$ & $.75 * *$ & $.24^{* *}$ & .07 & -.08 & -.09 & $-.18 * *$ & $-.10^{* * *}$ \\
\hline 4. Prayer & & & & 1 & $.18^{* *}$ & $.54 * *$ & $.68^{* *}$ & $.64 * *$ & $.15^{* *}$ & .02 & -.07 & -.09 & -.08 & -.02 \\
\hline 5. Medit. & & & & & 1 & .01 & .03 & .07 & .00 & $-.12 * *$ & .05 & .01 & .09 & $.11^{*}$ \\
\hline 6. Fund. & & & & & & 1 & $.80^{* *}$ & $.74 * *$ & $.32^{* *}$ & $.32^{* *}$ & $-.29 * *$ & -.07 & $-.40 * *$ & $-.35 * *$ \\
\hline 7. R. texts & & & & & & & 1 & $.76^{* *}$ & $.30^{* * *}$ & $.19 * *$ & $-.22 * *$ & -.07 & $-.28 * *$ & $-.21^{* *}$ \\
\hline 8. Favorit. & & & & & & & & 1 & $.25^{* *}$ & $.15^{* *}$ & $-.18 * *$ & $-.08 * *$ & $-.21 * *$ & $-.17 * *$ \\
\hline 9. Harsh Pun. & & & & & & & & & 1 & $.27 * *$ & $-.16^{* *}$ & $-.10 * *$ & $-.26 * *$ & $-.27 * *$ \\
\hline 10. Good/bad & & & & & & & & & & 1 & $-.18 * *$ & $-.10^{*}$ & $-.28 * *$ & $-.28 * *$ \\
\hline 11. Qual. Life & & & & & & & & & & & 1 & .00 & $.27^{* *}$ & $.34 * *$ \\
\hline 12. Per. Choice & & & & & & & & & & & & 1 & -.03 & -.05 \\
\hline 13. C.C. Threat & & & & & & & & & & & & & 1 & .72 \\
\hline 14. Env. Infl. & & & & & & & & & & & & & & 1 \\
\hline
\end{tabular}


Table 7

Direct associations between religiousness and political attitudes -full sample $(N=481)$

\begin{tabular}{|c|c|c|c|c|c|c|c|c|c|c|c|c|}
\hline & \multicolumn{3}{|c|}{ Capital Punishment } & \multicolumn{3}{|c|}{ Euthanasia } & \multicolumn{3}{|c|}{ Abortion } & \multicolumn{3}{|c|}{ Environmentalism } \\
\hline & $\mathrm{B}($ S.E. $)$ & $\beta$ & C.R. & $\mathrm{B}(S . E)$. & $\beta$ & C.R. & $\mathrm{B}($ S.E. $)$ & $\beta$ & C.R. & $\mathrm{B}($ S.E. $)$ & $\beta$ & C.R. \\
\hline Attendance & $-2.43(1.04)^{*}$ & -.13 & -2.34 & $-2.02(1.29)$ & -.08 & -1.57 & $-3.91(1.01)^{* * *}$ & -.16 & -3.64 & $0.08(0.80)$ & .01 & 0.10 \\
\hline Meditation & $1.36(1.39)$ & .05 & 0.98 & $2.04(1.73)$ & .06 & 1.18 & $1.21(1.34)$ & .04 & 0.91 & $0.13(1.08)$ & .01 & 0.12 \\
\hline Spirituality & $-5.14(1.45)^{* * *}$ & -.22 & -3.55 & $-4.78(1.79) * *$ & -.16 & -2.68 & $-3.91(1.39) * *$ & -.14 & -2.82 & $-1.43(1.11)$ & -.07 & -1.28 \\
\hline Female & $-0.33(2.33)$ & -.01 & -0.14 & $-8.24(2.91)^{* *}$ & -.14 & -2.83 & $-0.76(2.24)$ & -.01 & -0.33 & $-2.06(1.81)$ & -.05 & -1.14 \\
\hline SES & $1.34(1.66)$ & .04 & 0.81 & $5.74(2.07) * *$ & .13 & 2.77 & $3.01(1.60)$ & .07 & 1.88 & $-2.78(1.29)^{*}$ & -.09 & -2.15 \\
\hline Non-white & $-0.31(3.34)$ & -.01 & -0.09 & $-7.68(4.17)$ & -.09 & -1.84 & $4.68(3.22)$ & .06 & 1.46 & $2.02(2.60)$ & .04 & 0.78 \\
\hline RWA & $8.34(2.04)^{* * *}$ & .25 & 4.10 & $-5.40(2.50)^{*}$ & -.13 & -2.16 & $-8.63(1.96) * * *$ & -.22 & -4.40 & $-2.10(1.55)$ & -.07 & -1.35 \\
\hline $\begin{array}{l}\text { Liberal } \\
\text { views } \\
\text { (youth) }\end{array}$ & $-8.17(1.27)^{* * *}$ & -.43 & -6.45 & $4.16(1.53)^{* *}$ & .17 & 2.71 & $8.80(1.22)^{* * *}$ & .39 & 7.19 & $8.35(1.01)^{* * *}$ & .51 & 8.23 \\
\hline
\end{tabular}


Table 8

Direct associations between religiousness and informational assumptions for capital punishment - full sample $(N=481)$

\begin{tabular}{|c|c|c|c|c|c|c|c|c|c|c|c|c|}
\hline & \multicolumn{3}{|c|}{ Harsh Punishment } & \multicolumn{3}{|c|}{ Good/bad 1} & \multicolumn{3}{|c|}{ Good/bad 2} & \multicolumn{3}{|c|}{ Good/bad 3} \\
\hline & $\mathrm{B}(S . E)$. & $\beta$ & C.R. & $\mathrm{B}($ S.E. $)$ & $\beta$ & C.R. & $\mathrm{B}(S . E)$. & $\beta$ & C.R. & $\mathrm{B}(S . E)$. & $\beta$ & C.R. \\
\hline Attendance & $-0.05(0.03)$ & -.07 & -1.47 & $-0.06(0.04)$ & -.07 & -1.44 & $-0.04(0.05)$ & -.04 & -0.75 & $0.06(0.03)$ & .09 & 1.81 \\
\hline Meditation & $0.02(0.05)$ & .02 & 0.47 & $-0.10(0.06)$ & -.08 & -1.80 & $-0.01(0.06)$ & -.01 & -0.21 & $-0.09(0.04)^{*}$ & -.10 & -2.11 \\
\hline Spirituality & $0.06(0.05)$ & .06 & 1.17 & $0.05(0.06)$ & .04 & 0.83 & $-0.12(0.07)$ & -.10 & -1.81 & $-0.11(0.05)^{*}$ & -.14 & -2.36 \\
\hline Female & $-0.14(0.08)$ & -.08 & -1.82 & $-0.04(0.10)$ & -.02 & -0.43 & $-0.15(0.11)$ & -.06 & -1.36 & $0.04(0.07)$ & .03 & 0.61 \\
\hline SES & $0.05(0.06)$ & .04 & 0.98 & $-0.06(0.07)$ & -.04 & -0.89 & $0.16(0.08)^{*}$ & .09 & 2.06 & $0.13(0.05)^{*}$ & .11 & 2.50 \\
\hline Non-white & $0.07(0.11)$ & .03 & 0.61 & $0.10(0.14)$ & .03 & 0.72 & $0.05(0.15)^{* *}$ & .02 & -2.71 & $-0.10(0.10)$ & -.05 & -0.99 \\
\hline RWA & $0.60(0.07)^{* * *}$ & .48 & 8.99 & $0.59(0.08) * * *$ & .38 & 7.27 & $0.12(0.09)$ & .07 & 1.27 & $0.03(0.06)$ & .03 & 0.46 \\
\hline $\begin{array}{l}\text { Liberal } \\
\text { views } \\
\text { (youth) }\end{array}$ & $-0.15(0.04)^{* * *}$ & -.20 & -3.82 & $-0.08(0.05)$ & -.08 & -1.63 & $-0.15(0.06) * *$ & -.15 & -2.71 & $-0.08(0.04)^{*}$ & -.11 & -2.08 \\
\hline $\begin{array}{l}\text { Note: } * p<.0 \\
\text { Harsh punish } \\
\text { Good/bad pei } \\
\text { Good/bad 1: } \\
\text { Good/bad 2: } \\
\text { Good/bad 3: }\end{array}$ & $\begin{array}{l}* * p<.01, * * * p \\
\text { ent: } \mathrm{X}^{2}(16)=40 \\
\text { on: } \mathrm{X}^{2}(3)=30.1 \\
\text { here are two typ } \\
\text { here is no such } \mathrm{t} \\
\text { veryone has a lit }\end{array}$ & $\begin{array}{l}<.001 \\
52, \mathrm{C} \\
6, \mathrm{CFI} \\
\mathrm{s} \text { of } \mathrm{p} \\
\text { ing as } \\
\text { le bit }\end{array}$ & $\begin{array}{l}=.98, \\
6, \mathrm{RN} \\
\text { le in th } \\
\text { good } \\
\text { ood a }\end{array}$ & $\begin{array}{l}\text { SEA }=.06 \\
\mathrm{~A}=.14 \\
\text { vorld: good } \mathrm{p} \\
\text { son" or a "ba } \\
\text { a little bit of } \mathrm{b}\end{array}$ & so & $\mathrm{Re}$ & $\begin{array}{l}\text { hings and b } \\
\text { coded } \\
\text { e coded }\end{array}$ & eop & 10 & things & & \\
\hline
\end{tabular}


Table 9

Direct associations between religiousness and informational assumptions for euthanasia - full sample $(N=481)$

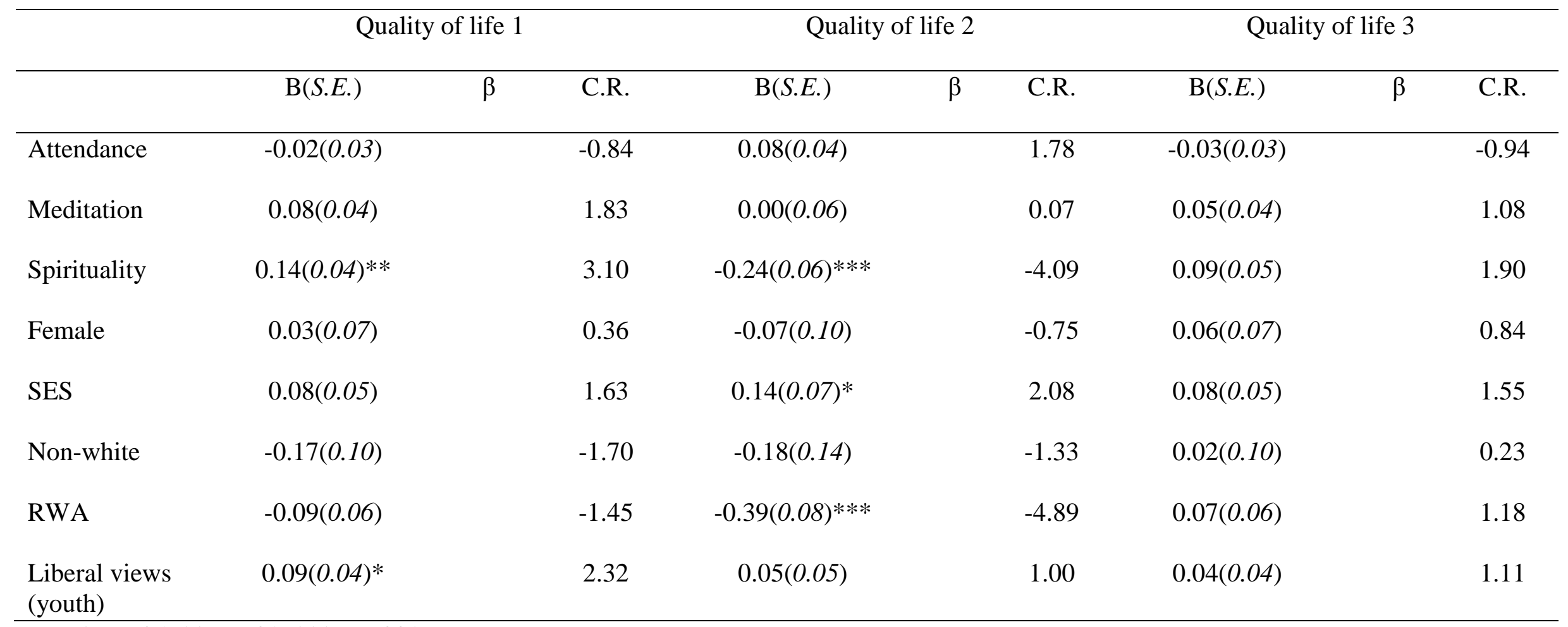

Note: $* p<.05, * * p<.01, * * * p<.001$

Model fit: $\mathrm{X}^{2}(3)=153.15, \mathrm{CFI}=.80, \mathrm{RMSEA}=.32$

Quality of life 1: Maintaining a good quality of life is more important than how long it is

Quality of life 2: We should strive to keep people alive as long as possible even if their quality of life is compromised - Reverse coded

Quality of life 3: Living a happy life is more important than living a long life 
Table 10

Direct associations between religiousness and informational assumptions for euthanasia and abortion - full sample (N=481)

\begin{tabular}{|c|c|c|c|c|c|c|c|c|c|}
\hline & \multicolumn{3}{|c|}{ Personal choice 1} & \multicolumn{3}{|c|}{ Personal choice 2} & \multicolumn{3}{|c|}{ Personal choice 3} \\
\hline & $\mathrm{B}($ S.E. $)$ & $\beta$ & C.R. & $\mathrm{B}($ S.E. $)$ & $\beta$ & C.R. & $\mathrm{B}(S . E)$. & $\beta$ & C.R. \\
\hline Attendance & $0.00(0.03)$ & .00 & -0.00 & $0.04(0.04)$ & .06 & 1.06 & $-0.05(0.05)$ & -.06 & -1.21 \\
\hline Meditation & $0.05(0.04)$ & .06 & 1.34 & $-0.02(0.05)$ & -.02 & -0.50 & $-0.00(0.06)$ & -.00 & -0.03 \\
\hline Spirituality & $0.02(0.04)$ & .02 & 0.40 & $-0.03(0.05)$ & -.03 & -0.59 & $-0.03(0.06)$ & -.02 & -0.41 \\
\hline Female & $-0.14(0.07)^{*}$ & -.10 & -2.08 & $-0.06(0.08)$ & -.04 & -0.81 & $-0.17(0.10)$ & -.08 & -1.70 \\
\hline SES & $-0.03(0.05)$ & -.03 & -0.59 & $0.02(0.06)$ & .01 & 0.28 & $0.01(0.07)$ & .01 & 0.17 \\
\hline Non-white & $-0.06(0.10)$ & -.03 & -0.60 & $-0.23(0.11)^{*}$ & -.10 & -2.10 & $0.11(0.14)$ & .04 & 0.76 \\
\hline RWA & $-0.09(0.06)$ & -.09 & -1.56 & $-0.29(0.07) * * *$ & -.24 & -4.34 & $0.11(0.09)$ & .07 & 1.29 \\
\hline $\begin{array}{l}\text { Liberal views } \\
\text { (youth) }\end{array}$ & $0.06(0.04)$ & .09 & 1.71 & $-0.04(0.04)$ & -.05 & -0.87 & $0.03(0.05)$ & .03 & 0.52 \\
\hline
\end{tabular}

Note: $* p<.05, * * p<.01, * * * p<.001$

Model fit: $\mathrm{X}^{2}(3)=16.66, \mathrm{CFI}=.98, \mathrm{RMSEA}=.10$

Personal choice 1: It is important for people to make their own choices

Personal choice 2: When it comes to making decisions, it is sometimes necessary for others to intervene so people don't make wrong choices -

Reverse coded

Personal choice 3: When making a decision, people always know what is best for themselves 
Table 11

Direct associations between religiousness and informational assumptions for environmentalism - full sample $(N=481)$

\begin{tabular}{|c|c|c|c|c|c|c|}
\hline & \multicolumn{3}{|c|}{ Climate Change Threat } & \multicolumn{3}{|c|}{ Environmental Influence } \\
\hline & $\mathrm{B}(S . E)$. & $\beta$ & C.R. & $\mathrm{B}(S . E)$. & $\beta$ & C.R. \\
\hline Attendance & $-0.03(0.03)$ & -.05 & -0.94 & $0.02(0.03)$ & .03 & 0.62 \\
\hline Meditation & $0.06(0.04)$ & .07 & 1.53 & $0.06(0.04)$ & .08 & 1.58 \\
\hline Spirituality & $-0.03(0.04)$ & -.04 & -0.66 & $-0.00(0.04)$ & -.00 & -0.02 \\
\hline Female & $-0.03(0.06)$ & -.02 & -0.40 & $0.04(0.06)$ & .03 & 0.61 \\
\hline SES & $-0.09(0.04)^{*}$ & -.09 & -2.14 & $-0.10(0.04)^{*}$ & -.11 & -2.32 \\
\hline Non-white & $0.02(0.09)$ & .01 & 0.24 & $0.09(0.09)$ & .05 & 1.01 \\
\hline RWA & $-0.01(0.05)$ & -.01 & -0.11 & $-0.02(0.05)$ & -.02 & -0.36 \\
\hline Liberal views (youth) & $0.31(0.03)^{* * *}$ & .51 & 9.00 & $0.25(0.03)^{* * *}$ & .48 & 7.30 \\
\hline
\end{tabular}

Note: $* p<.05, * * p<.01, * * * p<.001$

Climate Change Threat: $\mathrm{X}^{2}(16)=26.12, \mathrm{CFI}=.99, \mathrm{RMSEA}=.04$

Environmentalism: $\mathrm{X}^{2}(16)=22.47, \mathrm{CFI}=.99, \mathrm{RMSEA}=.03$ 
Table 12

Direct associations between harsh punishments and capital punishment - full sample $(N=481)$

\begin{tabular}{|c|c|c|c|}
\hline & $\mathrm{B}($ S.E. $)$ & $\beta$ & C.R. \\
\hline Harsh punishment & $25.15(3.58) * * *$ & .59 & -4.70 \\
\hline Gender & $0.95(2.21)$ & .02 & 0.43 \\
\hline SES & $-0.48(1.57)$ & -.01 & -0.31 \\
\hline Non-white & $-5.06(3.08)$ & -.07 & -1.64 \\
\hline RWA & $-5.14(2.09) *$ & -.15 & -2.46 \\
\hline Liberal views (youth) & $-5.67(1.21)^{* * *}$ & -.27 & -4.70 \\
\hline
\end{tabular}

Note: $* p<.05, * * p<.01, * * * p<.001$

Model fit: $\mathrm{X}^{2}(38)=205.91, \mathrm{CFI}=.89, \mathrm{RMSEA}=.10$ 
Table 13

Direct associations between good/bad person and capital punishment-full sample $(N=481)$

\begin{tabular}{|c|c|c|c|c|c|c|c|c|c|}
\hline & \multicolumn{3}{|c|}{$\begin{array}{c}\text { Good/bad person } 1 \\
\mathrm{X}^{2}(20)=152.29, \mathrm{CFI}=.87 \\
\mathrm{RMSEA}=.12\end{array}$} & \multicolumn{3}{|c|}{$\begin{array}{c}\text { Good/bad person } 2 \\
\mathrm{X}^{2}(20)=150.82, \mathrm{CFI}=.86 \\
\mathrm{RMSEA}=.12\end{array}$} & \multicolumn{3}{|c|}{$\begin{array}{c}\text { Good/bad person } 3 \\
\mathrm{X}^{2}(20)=151.86, \mathrm{CFI}=.86 \\
\mathrm{RMSEA}=.12\end{array}$} \\
\hline & $\mathrm{B}($ S.E. $)$ & $\beta$ & C.R. & $\mathrm{B}($ S.E. $)$ & $\beta$ & C.R. & $\mathrm{B}($ S.E. $)$ & $\beta$ & C.R. \\
\hline Good/bad person & $3.97(1.05)^{* * *}$ & .20 & 3.75 & $3.18(0.96)^{* * *}$ & .16 & 3.30 & $-1.52(1.41)$ & -.05 & -1.07 \\
\hline Gender & $-0.64(1.24)$ & -.01 & -0.30 & $-0.41(2.24)$ & -.01 & -0.18 & $-0.86(2.24)$ & -.02 & -0.38 \\
\hline SES & $0.48(1.52)$ & .01 & 0.31 & $-0.20(1.60)$ & -.01 & -0.12 & $0.45(1.61)$ & .01 & 0.28 \\
\hline Non-white & $-2.78(2.99)$ & -.04 & -0.93 & $-3.00(3.12)$ & -.05 & -0.96 & $-3.25(3.14)$ & -.05 & -1.03 \\
\hline RWA & $1.89(1.79)$ & .06 & 1.06 & $4.33(1.77)^{*}$ & .13 & 2.45 & $4.38(1.77)^{*}$ & .14 & 2.47 \\
\hline Liberal views (youth) & $-7.28(1.18)^{* * *}$ & -.37 & -6.19 & $-7.53(1.22) * * *$ & -.37 & -6.18 & $-8.01(1.23)^{* * *}$ & -.39 & -6.51 \\
\hline
\end{tabular}

Note: $* p<.05, * * p<.01, * * * p<.001$

Good/bad 1: There are two types of people in the world: good people who do good things and bad people who do bad things

Good/bad 2: There is no such thing as a "good person" or a "bad person" - Reverse coded

Good/bad 3: Everyone has a little bit of good and a little bit of bad in them - Reverse coded 
Table 14

Direct associations between quality of life and euthanasia - full sample $(N=481)$

\begin{tabular}{|c|c|c|c|c|c|c|c|c|c|}
\hline & \multicolumn{3}{|c|}{$\begin{array}{c}\text { Quality of life } \mathbf{1} \\
\mathrm{X}^{2}(20)=55.00, \mathrm{CFI}=.97 \\
\mathrm{RMSEA}=.06\end{array}$} & \multicolumn{3}{|c|}{$\begin{array}{c}\text { Quality of life } 2 \\
\mathrm{X}^{2}(20)=56.66, \mathrm{CFI}=.97 \\
\text { RMSEA }=.06\end{array}$} & \multicolumn{3}{|c|}{$\begin{array}{c}\text { Quality of life } 3 \\
\mathrm{X}^{2}(373)=54.08, \mathrm{CFI}=.97 \\
\mathrm{RMSEA}=.06\end{array}$} \\
\hline & $\mathrm{B}(S . E)$. & $\beta$ & C.R. & $\mathrm{B}(S . E)$. & $\beta$ & C.R. & $\mathrm{B}(S . E)$. & $\beta$ & C.R. \\
\hline Quality of life & $5.02(1.79)^{* *}$ & .13 & 2.80 & $12.83(1.28)^{* * *}$ & .47 & 10.06 & $3.97(1.79)^{* * *}$ & .10 & -4.26 \\
\hline Gender & $-8.60(2.84)^{* *}$ & -.15 & -3.03 & $-7.08(2.58)^{* *}$ & -.12 & -2.74 & $-8.67(2.85)^{* *}$ & -.15 & -3.04 \\
\hline SES & $3.70(2.02)$ & .08 & 1.83 & $2.49(1.84)$ & .06 & 1.35 & $3.82(2.03)$ & .09 & 1.88 \\
\hline Non-white & $-8.47(3.96)^{*}$ & -.10 & -2.14 & $-5.44(3.61)$ & -.06 & -1.51 & $-9.19(3.97)^{*}$ & -.11 & -2.31 \\
\hline RWA & $-9.07(2.24) * * *$ & -.22 & -4.06 & $-2.65(2.11)$ & -.06 & -1.25 & $-9.61(2.25)^{* * *}$ & -.23 & -4.26 \\
\hline Liberal views (youth) & $4.57(1.48)^{* *}$ & .17 & 3.09 & $4.10(1.34)^{* *}$ & .16 & 3.05 & $4.81(1.48)^{* *}$ & .18 & 3.25 \\
\hline
\end{tabular}

Note: $* p<.05, * * p<.01, * * * p<.001$

Quality of life 1: Maintaining a good quality of life is more important than how long it is

Quality of life 2: We should strive to keep people alive as long as possible even if their quality of life is compromised - Reverse coded

Quality of life 3: Living a happy life is more important than living a long life 
Table 15

Direct associations between personal choice and euthanasia-full sample $(N=481)$

\begin{tabular}{|c|c|c|c|c|c|c|c|c|c|}
\hline & \multicolumn{3}{|c|}{$\begin{array}{c}\text { Personal choice } 1 \\
\mathrm{X}^{2}(20)=58.60, \mathrm{CFI}=.97 \\
\mathrm{RMSEA}=.06\end{array}$} & \multicolumn{3}{|c|}{$\begin{array}{c}\text { Personal choice } 2 \\
\mathrm{X}^{2}(20)=52.98, \mathrm{CFI}=.97 \\
\mathrm{RMSEA}=.06\end{array}$} & \multicolumn{3}{|c|}{$\begin{array}{c}\text { Personal choice } 3 \\
\mathrm{X}^{2}(20)=60.05, \mathrm{CFI}=.96 \\
\mathrm{RMSEA}=.07\end{array}$} \\
\hline & $\mathrm{B}($ S.E. $)$ & $\beta$ & C.R. & $\mathrm{B}($ S.E. $)$ & $\beta$ & C.R. & $\mathrm{B}(S . E)$. & $\beta$ & C.R. \\
\hline Personal choice & $4.49(1.92)^{*}$ & .11 & 2.33 & $-4.47(1.68)^{* *}$ & -.13 & -2.67 & $-1.49(1.30)$ & -.05 & -1.15 \\
\hline Gender & $-7.76(2.85)^{* *}$ & -.13 & -2.72 & $-8.68(2.85)^{* *}$ & -.15 & -3.05 & $-8.66(2.87)^{* *}$ & -.15 & -3.02 \\
\hline SES & $4.26(2.02)^{*}$ & .10 & 2.11 & $2.24(2.02)^{*}$ & .10 & 2.09 & $4.14(2.04)^{*}$ & .09 & 2.03 \\
\hline Non-white & $-8.75(3.96) *$ & -.10 & -2.21 & $-10.00(3.99)^{*}$ & -.12 & -2.51 & $-8.76(3.99)^{*}$ & -.10 & -2.20 \\
\hline RWA & $-8.79(2.24) * * *$ & -.21 & -3.92 & $-10.46(2.30)^{* * *}$ &.- .25 & -4.56 & $-9.06(2.26)^{* * *}$ & -.22 & -4.02 \\
\hline Liberal views (youth) & $4.69(1.48)^{* *}$ & .18 & 3.17 & $4.79(1.48)^{* *}$ & .18 & 3.24 & $5.01(1.49)^{* * *}$ & .19 & 3.37 \\
\hline
\end{tabular}

Note: $* p<.05, * * p<.01, * * * p<.001$ 
Table 16

Direct associations between personal choice and abortion - full sample $(N=481)$

\begin{tabular}{|c|c|c|c|c|c|c|c|c|c|}
\hline & \multicolumn{3}{|c|}{$\begin{array}{c}\text { Personal choice } 1 \\
\mathrm{X}^{2}(20)=79.30, \mathrm{CFI}=.96 \\
\mathrm{RMSEA}=.08\end{array}$} & \multicolumn{3}{|c|}{$\begin{array}{c}\text { Personal choice } 2 \\
\mathrm{X}^{2}(20)=64.67, \mathrm{CFI}=.97 \\
\mathrm{RMSEA}=.07\end{array}$} & \multicolumn{3}{|c|}{$\begin{array}{c}\text { Personal choice } 3 \\
\mathrm{X}^{2}(20)=63.66, \mathrm{CFI}=.97 \\
\mathrm{RMSEA}=.07\end{array}$} \\
\hline & $\mathrm{B}($ S.E. $)$ & $\beta$ & C.R. & $\mathrm{B}($ S.E. $)$ & $\beta$ & C.R. & $\mathrm{B}($ S.E. $)$ & $\beta$ & C.R. \\
\hline Personal choice & $4.45(1.51)^{* *}$ & .12 & 2.95 & $0.69(1.32)$ & .02 & 0.53 & $1.07(1.02)$ & .04 & 1.05 \\
\hline Gender & $-0.15(2.22)$ & -.00 & -0.07 & $-0.76(2.24)$ & -.01 & 2.24 & $-0.62(2.24)$ & -.01 & -0.28 \\
\hline SES & $1.44(1.57)$ & .04 & 0.92 & $1.32(1.59)$ & .03 & 0.83 & $1.34(1.59)$ & .03 & 0.84 \\
\hline Non-white & $4.24(3.08)$ & .06 & 1.38 & $4.30(3.14)$ & .06 & 1.37 & $4.03(3.12)$ & .05 & 1.29 \\
\hline RWA & $-12.87(1.83)^{* * *}$ & -.33 & -7.04 & $-13.15(1.89)^{* * *}$ & -.34 & -6.97 & $-13.42(1.85) * * *$ & -.35 & -7.25 \\
\hline Liberal views (youth) & $4.45(1.51)^{* *}$ & .36 & 5.95 & $9.12(1.23) * * *$ & .37 & 7.42 & $9.05(1.23) * * *$ & .37 & 7.39 \\
\hline
\end{tabular}

Note: $* p<.05, * * p<.01, * * * p<.001$ 
Table 17

Direct associations between climate change threat and environmental influence and environmentalism-full sample $(N=481)$

\begin{tabular}{|c|c|c|c|c|c|c|}
\hline & \multicolumn{3}{|c|}{$\begin{array}{c}\text { Climate Change Threat } \\
\mathrm{X}^{2}(38)=41.92, \mathrm{CFI}=1.00, \mathrm{RMSEA}=.02\end{array}$} & \multicolumn{3}{|c|}{$\begin{array}{c}\text { Environmental Influence } \\
\mathrm{X}^{2}(38)=47.57, \mathrm{CFI}=.99, \mathrm{RMSEA}=.02\end{array}$} \\
\hline & $\mathrm{B}($ S.E. $)$ & $\beta$ & C.R. & $\mathrm{B}(S . E)$. & $\beta$ & C.R. \\
\hline Climate Change Threat & $20.50(1.83)^{* * *}$ & .73 & 11.22 & & & \\
\hline $\begin{array}{l}\text { Environmental } \\
\text { Influence }\end{array}$ & & & & $23.44(2.66)^{* * *}$ & .69 & 8.81 \\
\hline Gender & $-0.78(1.41)$ & -.02 & 0.58 & $-2.37(1.56)$ & -.06 & -1.52 \\
\hline SES & $-0.83(1.02)$ & -.03 & -0.81 & $-0.88(1.13)$ & -.03 & -0.79 \\
\hline Non-white & $1.95(1.98)$ & .04 & 0.99 & $-0.02(2.18)$ & .00 & -0.01 \\
\hline RWA & $-3.15(1.12)^{* *}$ & -.11 & -2.81 & $3.57(1.23)^{* *}$ & -.13 & -2.90 \\
\hline Liberal views (youth) & $1.35(0.86)$ & .08 & 1.56 & $2.31(0.96)^{*}$ & .13 & 2.42 \\
\hline
\end{tabular}

Note: $* p<.05, * * p<.01, * * * p<.001$ 
Table 18

Indirect effects for Good/bad Person Item One on Capital Punishment - full sample $(N=481)$

\begin{tabular}{|c|c|c|c|c|c|c|c|c|c|c|c|c|}
\hline & \multicolumn{3}{|c|}{ Good/bad 1} & \multicolumn{3}{|c|}{ Good/bad 2} & \multicolumn{3}{|c|}{ Good/bad 3} & \multicolumn{3}{|c|}{ Capital Punishment } \\
\hline & $\mathrm{B}($ S.E. $)$ & $\beta$ & C.R. & $\mathrm{B}(S . E)$. & $\beta$ & C.R. & $\mathrm{B}(S . E)$. & $\beta$ & C.R. & $\mathrm{B}(S . E)$. & $\beta$ & C.R. \\
\hline Attendance & $-0.06(0.04)$ & -.07 & -1.40 & & & & & & & $-1.77(0.97)$ & -.10 & -1.82 \\
\hline Meditation & $-0.10(0.06)$ & -.07 & -1.70 & & & & & & & $1.24(1.31)$ & .04 & 0.95 \\
\hline Spirituality & $0.08(0.06)$ & .07 & 1.31 & & & & & & & $-5.35(1.37) * * *$ & -.23 & -3.90 \\
\hline Good 1 & & & & & & & & & & $3.60(1.08)^{* * *}$ & .17 & 3.33 \\
\hline Good 2 & & & & & & & & & & $2.33(0.96)^{*}$ & .12 & 2.44 \\
\hline Good 3 & & & & & & & & & & $-2.85(1.39)^{*}$ & -.10 & -2.05 \\
\hline Female & $-0.04(0.07)$ & -.20 & -0.46 & $-0.16(0.11)$ & -.07 & -1.50 & $0.03(0.07)$ & .02 & 0.47 & $0.38(2.17)$ & .01 & 0.18 \\
\hline SES & $-.06(0.07)$ & -.04 & -0.93 & $0.14(0.08)$ & .08 & 1.81 & $0.14(0.05)^{* *}$ & .12 & 2.66 & $1.60(1.60)$ & .05 & 1.01 \\
\hline Non-white & $0.08(0.14)$ & .03 & 0.61 & $-0.01(0.15)$ & -.00 & -0.08 & $-0.18(0.10)$ & -.08 & -1.78 & $-1.84(3.32)$ & -.03 & -0.59 \\
\hline RWA & $0.57(0.08) * * *$ & .37 & 7.08 & $0.03(0.08)$ & .02 & 0.37 & $-0.01(0.06)$ & -.01 & -0.18 & $6.11(1.96) * *$ & .19 & 3.32 \\
\hline $\begin{array}{l}\text { Liberal views } \\
\text { (youth) }\end{array}$ & $-0.08(0.05)$ & -.08 & -1.57 & $-0.13(0.06)^{*}$ & -.13 & -2.41 & $-0.07(0.04)$ & -.11 & -1.92 & $-8.40(1.20)^{* * *}$ & -.41 & -6.98 \\
\hline
\end{tabular}

Note: $* p<.05, * * p<.01, * * * p<.001$

Model fit: $\mathrm{X}^{2}(41)=187.95, \mathrm{CFI}=.96, \mathrm{RMSEA}=.14$

Indirect effect: $\mathrm{B}=-.34, p<.05$

Good/bad 1: There are two types of people in the world: good people who do good things and bad people who do bad things

Good/bad 2: There is no such thing as a "good person" or a "bad person" - Reverse coded

Good/bad 3: Everyone has a little bit of good and a little bit of bad in them - Reverse coded 
Table 19

Indirect effects for Good/bad Person Item Three on Capital Punishment - full sample $(N=481)$

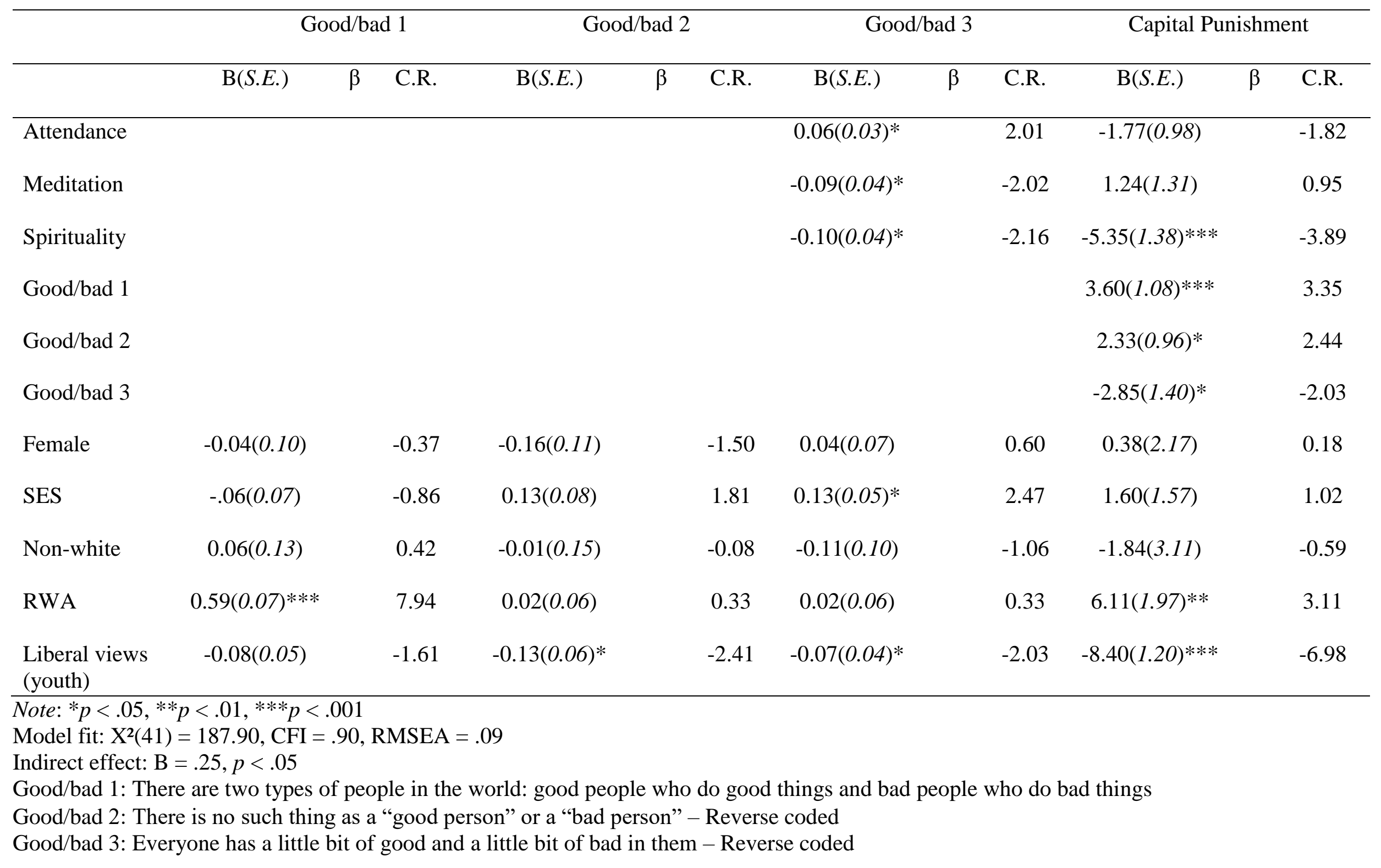


Table 20

Indirect effects for Quality of Life Item Two on Euthanasia - full sample $(N=481)$

\begin{tabular}{|c|c|c|c|c|c|c|c|c|c|c|c|c|}
\hline & \multicolumn{3}{|c|}{ Quality 1} & \multicolumn{3}{|c|}{ Quality 2} & \multicolumn{3}{|c|}{ Quality 3} & \multicolumn{3}{|c|}{ Euthanasia } \\
\hline & $\mathrm{B}(S . E)$. & $\beta$ & C.R. & $\mathrm{B}(S . E)$. & $\beta$ & C.R. & $\mathrm{B}(S . E)$. & $\beta$ & C.R. & $\mathrm{B}(S . E)$. & $\beta$ & C.R. \\
\hline Attendance & & & & $0.08(0.04)$ & & 1.78 & & & & $-3.04(1.14)^{* *}$ & -.13 & -2.68 \\
\hline Meditation & & & & $0.00(0.06)$ & & 0.07 & & & & $1.87(1.52)$ & .05 & 1.23 \\
\hline Spirituality & & & & $-0.24(0.06)$ & & -4.09 & & & & $-2.09(1.60)$ & -.07 & 1.23 \\
\hline Quality 1 & & & & & & & & & & $1.89(1.59)$ & .05 & 1.19 \\
\hline Quality 2 & & & & & & & & & & $12.21(1.27)^{* * *}$ & .45 & 9.64 \\
\hline Quality 3 & & & & & & & & & & $1.95(1.58)$ & .05 & 1.23 \\
\hline Female & $0.04(0.07)$ & .03 & 0.56 & $-0.07(0.10)$ & -.03 & -0.75 & $0.07(0.07)$ & .05 & 0.95 & $-6.94(2.54)^{* *}$ & -.12 & -2.73 \\
\hline SES & $0.09(0.05)$ & .08 & 2.08 & $0.14(0.07)^{*}$ & .09 & 2.08 & $0.08(0.05)$ & .07 & 1.68 & $3.25(1.84)$ & .07 & 1.77 \\
\hline Non-white & $-0.08(0.10)$ & -.04 & -0.81 & $-0.18(0.14)$ & -.06 & -1.33 & $0.08(0.10)$ & .04 & 0.77 & $-5.01(3.64)$ & -.06 & -1.34 \\
\hline RWA & $-.02(0.06)$ & -.02 & -0.32 & $-0.39(0.08)^{* * *}$ & -.26 & -4.89 & $0.11(0.06)$ & .10 & 1.95 & $-0.70(2.21)$ & -.02 & -0.32 \\
\hline $\begin{array}{l}\text { Liberal views } \\
\text { (youth) }\end{array}$ & $0.07(0.04)^{*}$ & .11 & 1.98 & $0.05(0.05)$ & .05 & 1.00 & $0.04(0.04)$ & .05 & 0.94 & $3.39(1.33)^{*}$ & .13 & 2.56 \\
\hline
\end{tabular}

Note: $* p<.05, * * p<.01, * * * p<.001$

Model fit: $\mathrm{X}^{2}(41)=245.31, \mathrm{CFI}=.89, \mathrm{RMSEA}=.10$

Indirect effect: $\mathrm{B}=-2.94, p<.05$

Quality 1: Maintaining a good quality of life is more important than how long it is

Quality 2: We should strive to keep people alive as long as possible even if their quality of life is compromised - Reverse coded

Quality 3: Living a happy life is more important than living a long life - Reverse coded 
Table 21

Direct associations between religiousness and political attitudes - religious sample $(n=385)$

\begin{tabular}{|c|c|c|c|c|c|c|c|c|c|c|c|c|}
\hline & \multicolumn{3}{|c|}{ Capital Punishment } & \multicolumn{3}{|c|}{ Euthanasia } & \multicolumn{3}{|c|}{ Abortion } & \multicolumn{3}{|c|}{ Environmentalism } \\
\hline & $\mathrm{B}($ S.E. $)$ & $\beta$ & C.R. & $\mathrm{B}(S . E)$. & $\beta$ & C.R. & $\mathrm{B}(S . E)$. & $\beta$ & C.R. & $\mathrm{B}($ S.E. $)$ & $\beta$ & C.R. \\
\hline Devotionalism & $-21.41(10.08)^{*}$ & -.68 & -2.12 & $-23.82(13.05)$ & -.57 & -1.83 & $-19.13(9.74)^{*}$ & -.53 & -1.96 & $14.75(7.97)$ & .58 & 1.85 \\
\hline Spirituality & $11.26(7.59)$ & .34 & 1.48 & $29.64(10.07)^{* *}$ & .68 & 2.94 & $19.00(7.51)^{*}$ & .50 & 2.53 & $-3.03(5.92)$ & -.11 & -0.51 \\
\hline $\begin{array}{l}\text { Religious } \\
\text { conservativism }\end{array}$ & $2.17(8.20)$ & .05 & 0.27 & $-20.21(10.77)$ & -.37 & -1.89 & $-16.33(8.03)^{*}$ & -.34 & -2.03 & $-18.95(6.79)^{* *}$ & -.54 & -2.79 \\
\hline Female & $-0.62(2.53)$ & -.01 & -0.25 & $-9.02(3.36)^{* *}$ & -.15 & -2.69 & $-0.62(2.48)$ & .01 & 0.25 & $-0.92(2.01)$ & -.02 & -0.46 \\
\hline SES & $0.85(1.85)$ & .03 & 0.46 & $3.23(2.45)$ & .07 & 1.32 & $2.19(1.82)$ & .06 & 1.20 & $-2.78(1.48)$ & -.01 & -1.89 \\
\hline Non-white & $1.45(3.69)$ & .02 & 0.39 & $-2.65(4.88)$ & -.03 & -0.54 & $9.35(3.65)^{*}$ & .13 & 2.56 & $3.80(2.94)$ & .07 & 1.30 \\
\hline RWA & $5.19(3.17)$ & .15 & 1.64 & $0.40(4.15)$ & .01 & 0.10 & $-7.41(3.11)^{*}$ & -.18 & -2.39 & $3.77(2.54)$ & .13 & 1.48 \\
\hline $\begin{array}{l}\text { Liberal views } \\
\text { (youth) }\end{array}$ & $-9.18(1.53)^{* * *}$ & -.43 & -6.02 & $3.37(1.90)$ & .12 & 1.78 & $5.27(1.44) * * *$ & .23 & 3.67 & $7.83(1.23)^{* * *}$ & .44 & 6.38 \\
\hline
\end{tabular}

Note: $* p<.05, * * p<.01, * * * p<.001$

Model fit: $\mathrm{X}^{2}(373)=906.37, \mathrm{CFI}=.91, \mathrm{RMSEA}=.06$ 
Table 22

Direct associations between religiousness and informational assumptions for capital punishment - religious sample ( $n=385)$

\begin{tabular}{|c|c|c|c|c|c|c|c|c|c|c|c|c|}
\hline & \multicolumn{3}{|c|}{ Harsh Punishment } & \multicolumn{3}{|c|}{ Good/bad 1} & \multicolumn{3}{|c|}{ Good/bad 2} & \multicolumn{3}{|c|}{ Good/bad 3} \\
\hline & $\mathrm{B}(S . E)$. & $\beta$ & C.R. & $\mathrm{B}(S . E)$. & $\beta$ & C.R. & $\mathrm{B}(S . E)$. & $\beta$ & C.R. & $\mathrm{B}(S . E)$. & $\beta$ & C.R. \\
\hline Devotionalism & $-0.40(0.23)$ & -.53 & -1.73 & $-0.63(0.43)$ & -.42 & -1.45 & $-0.85(0.48)$ & -.55 & -1.76 & $-0.04(0.31)$ & -.04 & -0.14 \\
\hline Spirituality & $0.41(0.17)^{*}$ & .52 & 2.34 & $0.03(0.32)$ & .02 & 0.09 & $0.41(0.36)$ & .25 & 1.14 & $-0.66(0.23)^{* *}$ & -.60 & -2.85 \\
\hline $\begin{array}{l}\text { Religious } \\
\text { conservativism }\end{array}$ & $0.02(0.19)$ & .02 & 0.12 & $0.76(0.37)^{*}$ & .39 & 2.07 & $0.29(0.40)$ & .15 & 0.74 & $1.10(0.27) * * *$ & .79 & 4.04 \\
\hline Female & $-0.10(0.06)$ & -.10 & -1.78 & $-0.04(0.11)$ & -.02 & -0.35 & $-0.15(0.12)$ & -.07 & -1.27 & $-0.03(0.08)$ & -.02 & -0.42 \\
\hline SES & $-0.01(0.04)$ & -.01 & -0.13 & $-0.10(0.08)$ & -.07 & -1.27 & $0.09(0.09)$ & .06 & 1.06 & $0.16(0.06)^{* *}$ & .15 & 2.81 \\
\hline Non-white & $0.11(0.09)$ & .07 & 1.35 & $0.19(0.16)$ & .06 & 1.21 & $0.14(0.18)$ & .04 & 0.80 & $-0.24(0.12)^{*}$ & -.11 & -2.02 \\
\hline RWA & $0.32(0.08) * * *$ & .38 & 4.17 & $0.40(0.14)^{* *}$ & .24 & 2.86 & $0.01(0.15)$ & .01 & 0.07 & $-0.23(0.10)^{*}$ & -.19 & -2.24 \\
\hline $\begin{array}{l}\text { Liberal views } \\
\text { (youth) }\end{array}$ & $-0.13(0.03)^{* * *}$ & -.25 & -3.65 & $-0.06(0.06)$ & -.06 & -0.96 & $-0.15(0.07)^{*}$ & -.15 & -2.21 & $0.04(0.05)$ & .05 & 0.85 \\
\hline
\end{tabular}

Note: $* p<.05, * * p<.01, * * * p<.001$

Harsh punishment: $\mathrm{X}^{2}(104)=258.94, \mathrm{CFI}=.96, \mathrm{RMSEA}=.06$

Good/bad person: $\mathrm{X}^{2}(88)=263.76, \mathrm{CFI}=.95, \mathrm{RMSEA}=.07$

Good/bad 1: There are two types of people in the world: good people who do good things and bad people who do bad things

Good/bad 2: There is no such thing as a "good person" or a "bad person" - Reverse coded

Good/bad 3: Everyone has a little bit of good and a little bit of bad in them - Reverse coded 
Table 23

Direct associations between religiousness and informational assumptions for euthanasia - religious sample $(n=385)$

\begin{tabular}{|c|c|c|c|c|c|c|c|c|c|}
\hline & \multicolumn{3}{|c|}{ Quality of life 1} & \multicolumn{3}{|c|}{ Quality of life 2} & \multicolumn{3}{|c|}{ Quality of life 3} \\
\hline & $\mathrm{B}($ S.E. $)$ & $\beta$ & C.R. & $\mathrm{B}($ S.E. $)$ & $\beta$ & C.R. & $\mathrm{B}($ S.E. $)$ & $\beta$ & C.R. \\
\hline Devotionalism & $0.09(0.29)$ & .09 & 0.33 & $-0.50(0.41)$ & -.34 & -1.22 & $-0.14(0.30)$ & -.13 & -0.46 \\
\hline Spirituality & $0.65(0.22)^{* *}$ & .61 & 3.00 & $0.65(0.31)^{*}$ & .42 & 2.07 & $0.39(0.23)$ & .35 & 1.70 \\
\hline $\begin{array}{l}\text { Religious } \\
\text { conservativism }\end{array}$ & $-0.84(0.26)^{* *}$ & -.62 & -3.27 & $-0.58(0.36)$ & -.30 & -1.62 & $-0.26(0.26)$ & -.19 & -0.98 \\
\hline Female & $0.07(0.08)$ & .05 & 0.89 & $-0.09(0.11)$ & -.04 & -0.78 & $0.07(0.08)$ & .05 & 0.85 \\
\hline SES & $0.08(0.06)$ & .07 & 1.33 & $0.10(0.08)$ & .06 & 1.20 & $0.04(0.06)$ & .04 & 0.67 \\
\hline Non-white & $-0.03(0.11)$ & -.01 & -0.27 & $-0.17(0.16)$ & -.06 & 0.20 & $0.14(0.12)$ & .06 & 1.56 \\
\hline RWA & $0.13(0.10)$ & .12 & 1.39 & $-0.27(0.14)^{*}$ & -.16 & -2.00 & $0.16(0.10)$ & .13 & 1.59 \\
\hline $\begin{array}{l}\text { Liberal views } \\
\text { (youth) }\end{array}$ & $0.01(0.04)$ & .02 & 0.28 & $0.01(0.06)$ & .01 & 0.20 & $0.02(0.05)$ & .02 & 0.35 \\
\hline
\end{tabular}

Note: $* p<.05, * * p<.01, * * * p<.001$

Model fit: $\mathrm{X}^{2}(88)=243.94 .25, \mathrm{CFI}=.95, \mathrm{RMSEA}=.07$

Quality of life 1: Maintaining a good quality of life is more important than how long it is

Quality of life 2: We should strive to keep people alive as long as possible even if their quality of life is compromised - Reverse coded

Quality of life 3: Living a happy life is more important than living a long life 
Table 24

Direct associations between religiousness and informational assumptions for euthanasia and abortion-religious sample $(n=385)$

\begin{tabular}{|c|c|c|c|c|c|c|c|c|c|}
\hline & \multicolumn{3}{|c|}{ Personal choice 1} & \multicolumn{3}{|c|}{ Personal choice 2} & \multicolumn{3}{|c|}{ Personal choice 3} \\
\hline & $\mathrm{B}(S . E)$. & $\beta$ & C.R. & $\mathrm{B}(S . E)$. & $\beta$ & C.R. & $\mathrm{B}(S . E)$. & $\beta$ & C.R. \\
\hline Devotionalism & $0.44(0.30)$ & .45 & 1.45 & $-0.01(0.31)$ & -.01 & -0.02 & $-0.96(0.47)^{*}$ & -.66 & -2.04 \\
\hline Spirituality & $0.09(0.22)$ & .09 & 0.42 & $-0.55(0.24)^{*}$ & -.46 & -2.27 & $0.16(0.35)$ & .10 & 0.46 \\
\hline $\begin{array}{l}\text { Religious } \\
\text { conservativism }\end{array}$ & $-0.80(0.26)^{* *}$ & -.63 & -3.11 & $0.76(0.27)^{* *}$ & .51 & 2.81 & $1.23(0.40)^{* *}$ & .64 & 3.07 \\
\hline Female & $-0.08(0.08)$ & -.06 & -1.06 & $-0.06(0.08)$ & -.04 & -0.74 & $-0.28(0.12)^{*}$ & -.13 & -1.06 \\
\hline SES & $0.02(0.06)$ & .02 & 0.39 & $0.04(0.06)$ & .03 & 0.61 & $-0.02(0.09)$ & -.01 & -0.23 \\
\hline Non-white & $0.13(0.11)$ & .06 & 1.12 & $-0.27(0.12)^{*}$ & -.11 & -2.19 & $0.06(0.17)$ & .02 & 0.32 \\
\hline RWA & $0.11(0.10)$ & .10 & 1.10 & $-0.57(0.10)^{* * *}$ & -.44 & -5.48 & $-0.24(0.15)$ & -.14 & -1.60 \\
\hline $\begin{array}{l}\text { Liberal views } \\
\text { (youth) }\end{array}$ & $-0.02(0.04)^{* * *}$ & -.03 & -0.52 & $-0.00(0.05)$ & -.00 & -0.01 & $0.09(0.08)$ & .09 & 1.38 \\
\hline
\end{tabular}

Note: $* p<.05, * * p<.01, * * * p<.001$

Model fit: $\mathrm{X}^{2}(88)=235.64, \mathrm{CFI}=.96, \mathrm{RMSEA}=.07$

Personal choice 1: It is important for people to make their own choices

Personal choice 2: When it comes to making decisions, it is sometimes necessary for others to intervene so people don't make wrong choices -

Reverse coded

Personal choice 3: When making a decision, people always know what is best for themselves 
Table 25

Direct associations between religiousness and informational assumptions for environmentalism - religious sample $(n=385)$

\begin{tabular}{|c|c|c|c|c|c|c|}
\hline & \multicolumn{3}{|c|}{ Climate Change Threat } & \multicolumn{3}{|c|}{ Environmental Influence } \\
\hline & $\mathrm{B}(S . E)$. & $\beta$ & C.R. & $\mathrm{B}(S . E)$. & $\beta$ & C.R. \\
\hline Devotionalism & $0.47(0.26)$ & .53 & 1.84 & $0.47(0.25)$ & .65 & 1.87 \\
\hline Spirituality & $0.22(0.19)$ & .24 & 1.17 & $0.12(0.19)$ & .15 & 0.63 \\
\hline $\begin{array}{l}\text { Religious } \\
\text { conservativism }\end{array}$ & $-1.03(0.23)^{* * *}$ & -.88 & -4.39 & $-0.81(0.23) * * *$ & -.84 & -3.56 \\
\hline Female & $0.03(0.07)$ & .02 & 0.47 & $0.10(0.06)^{* *}$ & .10 & 1.62 \\
\hline SES & $-0.09(0.05)$ & -.09 & -1.83 & $-0.05(0.05)$ & -.07 & -1.10 \\
\hline Non-white & $0.07(0.10)$ & .04 & 0.70 & $0.12(0.09)$ & .08 & 1.27 \\
\hline RWA & $0.25(0.09)^{* *}$ & .25 & 2.95 & $0.23(0.08) * *$ & .28 & 2.81 \\
\hline Liberal views (youth) & $0.25(0.04)^{* * *}$ & .43 & 6.37 & $0.23(0.04)^{* * *}$ & .46 & 5.81 \\
\hline
\end{tabular}

Note: $* p<.05, * * p<.01, * * * p<.001$

Climate change threat: $\mathrm{X}^{2}(104)=279.97, \mathrm{CFI}=.95, \mathrm{RMSEA}=.07$

Environmentalism: $\mathrm{X}^{2}(104)=268.75, \mathrm{CFI}=.95, \mathrm{RMSEA}=.07$ 
Table 26

Direct associations between harsh punishments and capital punishment - religious sample $(n=385)$

\begin{tabular}{|c|c|c|c|}
\hline & $\mathrm{B}($ S.E. $)$ & $\beta$ & C.R. \\
\hline Harsh punishment & $21.74(3.65)^{* * *}$ & -52 & 5.95 \\
\hline Gender & $1.21(2.57)$ & .03 & 0.47 \\
\hline SES & $0.78(1.81)$ & .02 & 0.43 \\
\hline Non-white & $-4.32(3.69)$ & -.06 & -1.17 \\
\hline RWA & $-4.21(2.48)$ & -.11 & -1.69 \\
\hline Liberal views (youth) & $-6.35(1.45) * * *$ & -.28 & -4.39 \\
\hline
\end{tabular}

Note: $* p<.05, * * p<.01, * * * p<.001$

Model fit: $\mathrm{X}^{2}(38)=161.05, \mathrm{CFI}=.89, \mathrm{RMSEA}=.09$ 
Table 27

Direct associations between good/bad person and capital punishment - religious sample $(n=385)$

\begin{tabular}{|c|c|c|c|c|c|c|c|c|c|}
\hline & \multicolumn{3}{|c|}{$\begin{array}{c}\text { Good/bad person } 1 \\
\mathrm{X}^{2}(20)=116.77, \mathrm{CFI}=.87 \\
\mathrm{RMSEA}=.12\end{array}$} & \multicolumn{3}{|c|}{$\begin{array}{c}\text { Good } / \text { bad person } 2 \\
\mathrm{X}^{2}(20)=111.53, \mathrm{CFI}=.86 \\
\mathrm{RMSEA}=.11\end{array}$} & \multicolumn{3}{|c|}{$\begin{array}{c}\text { Good/bad person } 3 \\
\mathrm{X}^{2}(20)=110.97, \mathrm{CFI}=.86 \\
\mathrm{RMSEA}=.11\end{array}$} \\
\hline & $\mathrm{B}(S . E)$. & $\beta$ & C.R. & $\mathrm{B}(S . E)$. & $\beta$ & C.R. & $\mathrm{B}(S . E)$. & $\beta$ & C.R. \\
\hline Good/bad person & $4.96(1.18) * * *$ & .25 & 4.22 & $3.64(1.13)^{*}$ & .18 & 3.21 & $-1.59(1.65)$ & -.05 & -0.96 \\
\hline Gender & $-0.29(2.35)$ & -.01 & -0.13 & $-0.20(2.56)$ & -.00 & -0.08 & $-0.79(2.56)$ & -.02 & -0.31 \\
\hline SES & $1.55(1.67)$ & .05 & 0.93 & $0.70(1.82)$ & .02 & 0.38 & $1.35(1.84)$ & .04 & 0.73 \\
\hline Non-white & $-1.11(3.38)$ & -.02 & -0.33 & $-1.16(3.67)$ & -.02 & -0.32 & $-1.13(3.70)$ & -.02 & -0.30 \\
\hline RWA & $0.54(2.09)$ & .02 & 0.26 & $3.65(2.18)$ & .10 & 1.67 & $3.67(2.20)$ & .10 & 1.67 \\
\hline Liberal views (youth) & $-7.38(1.35) * * *$ & -.37 & -5.47 & $-8.03(1.45)^{* * *}$ & -.37 & -5.55 & $-8.54(1.46) * * *$ & -.40 & -5.84 \\
\hline
\end{tabular}

Note: $* p<.05, * * p<.01, * * * p<.001$

Good/bad 1: There are two types of people in the world: good people who do good things and bad people who do bad things

Good/bad 2: There is no such thing as a "good person" or a "bad person" - Reverse coded

Good/bad 3: Everyone has a little bit of good and a little bit of bad in them - Reverse coded 
Table 28

Direct associations between personal choice and euthanasia - religious sample $(n=385)$

\begin{tabular}{|c|c|c|c|c|c|c|c|c|c|}
\hline & \multicolumn{3}{|c|}{$\begin{array}{c}\text { Quality of life } 1 \\
\mathrm{X}^{2}(20)=51.95, \mathrm{CFI}=.96 \\
\mathrm{RMSEA}=.07\end{array}$} & \multicolumn{3}{|c|}{$\begin{array}{c}\text { Quality of life } 2 \\
\mathrm{X}^{2}(20)=51.87, \mathrm{CFI}=.96 \\
\text { RMSEA }=.07\end{array}$} & \multicolumn{3}{|c|}{$\begin{array}{c}\text { Quality of life } 3 \\
\mathrm{X}^{2}(20)=49.65, \mathrm{CFI}=.96 \\
\mathrm{RMSEA}=.06\end{array}$} \\
\hline & $\mathrm{B}(S . E)$. & $\beta$ & C.R. & $\mathrm{B}($ S.E. $)$ & $\beta$ & C.R. & $\mathrm{B}($ S.E. $)$ & $\beta$ & C.R. \\
\hline Quality of life & $4.75(2.23)^{*}$ & .12 & 2.13 & $12.46(1.50)^{* * *}$ & .44 & 8.30 & $3.95(2.16)$ & 0.10 & 1.83 \\
\hline Gender & $-9.51(3.40)^{* *}$ & -.16 & -2.80 & $-7.97(3.11)^{*}$ & -.13 & -2.56 & $-9.47(3.41)^{* *}$ & -.16 & -2.78 \\
\hline SES & $3.52(2.42)$ & .08 & 1.46 & $2.63(2.21)$ & .06 & 1.19 & $3.76(2.42)$ & .08 & 1.56 \\
\hline Non-white & $-5.03(4.87)$ & -.06 & -1.03 & $-1.97(4.47)$ & -.02 & -0.44 & $-5.65(4.90)$ & -.07 & -1.15 \\
\hline RWA & $-4.90(2.89)$ & -.10 & -1.70 & $0.73(2.71)$ & .02 & 0.27 & $-5.30(2.92)$ & -.11 & -1.82 \\
\hline Liberal views (youth) & $7.85(1.83)^{* *}$ & .21 & 3.20 & $5.18(1.67)^{* *}$ & .18 & 3.10 & $6.05(1.83)^{* * *}$ & .21 & 3.31 \\
\hline
\end{tabular}

Note: $* p<.05, * * p<.01, * * * p<.001$

Quality of life 1: Maintaining a good quality of life is more important than how long it is

Quality of life 2: We should strive to keep people alive as long as possible even if their quality of life is compromised - Reverse coded

Quality of life 3: Living a happy life is more important than living a long life 
Table 29

Direct associations between personal choice and euthanasia - religious sample $(n=385)$

\begin{tabular}{|c|c|c|c|c|c|c|c|c|c|}
\hline & \multicolumn{3}{|c|}{$\begin{array}{c}\text { Personal choice } 1 \\
\mathrm{X}^{2}(20)=53.09, \text { CFI }=.96 \\
\text { RMSEA }=.07\end{array}$} & \multicolumn{3}{|c|}{$\begin{array}{c}\text { Personal choice } 2 \\
\mathrm{X}^{2}(20)=49.02, \mathrm{CFI}=.96 \\
\mathrm{RMSEA}=.06\end{array}$} & \multicolumn{3}{|c|}{$\begin{array}{c}\text { Personal choice } 3 \\
\mathrm{X}^{2}(20)=51.19, \mathrm{CFI}=.96 \\
\mathrm{RMSEA}=.07\end{array}$} \\
\hline & $\mathrm{B}($ S.E. $)$ & $\beta$ & C.R. & $\mathrm{B}(S . E)$. & $\beta$ & C.R. & $\mathrm{B}($ S.E. $)$ & $\beta$ & C.R. \\
\hline Personal choice & $4.50(2.34)$ & .10 & 1.92 & $-2.66(2.12)$ & -.07 & -1.25 & $-1.67(1.57)$ & -.06 & -1.07 \\
\hline Gender & $-8.76(3.40)^{*}$ & -.15 & -2.58 & $-9.34(3.42)^{* *}$ & -.15 & -2.73 & $-9.62(3.45)^{* *}$ & -.16 & -2.79 \\
\hline SES & $3.93(2.41)$ & .09 & 1.63 & $4.06(2.43)$ & .09 & 1.67 & $4.01(2.43)$ & .09 & 0.10 \\
\hline Non-white & $-5.48(4.88)$ & -.06 & -1.12 & $-5.76(4.94)$ & -.07 & -1.17 & $-4.89(4.91)$ & -.06 & -1.00 \\
\hline RWA & $-4.39(2.89)$ & -.09 & -1.52 & $-5.88(3.06)$ & -.12 & -1.92 & $-4.62(2.91)$ & -.10 & -1.59 \\
\hline Liberal views (youth) & $6.13(1.82)^{* * *}$ & .22 & 3.36 & $6.07(1.84)^{* * *}$ & .21 & 3.30 & $6.30(1.84)^{* * *}$ & .22 & 3.43 \\
\hline
\end{tabular}

Note: $* p<.05, * * p<.01, * * * p<.001$ 
Table 30

Direct associations between personal choice and abortion - religious sample $(n=385)$

\begin{tabular}{|c|c|c|c|c|c|c|c|c|c|}
\hline & \multicolumn{3}{|c|}{$\begin{array}{c}\text { Personal choice } 1 \\
\mathrm{X}^{2}(20)=76.04, \mathrm{CFI}=.94 \\
\mathrm{RMSEA}=.09\end{array}$} & \multicolumn{3}{|c|}{$\begin{array}{c}\text { Personal choice } 2 \\
\mathrm{X}^{2}(20)=63.83, \mathrm{CFI}=.95 \\
\mathrm{RMSEA}=.08\end{array}$} & \multicolumn{3}{|c|}{$\begin{array}{c}\text { Personal choice } 3 \\
\mathrm{X}^{2}(20)=65.33, \mathrm{CFI}=.95 \\
\mathrm{RMSEA}=.08\end{array}$} \\
\hline & $\mathrm{B}(S . E)$. & $\beta$ & C.R. & $\mathrm{B}(S . E)$. & $\beta$ & C.R. & $\mathrm{B}(S . E)$. & $\beta$ & C.R. \\
\hline Personal choice & $2.88(1.81)$ & .08 & 1.59 & $1.95(1.63)$ & .06 & 1.19 & $0.56(1.21)$ & .02 & 0.46 \\
\hline Gender & $0.64(2.61)$ & .01 & 0.25 & $0.52(2.62)$ & .01 & 0.20 & $0.55(2.64)$ & .01 & 0.21 \\
\hline SES & $2.39(1.86)$ & .06 & 1.29 & $2.39(1.87)$ & .06 & 1.28 & $2.43(1.87)$ & .06 & 1.30 \\
\hline Non-white & $5.95(3.77)$ & .08 & 1.58 & $6.75(3.81)$ & .09 & 1.77 & $6.18(3.79)$ & .08 & 1.63 \\
\hline RWA & $-13.40(2.35)^{* * *}$ & -.32 & -5.71 & $-12.84(2.45)^{* * *}$ & -.31 & -5.23 & $-13.73(2.37)^{* * *}$ & -.33 & -5.81 \\
\hline Liberal views (youth) & $7.50(1.46)^{* * *}$ & .30 & 5.14 & $7.71(1.47)^{* * *}$ & .31 & 5.24 & $7.56(1.47)^{* * *}$ & .30 & 5.15 \\
\hline
\end{tabular}

Note: $* p<.05, * * p<.01, * * * p<.001$ 
Table 31

Direct associations between climate change threat and environmental influence and environmentalism - religious sample $(n=385)$

\begin{tabular}{|c|c|c|c|c|c|c|}
\hline & \multicolumn{3}{|c|}{$\begin{array}{c}\text { Climate Change Threat } \\
\mathrm{X}^{2}(38)=53.27, \mathrm{CFI}=.99, \mathrm{RMSEA}=.03\end{array}$} & \multicolumn{3}{|c|}{$\begin{array}{c}\text { Environmental Influence } \\
\mathrm{X}^{2}(38)=49.84, \mathrm{CFI}=.99, \mathrm{RMSEA}=.03\end{array}$} \\
\hline & $\mathrm{B}(S . E)$. & $\beta$ & C.R. & $\mathrm{B}(S . E)$. & $\beta$ & C.R. \\
\hline Climate Change Threat & $20.19(2.29)^{* * *}$ & .72 & 8.83 & & & \\
\hline $\begin{array}{l}\text { Environmental } \\
\text { Influence }\end{array}$ & & & & $25.01(3.83)^{* * *}$ & .69 & 6.52 \\
\hline Gender & $-1.52(1.67)$ & -.04 & -0.91 & $-3.69(1.87)^{*}$ & -.10 & -1.98 \\
\hline SES & $-1.08(1.18)$ & -.04 & -0.91 & $-1.91(1.31)$ & -.07 & -1.46 \\
\hline Non-white & $1.32(2.40)$ & .02 & 0.55 & $-0.09(2.67)$ & -.00 & -0.04 \\
\hline RWA & $-1.79(1.43)$ & -.06 & -1.25 & $-2.63(1.61)$ & -.09 & -1.64 \\
\hline Liberal views (youth) & $1.61(1.11)$ & .10 & 1.45 & $1.83(1.34)$ & .11 & 1.37 \\
\hline
\end{tabular}

Note: $* p<.05, * * p<.01, * * * p<.001$ 
Table 32

Indirect effects for Harsh Punishments on Capital Punishment - religious sample $(n=385)$

\begin{tabular}{|c|c|c|c|c|c|c|}
\hline & \multicolumn{3}{|c|}{ Harsh Punishments } & \multicolumn{3}{|c|}{ Capital Punishment } \\
\hline & $\mathrm{B}(S . E)$. & $\beta$ & C.R. & $\mathrm{B}($ S.E. $)$ & $\beta$ & C.R. \\
\hline Devotionalism & $-0.44(0.25)$ & -.56 & -1.79 & $-12.82(9.88)$ & -.39 & -1.30 \\
\hline Spirituality & $.44(0.18)^{*}$ & .54 & 2.39 & $2.03(7.46)$ & .06 & 0.27 \\
\hline Religious conservativism & $0.03(0.20)$ & .03 & 0.16 & $1.55(8.10)$ & .04 & 0.19 \\
\hline Harsh punishments & & & & $20.50(3.75)^{* * *}$ & .49 & 5.46 \\
\hline Female & $-.11(0.06)$ & -.10 & -1.75 & $1.39(2.49)$ & .03 & 0.56 \\
\hline SES & $-.01(0.05)$ & -.01 & -0.17 & $1.02(1.80)$ & .03 & 0.57 \\
\hline Non-white & $0.12(0.09)$ & .08 & 1.35 & $-1.47(3.59)$ & -.02 & -0.41 \\
\hline RWA & $0.33(0.08) * * *$ & .38 & 4.11 & $-1.17(3.16)$ & -.03 & -0.37 \\
\hline Liberal views (youth) & $-0.13(0.04) * * *$ & -.25 & -3.70 & $-6.90(1.51) * * *$ & -.31 & -4.57 \\
\hline
\end{tabular}

Note: $* p<.05, * * p<.01, * * * p<.001$

Model fit: $\mathrm{X}^{2}(169)=438.11, \mathrm{CFI}=.94, \mathrm{RMSEA}=.07$

Indirect effect: $\mathrm{B}=8.97, p<.05$ 
Table 33

Indirect effects for Climate Change Threat on Environmentalism - religious sample $(n=385)$

\begin{tabular}{|c|c|c|c|c|c|c|}
\hline & \multicolumn{3}{|c|}{ Climate Change Threat } & \multicolumn{3}{|c|}{ Environmentalism } \\
\hline & $\mathrm{B}($ S.E. $)$ & $\beta$ & C.R. & $\mathrm{B}(S . E)$. & $\beta$ & C.R. \\
\hline Devotionalism & $0.49(0.27)$ & .54 & 1.83 & $4.01(6.50)$ & .15 & 0.62 \\
\hline Spirituality & $0.21(0.20)$ & .22 & 1.06 & $-7.33(4.70)$ & -.27 & -1.56 \\
\hline Religious conservativism & $-1.03(0.24)^{* * *}$ & -.86 & -4.29 & $3.35(6.33)$ & .10 & 0.53 \\
\hline Climate change threat & & & & $21.41(2.70) * * *$ & .74 & 7.94 \\
\hline Female & $0.03(0.07)$ & .02 & 0.37 & $-1.47(1.66)$ & -.04 & -0.88 \\
\hline SES & $-0.09(0.05)$ & -.10 & -1.89 & $-0.72(1.22)$ & -.03 & -0.59 \\
\hline Non-white & $0.09(0.10)$ & .05 & 0.88 & $1.92(2.43)$ & .05 & 0.79 \\
\hline RWA & $0.25(0.09)^{* *}$ & .25 & 2.90 & $-1.73(2.22)$ & -.06 & -0.78 \\
\hline Liberal views (youth) & $0.27(0.04)^{* * *}$ & .44 & 6.57 & $2.03(1.09)$ & .12 & 1.86 \\
\hline
\end{tabular}

Note: $* p<.05, * * p<.01, * * * p<.001$

Model fit: $\mathrm{X}^{2}(169)=359.83, \mathrm{CFI}=.96, \mathrm{RMSEA}=.06$

Indirect effect: $\mathrm{B}=-36.80, p<.01$ 
Table 34

Indirect effects for Environmental Influence on Environmentalism - religious sample $(n=385)$

\begin{tabular}{|c|c|c|c|c|c|c|}
\hline & \multicolumn{3}{|c|}{ Environmental Influence } & \multicolumn{3}{|c|}{ Environmentalism } \\
\hline & $\mathrm{B}(S . E)$. & $\beta$ & C.R. & $\mathrm{B}($ S.E. $)$ & $\beta$ & C.R. \\
\hline Devotionalism & $.48(0.25)$ & .64 & 1.89 & $2.30(7.62)$ & .09 & 0.30 \\
\hline Spirituality & $0.10(0.18)$ & .13 & 0.56 & $-5.65(5.27)$ & -.21 & -1.07 \\
\hline Religious conservativism & $-0.79(0.22)^{* * *}$ & -.82 & -3.55 & $1.95(7.45)$ & .06 & 0.26 \\
\hline Environmental influence & & & & $26.27(3.75)^{* * *}$ & .74 & 5.79 \\
\hline Female & $0.10(0.06)$ & .10 & 1.63 & $-3.62(1.92)$ & -.10 & -1.89 \\
\hline SES & $-.05(0.05)$ & -.06 & -1.05 & $-1.48(1.37)$ & -.05 & -1.09 \\
\hline Non-white & $0.12(0.09)$ & .08 & 1.30 & $0.67(2.76)$ & .01 & 0.24 \\
\hline RWA & $0.23(0.08)^{* *}$ & .27 & 2.80 & $-2.24(2.63)$ & -.07 & -0.85 \\
\hline Liberal views (youth) & $0.23(0.04)^{* * *}$ & .46 & 5.95 & $1.73(1.36)$ & .10 & 1.27 \\
\hline
\end{tabular}

Note: $* p<.05, * * p<.01, * * * p<.001$

Model fit: $\mathrm{X}^{2}(169)=352.90, \mathrm{CFI}=.96, \mathrm{RMSEA}=.06$

Indirect effect: $\mathrm{B}=-20.85, p<.05$ 
Appendix C - Figures

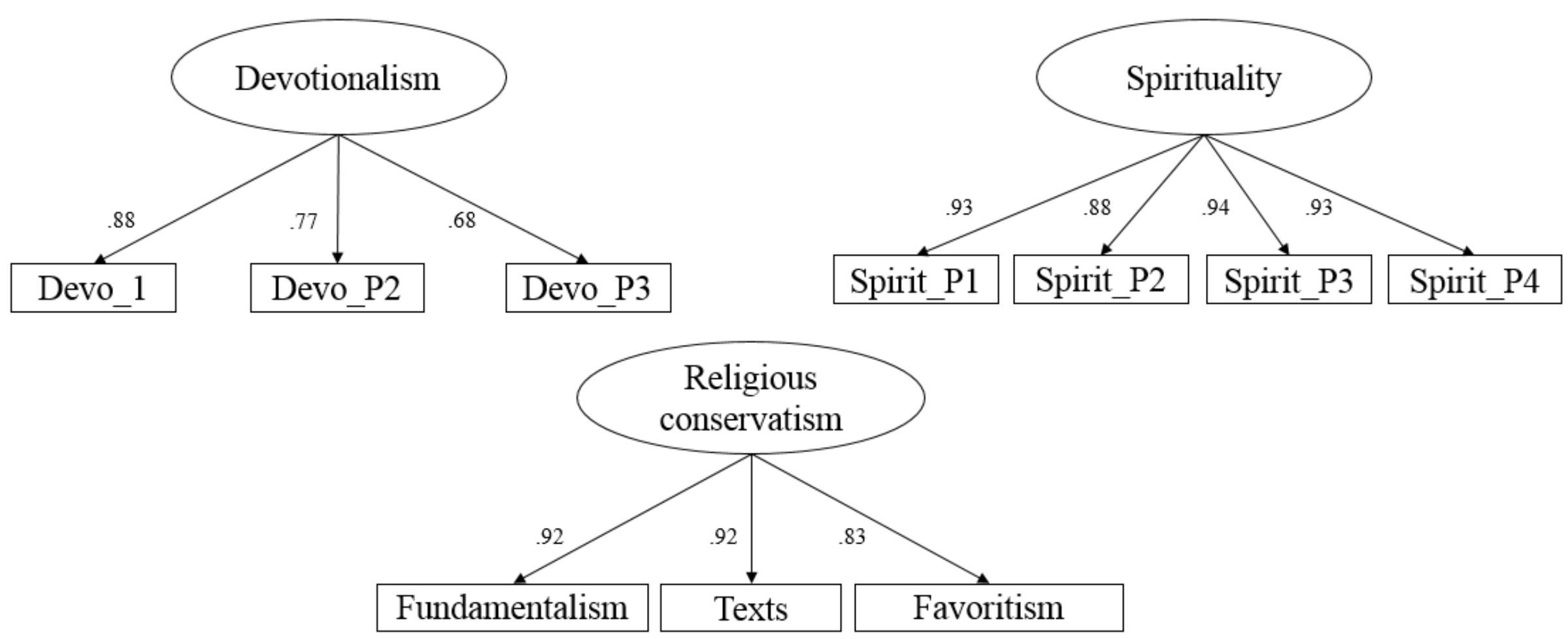

Figure 1. Confirmatory factor analysis for religious latent variables 

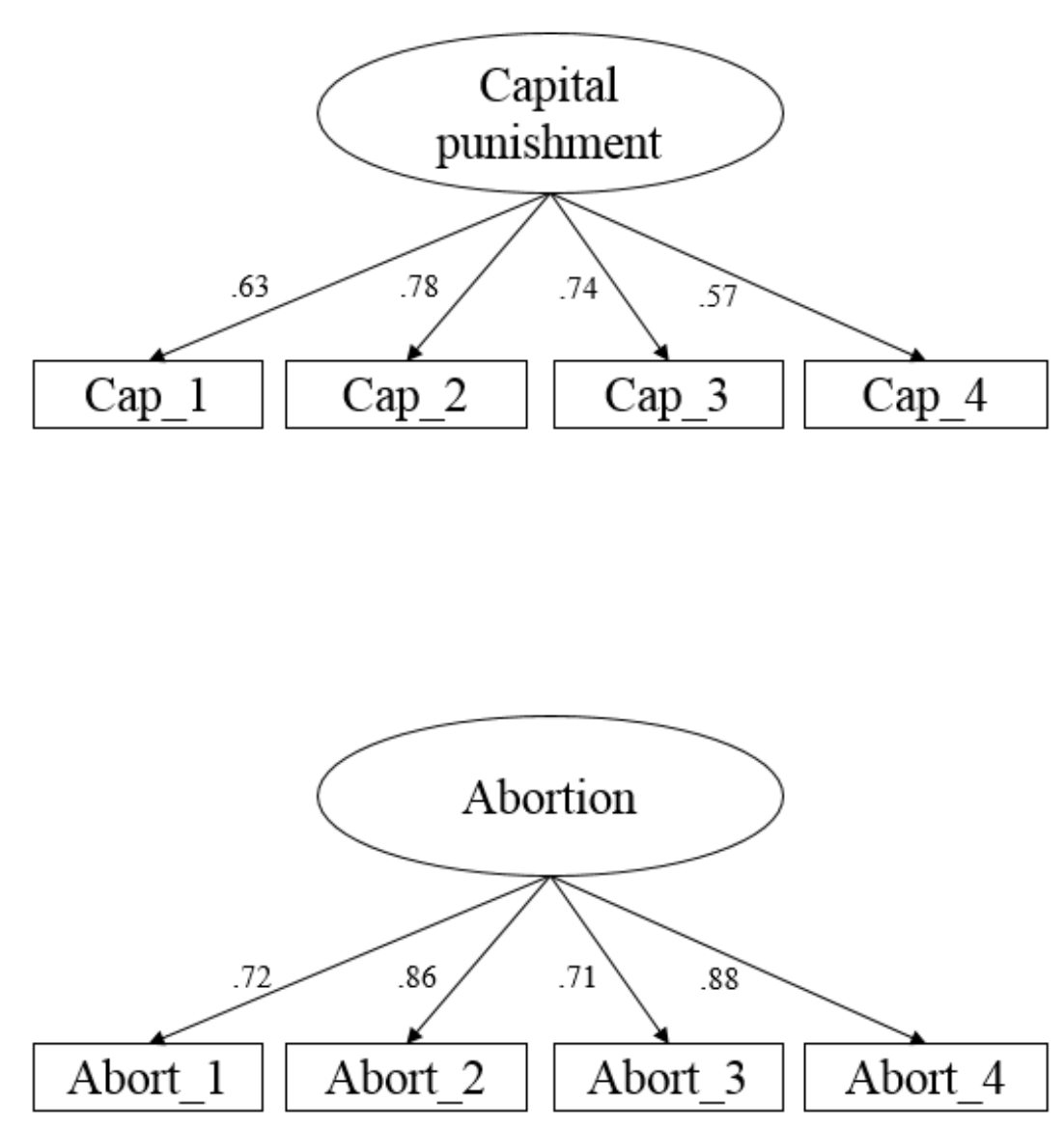

Figure 2. Confirmatory factor analysis for political attitude latent variables
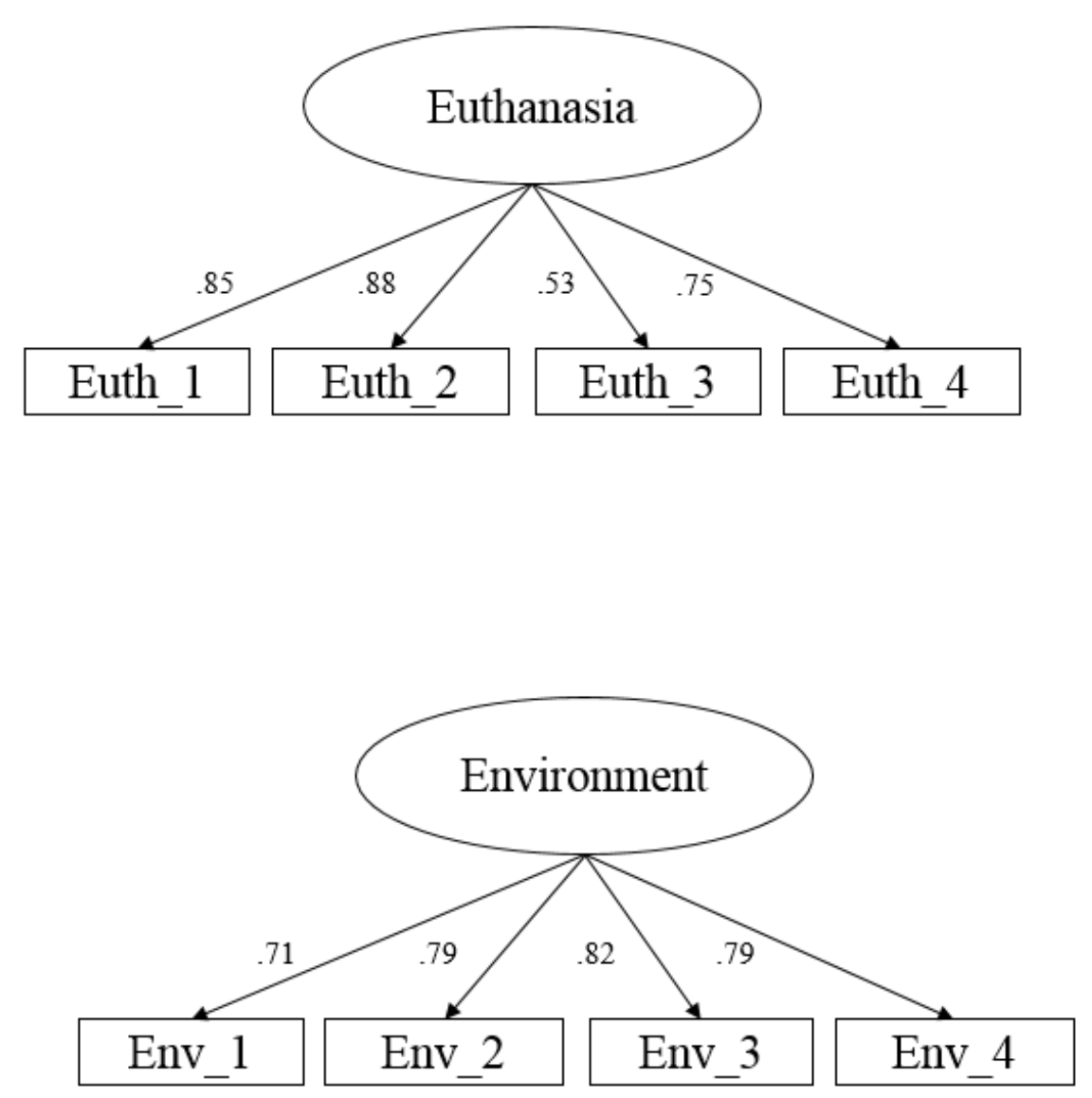

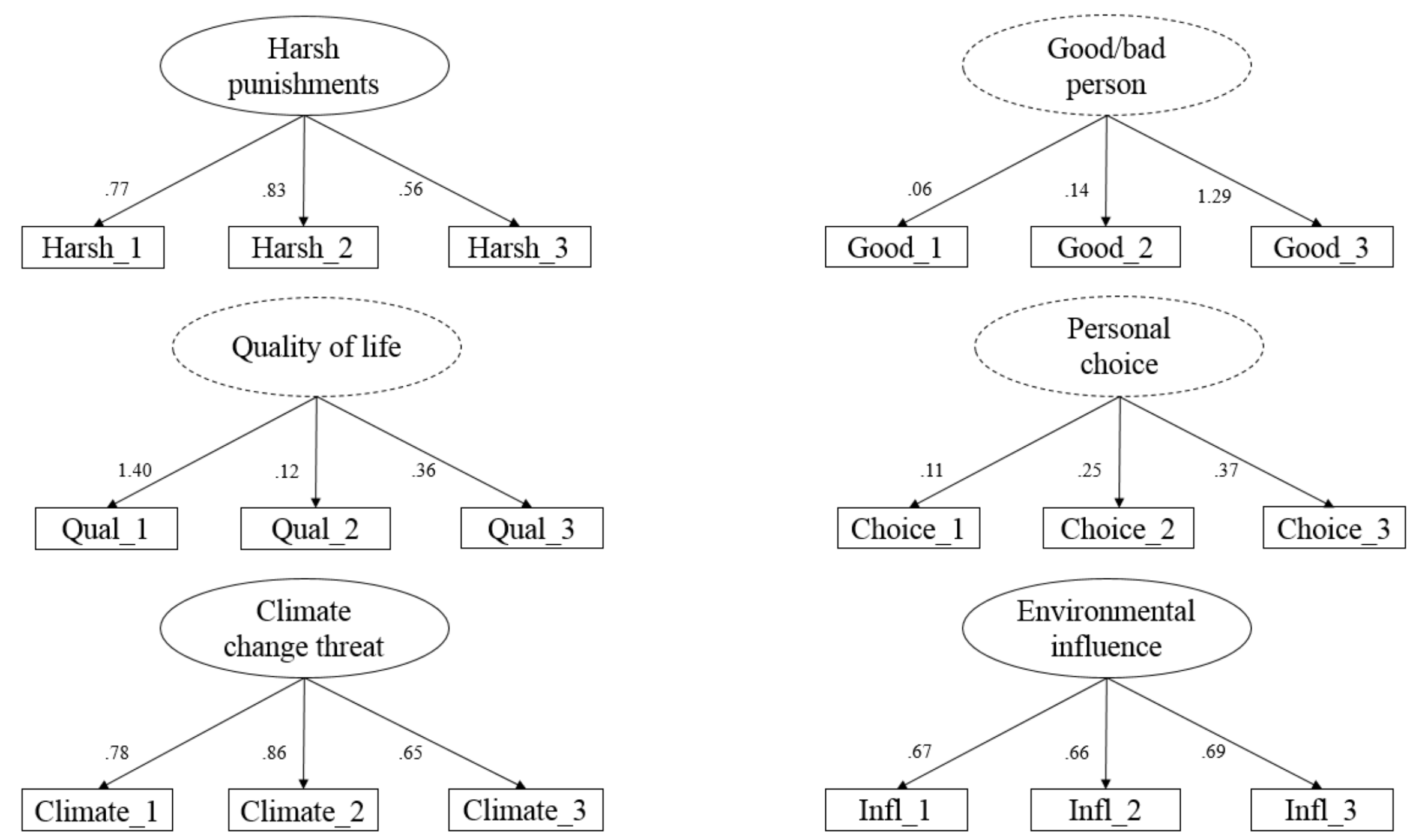

Figure 3. Confirmatory factor analysis for informational assumption latent variables NOTE: Dotted lines indicate that the latent construct was not used in analyses. 

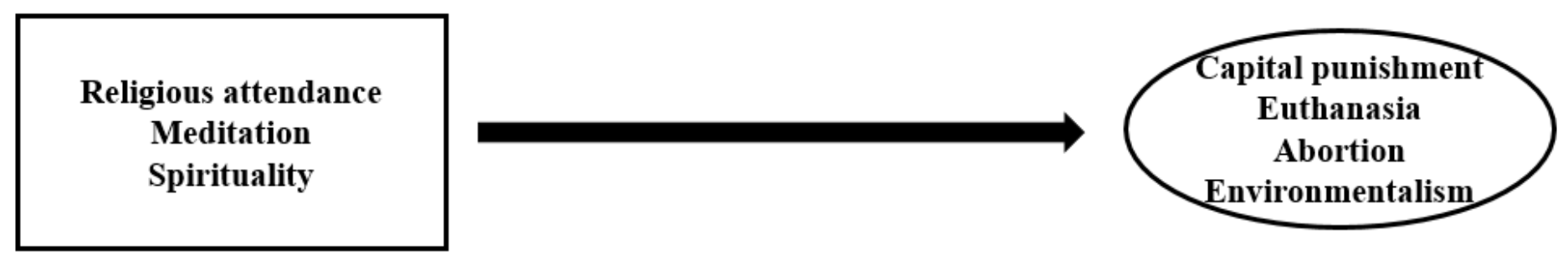

Figure 4. Conceptual model for direct effects: Full sample 


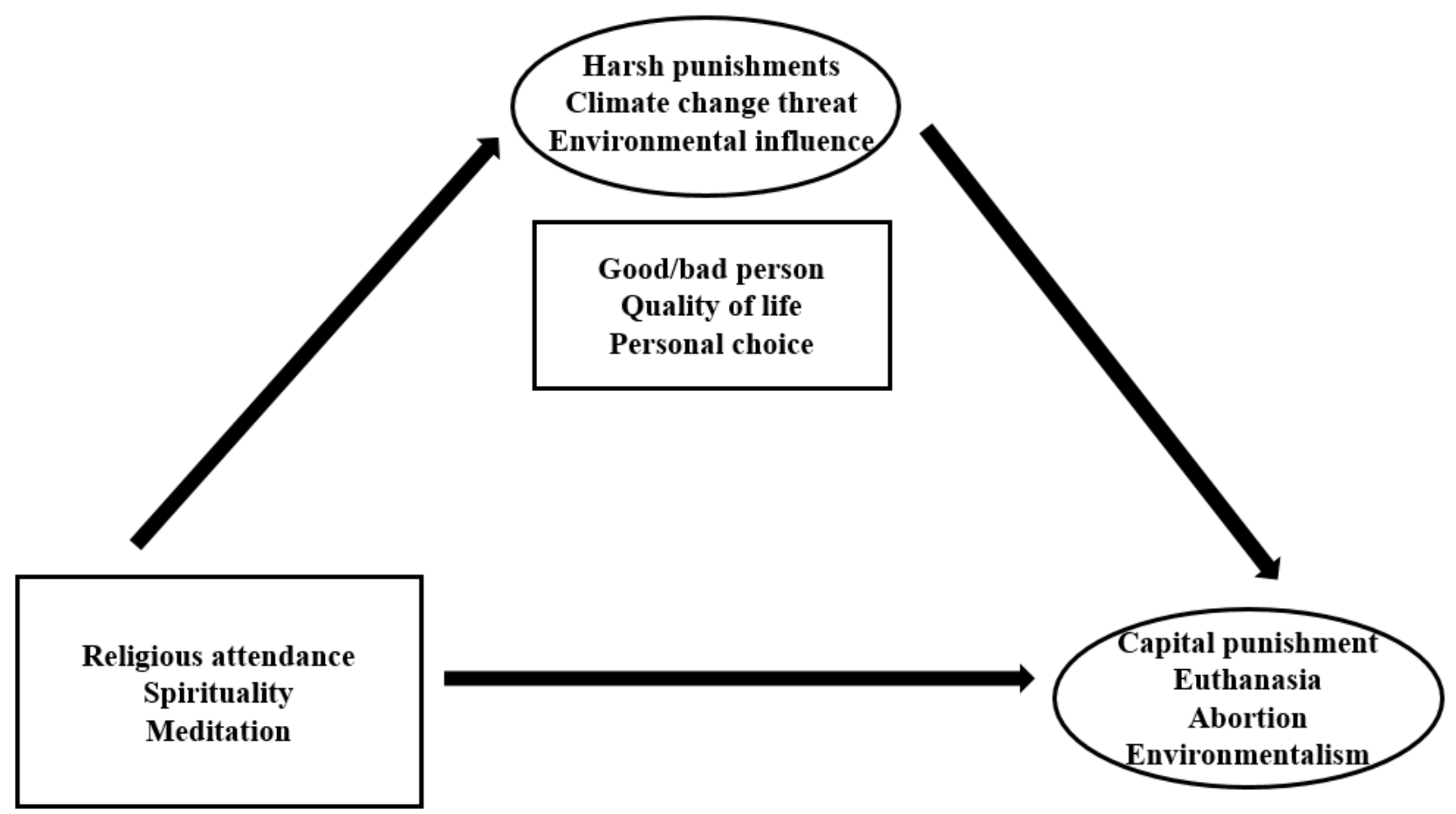

Figure 5. Conceptual model for indirect effects: Full sample 


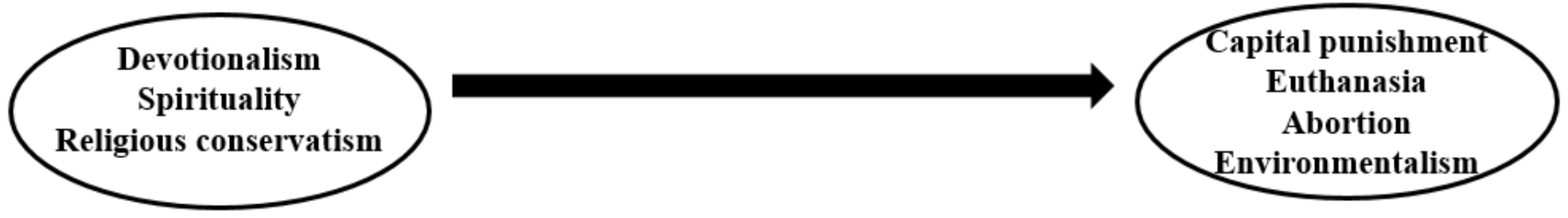

Figure 6. Conceptual model for direct effects: Religious sample 


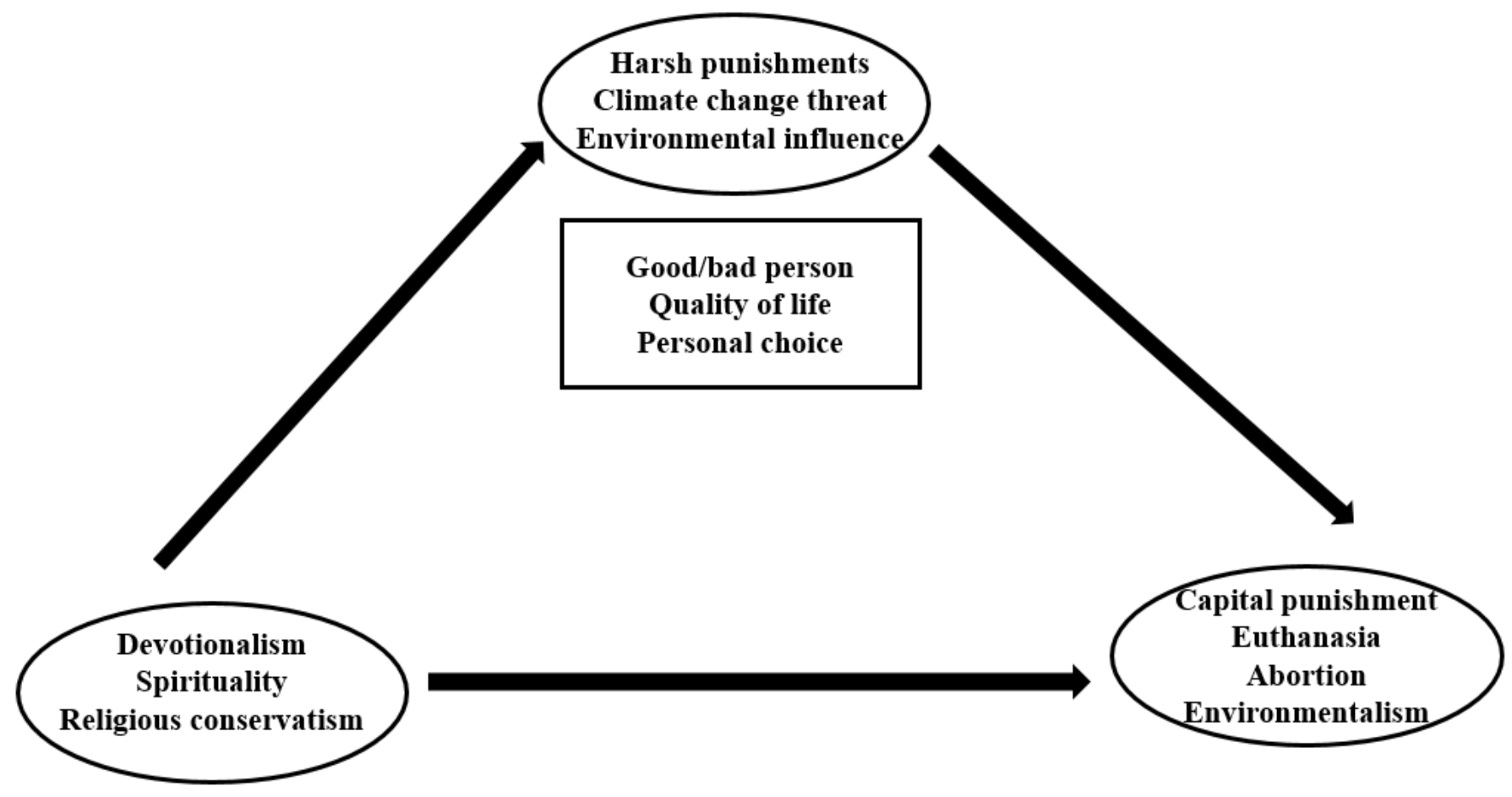

Figure 7. Conceptual model for indirect effects: Religious sample 


\section{Appendix D - Questionnaire}

\section{Demographics}

I am:

Male

Female

Other: (Please specify)

What school do you currently attend?

Colonial Forge High School

Dubois Central Catholic

Moshannon Valley High School

Springfield High School

How old are you?

13

14

15

16

17

18

19

20

21

What is your birth MONTH?

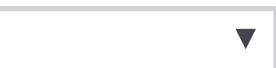

What is your birth DAY?

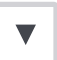


What is your birth YEAR?

\section{v}

What grade are you in?

Grade 9

Grade 10

Grade 11

Grade 12

Which of the following best describes you? Check all that apply.

American Indian or Alaska Native

Asian

Black or African American

Hispanic or Latino/Latina

Native Hawaiian or other Pacific Islander

White

Other: (Please specify)

Do you consider yourself to be:

Heterosexual or straight

Homosexual or gay/lesbian

Bisexual

Other: (Please specify) 
Which of the following best describes you?

Protestant Christian

Catholic Christian

Orthodox Christian

Jewish

Muslim

Buddhist

Hindu

No religious affiliation

Other: (Please specify)

\section{Religious affiliation}

What is your religious affiliation?

\section{Academics and family}

What are your educational plans after high school? Check all that apply.

I do not plan to graduate high school

I have no educational plans after high school

Attend a 2-year college or junior college

Attend a trade or vocational school

Attend a 4-year college or university

Join the Military

I have not decided

Other plans for training or education (please list)

What grades do you usually earn in school?

Mostly A's

About half A's and half B's

Mostly B's 
What grades do you usually earn in school?

Mostly A's

About half A's and half B's

Mostly B's

About half B's and half C's

Mostly C's

About half C's and half D's

Mostly D's

Mostly below D's

Which of the following statements best describes your family's financial situation?

We have a hard time buying the things we need.

We have just enough money for the things we need.

We have no problem buying the things we need and we can sometimes buy special things.

We have enough money to buy almost everything we want.

I would describe myself to be:

Very conservative

Somewhat conservative

Somewhat conservative, Somewhat liberal

Somewhat liberal

Very conservative

Who takes care of you MOST of the time? Select all that apply:

$\begin{array}{lrrll}\text { Mom Dad } & & \text { Step-mom } & \text { Step-dad } & \text { Grandmother } \\ \text { Grandfather } & \text { Aunt } & \text { Uncle } & \text { Older sibling } & \text { Other (Please specify) }\end{array}$

I would describe my [caregiver] to be:

Very conservative

Somewhat conservative

Somewhat conservative, Somewhat liberal

Somewhat liberal

Very liberal 


\section{Political attitudes}

How much do you agree or disagree with the following statements?

$$
0=\text { strongly disagree, } 100=\text { strongly agree }
$$

$\begin{array}{lllllllllll}0 & 10 & 20 & 30 & 40 & 50 & 60 & 70 & 80 & 90 & 100\end{array}$

I am in favor of the death penalty for $a$ person convicted of murder

The death penalty is imposed too often

The death penalty is applied unfairly in this country today

The death penalty should be imposed more often

Abortion should be illegal in all circumstances

Abortion laws in this country should be made stricter

While abortion should be generally illegal, there are certain circumstances where an exception should be made (e.g. rape, mother's life is in danger)

Women should be allowed to get an abortion if they choose to do so

Doctors should be allowed to painlessly end a patient's life if the patient requests it 
If a patient has an incurable disease, they should have the right to request life ending drugs from their doctor

It should be illegal for doctors to prescribe lifeending drugs even if a patient requests it

There should be a law preventing doctors from prescribing life-ending drugs for any reason $(R)$

Protection of the environment should be given priority even at the risk of curbing economic growth

The US government is doing too little in terms of protecting the environment

The US government should more strongly enforce federal environmental regulations

The US government should spend more government money on developing sources of clean energy such as solar and wind power

\section{Religiosity}

How frequently do you do the following?

\section{Attend religious services}

Attend religious social events

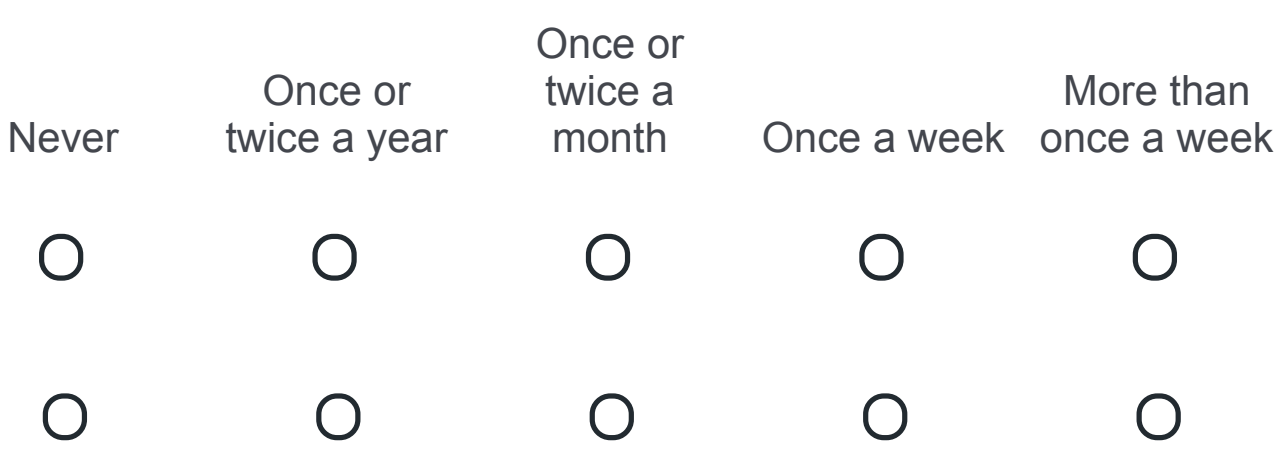

Once or twice a month 
Serve in a religious leadership role (e.g. greeter, acolyte,

0

0

0

0

reader, alter assistant)

How much do agree or disagree with the following?

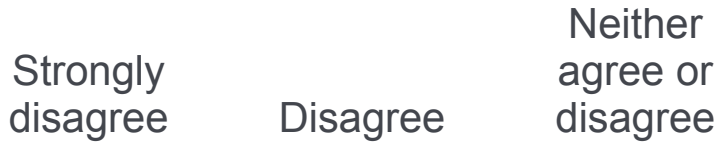

Agree

Strongly

agree

My ideas about

religion are one of the most important parts of

$0 \quad 0$

0

0

my philosophy of life

I find that my ideas on religion have a considerable influence on my views in other

0

0

0

0

0

areas

Believing as I do about religion is very important to being the kind of person I want

O

0

0

0

0

to be

If my ideas about religion were different, I believe that my way

of life would be very

0

0

0

0

0

different

Religion is a subject in which I am not particularly interested

O

0

0

0

0

I very often think about matters relating to religion

$0 \quad 0$

0 
My spirituality gives

me a feeling of

$0 \quad 0$

0

0

fulfillment

I maintain an inner

awareness of a higher

power's presence in

O 0

0

my life

Even when I

experience problems, I

can find a spiritual

peace within

I try to strengthen my

relationship with a

higher power

O $\mathrm{O}$

O

Maintaining my

spirituality is a priority

for me

A higher power helps

me to rise above my

immediate

0

0

0

0

0

circumstances

My spirituality helps

me to understand my

life's purpose

I experience a deep

communion with a

higher power

0

0

0

0

0

0

0

0

How frequently do you do the following?

Once or

twice a

Once or

More than

Never

month

twice a week Once a day

once a day

Pray in private

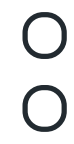

0

0

0

0

Meditate or chant

0

0

0

0

0

How much do you agree or disagree with the following? 
Strongly

disagree

God has given

humanity a complete, unfailing guide to

happiness and

salvation, which must

be totally followed

All of the religions in the world have flaws and wrong teachings. There is no perfectly true, right religion

When you get right down to it, there are only two kinds of people in the world: the Righteous, who will be rewarded by God; and the rest, who will not

Different religions and philosophies have different versions of the truth, and may be equally right in their own way

It is more important to be a good person than to believe in God and the right religion

No one religion is especially close to God, nor does God favor any particular group of believers

No single book of religious teachings contains all the intrinsic, fundamental truths about life

Parents should encourage their children to study all religions without bias, then make up their own minds about what to believe

O

O

$\mathrm{O}$
Neither agree or

disagree
$\mathrm{O}$

$\mathrm{O}$

$\mathrm{O}$

$\mathrm{O}$

$0 \quad 0$

$\mathrm{O}$

$\mathrm{O}$

$\begin{array}{lllll}0 & 0 & 0 & 0 & 0\end{array}$

$\mathrm{O} \quad \mathrm{O}$

$\mathrm{O}$

$\mathrm{O}$

$\mathrm{O}$

$\begin{array}{lllll}0 & 0 & 0 & 0 & 0\end{array}$
0

0
Strongly

agree 


\section{RELIGIOUSNESS AND POLITICAL ATTITUDES}

Whenever science and sacred scripture conflict, science is

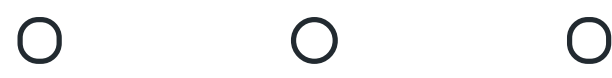

0

0

probably right

To lead the best, most meaningful life, one must belong to the one, true religion

The fundamentals of God's religion should never be tampered with, or compromised with others' beliefs

There is a particular set of religious teachings in this world that are so true, you can't go any "deeper" because they are the basic, bedrock message that God has given humanity

$0 \quad 0$<smiles>O</smiles><smiles>O</smiles>

$\mathrm{O} \quad \mathrm{O}$

$\mathrm{O}$

$\begin{array}{lllll}0 & 0 & 0 & 0\end{array}$

How much do you agree or disagree with the following?

Strongly

disagree

I believe that what is written in scripture is God's word and all it says is true

I believe that the stories described in scripture actually happened just as the book said it did

I believe that scripture is the inspired word of God

I feel that scripture is God's word, and is to be taken literally, word for word

0
Neither

agree or disagree

Agree

Strongly agree
0

0

0

0

0

O 0

O

$0 \quad 0$ 
Strongly

disagree
Neither

agree or

disagree
Strongly

agree

It is important for me to celebrate or practice on religious holidays with my family, friends, or members of my religious community

I closely identify with being a member of my religious group

I prefer to be with other people who are in the same religion as me

It is important to me for people of my religion to marry other people who are the same religion

O

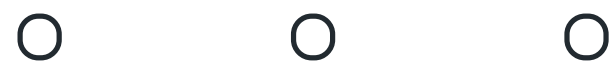

$\mathrm{O}$

O

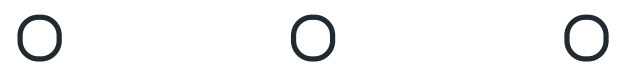

$\mathrm{O}$

$\mathrm{O}$

O $\quad 0 \quad 0$

$\mathrm{O}$

\section{Informational assumptions}

How much do you agree or disagree with the following statements?

$\begin{array}{lll}\text { Strongly } & \begin{array}{l}\text { Neither } \\ \text { agree or } \\ \text { disagree }\end{array} \quad \text { Disagree } & \text { disagree }\end{array}$

There are two types of people in the world: good people who do good things and bad people who do bad things

There is no such thing as a "good person" or a "bad person"

Everyone has a little bit of good and a little bit of bad in them

O 0


Strongly

disagree

Harsh punishments teach people what they can and cannot do

The harsher the punishment, the more effective it is at deterring crime

Harsh punishments are not always the most effective way to deter crime

Maintaining a good quality of life is more important than how long it is

We should strive to keep people alive as long as possible even if their quality of life is compromised

Living a happy life is more important than living a long life

It is important for people to make their own choices

When it comes to making decisions, it is sometimes necessary for others to intervene so people don't make wrong choices

When making a decision, people always know what is best for themselves

The behaviors of people now will affect the environment for future generations

People have the ability to both help and harm the environment

O
Neither

agree or

disagree

Disagree

O

$\mathrm{O}$

O

$\mathrm{O}$

Strongly

agree

Agree

$\mathrm{O}$

0

$\mathrm{O}$

O

$\begin{array}{llll}0 & 0 & 0\end{array}$

$\mathrm{O}$

$\mathrm{O}$

$\begin{array}{llll}0 & 0 & 0\end{array}$

$\mathrm{O}$

O $\quad 0$

$\mathrm{O}$

O

$\mathrm{O}$

$0 \quad 0 \quad 0$

$\mathrm{O}$

0

$\mathrm{O}$

$0 \quad 0 \quad 0$

$0 \quad 0$

$0 \quad 0 \quad 0$

$0 \quad 0$

$0 \quad 0 \quad 0$

O 0

$0 \quad 0 \quad 0$

$\mathrm{O}$

O 
The quality of the environment is getting worse because of

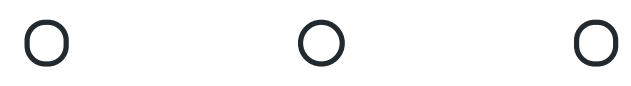

Agree agree

human activity

The effects of global warming have already begun affecting the environment

People should listen to scientists when they say that climate change is a serious threat to the Earth

It is possible for the effects of climate change to be stopped or reversed if people take steps to protect the environment

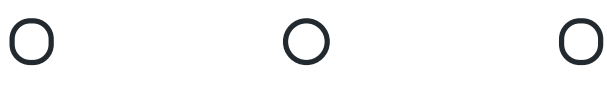

O

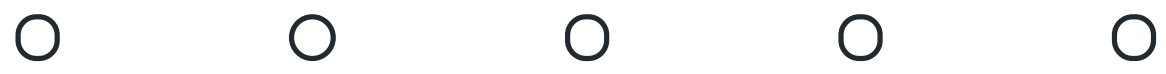

$0 \quad 0$

$\mathrm{O}$

\section{Social Dominance Orientation}

How much do you agree or disagree with the following statements?

Strongly

disagree

Some groups of people are simply not the equals of others

Some people are just more worthy than others

This country would be better off if we cared less about how equal all people were

Some people are just more deserving than others
Neither agree or disagree

Agree

Strongly agree

O

$\begin{array}{lllll}0 & 0 & 0 & 0 & 0\end{array}$

$\begin{array}{lllll}0 & 0 & 0 & 0 & 0\end{array}$ 
Strongly

disagree

It is not a problem if some people have more of a chance in life than others

Some people are just inferior to others

To get ahead in life, it is sometimes necessary to step on others

Increased economic equality

Increased social

equality

Equality

If people were treated more equally, we would have fewer problems in this country

In an ideal world, all nations would be equal

We should try to treat one another as equals as much as possible

It is important that we treat other countries as equals
Neither agree or disagree
Strongly agree

$\begin{array}{ccccc}0 & 0 & 0 & 0 & 0 \\ 0 & 0 & 0 & 0 & 0\end{array}$

O $\quad 0$

O

O

O

O 0 O

$\mathrm{O}$

$0 \quad 0$

$\begin{array}{llll}0 & 0 & 0\end{array}$

○

$\begin{array}{lllll}0 & 0 & 0 & 0 & 0\end{array}$

$\begin{array}{lllll}0 & 0 & 0 & 0 & 0\end{array}$

O $\quad 0$

O

\section{Right-wing authoritarianism}

How much do you agree or disagree with the following statements?

Strongly

disagree
Neither

agree or disagree
Agree
Strongly agree 
It is important for children to learn obedience to

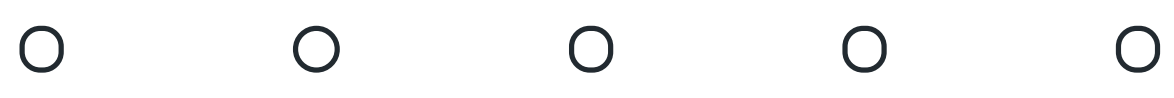

authorities

Authorities such as parents and our national leaders generally turn out to be right about things, and

O

0

0

0

0

the radicals and

protesters are almost

always wrong

It is always better to trust the judgment of the proper authorities in government and religion than to listen to other people

Our country will be great if we honor the ways of our forefathers

0

O 0

0

0 and do what the authorities tell us to do

What our country really needs is a strong, determined leader who will crush evil, and take us back to our true path 


\section{Appendix E - Glossary}

\section{Religiousness}

Institutional religion

Attendance at religious services: Frequency one attends religious services

Devotionalism: Sense of loyalty one feels toward their religious organization Spirituality

Connectedness to a higher power: Belief in and connection to a higher power such as God

Spiritual behaviors: Frequency of prayer and mediation

Religious conservativism

Religious fundamentalism: Degree to which one feels their religion is correct

Adherence to religious texts: Commitment to the laws set forth by religious writings such as the Bible

Religious in-group favoritism: Degree to which one prefers to surround themselves with people of their own religious group

\section{Political attitudes}

Capital punishment: Degree to which one favors the use of the death penalty Euthanasia: Degree to which one favors the legal option to use of physician-assisted suicide

Abortion: Degree to which one favors the legal option to have an abortion

Environmentalism: Degree to which one favors laws which seek to protect the environment

\section{Informational assumptions}

Harsh punishments: Degree to which one believes harsh punishments are effective at deterring crime

Good/bad person: Degree to which one believes that there are exclusively good and bad people in the world

Quality of life: Degree to which one values the quality of one's life over length of life Personal choice: Degree to which one believes people should make their own decisions Climate change threat: Degree to which one believes that climate change exists 
Environmental influence: Degree to which one believes that humans have the ability to impact the environment 